\title{
A STUDY OF \\ DYNAMIC ANALYSIS METHODS \\ AS RELATED TO \\ LMFBR PIPING SYSTEMS
}

TECHNICAL REPORT 237

PREPARED FOR

U S ATOMIC ENERGY COMMISSION

CONTRACT NO AT(04-3)-781

BRAUN PROJECT 4122-W

UNITED NUCLEAR PROJECT 2351 


\section{DISCLAIMER}

This report was prepared as an account of work sponsored by an agency of the United States Government. Neither the United States Government nor any agency Thereof, nor any of their employees, makes any warranty, express or implied, or assumes any legal liability or responsibility for the accuracy, completeness, or usefulness of any information, apparatus, product, or process disclosed, or represents that its use would not infringe privately owned rights. Reference herein to any specific commercial product, process, or service by trade name, trademark, manufacturer, or otherwise does not necessarily constitute or imply its endorsement, recommendation, or favoring by the United States Government or any agency thereof. The views and opinions of authors expressed herein do not necessarily state or reflect those of the United States Government or any agency thereof. 


\section{DISCLAIMER}

Portions of this document may be illegible in electronic image products. Images are produced from the best available original document. 


\section{$\begin{array}{lllllllllll}\text { G } & \mathbf{F} & \mathrm{B} & \mathrm{R} & \mathrm{A} & \mathrm{U} & \mathrm{N} & \boldsymbol{E} & \mathrm{G} & \mathrm{O}\end{array}$ \\ Engineers}

AL HAM B RA CALIFORNIA 91802

May 14, 1969

Mr H B Fry

Contracting officer, Contract AT (04-3)-781

AEC San Francisco

2111 Bancroft Way

Berkeley, California 94704

$\mathrm{BAL}-56$

Dear Mr Fry

\begin{tabular}{l} 
DYNAMIC ANALYSIS METHODS \\
TECHNICAL REPORT 237 \\
LMFBR PIPING DESIGN GUIDE \\
PROJECT $4122-\mathrm{W}$ \\
\hline
\end{tabular}

Transmitted herewith are two copies of the final report covering studies of dynamic analysis methods as related to LMFBR Piping systems.

The purpose of the study was to survey existing methods for analysis of the responses of LMFBR Piping systems to internal and external forces of both transient and cyclical nature. The results of the study will be incorporated into design guide procedures.

Comments on the report from receivers will be welcome but further revision is not contemplated.

RFD IS

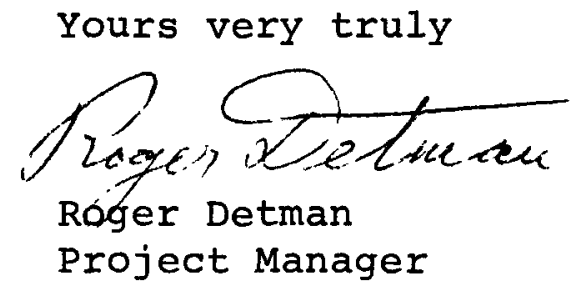




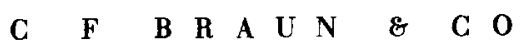

Project $4122-W$

AEC Contract AT (04-3)-781

May 14,1969

CC Mr H B Fry, Contracting Office -2

Director, RDT, HQ

Asst. Director, Project Management, RDT, HQ

Asst. Director, Plant Engineering, RDT, HQ

Asst. Director, Engineering Standards, RDT, HQ

Asst. Director, Reactor Engineering, RDT, HQ

Asst. Director, Reactor Technology, RDT, HQ

Chief, Liquid Metal Projects Br., RDT, HQ

Project Manager, LMEC, RDT, HQ -2

Program Manager, LMFBR, RDT, HQ

Chief, Facilities Br., RDT, HQ

Chief, Components Br., RDT, HQ

Chief, Instrumentation and control Br., RDT, HQ

Chief, L.M. Systems Br., RDT, HQ

Manager, SAN

Director, LMFBR Program Office (ANL)

RDT Senior Site Representative (AI) -2

Director, IMEC -3

Contract Representative, CP-AEC

United Nuclear Corporation

Dr R J Slember, Project Manager -10

R F Detman/Project File

J W Gascoyne -2

R B Hill/Project Engineering File

S F Khalaf

A M Lorenzen

$J$ E Soehrens

W C A Woods -2

Braun Reference Library

Civil Engineering 


$$
2 A N-781-237
$$

\title{
A STUDY OF DYNAMIC ANALYSIS METHODS AS RELATED TO LMFBR PIPING SYSTEMS
}

\author{
Technical Report 237
}

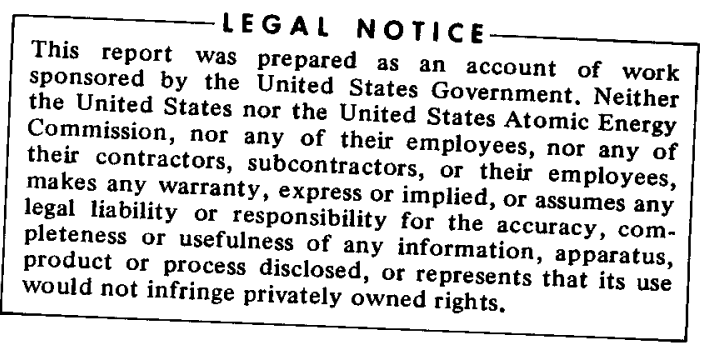

Prepared for U.S. Atomic Energy Commission

Contract No. AT(04-3)-781

Braun Project $4122-\mathrm{W}$

United Nuclear Project 2351

\author{
UNITED NUCLEAR CORPORATION \\ Research and Engineering Center \\ Elmsford, New York \\ May 14, 1969
}




\section{PREFACE}

This Technical Report is one of a series designed to present the findings of studies made by the authors in the development and verification of a Piping Design Guide for LMFBR sodium piping systems. It critically reviews methods of dynamic analysis, with an aim toward selecting those procedures and analytical methods most suitable for application to the design of LMFBR piping.

The following studies have so far been identified under this task.

\begin{tabular}{|c|c|c|}
\hline REPORT NO & TITLE & * ISSUE DATE \\
\hline 100 & $\begin{array}{l}\text { The Development and Verification of a } \\
\text { Design Guide for LMFBR Sodium Piping }\end{array}$ & $1-24-69$ \\
\hline 110 & LMFBR System Requirements & $10-25-68$ \\
\hline 210 & $\begin{array}{l}\text { A Study of Failure Theories as Related } \\
\text { to LMFBR Piping Systems }\end{array}$ & $1-31-69$ \\
\hline 214 & A Review of Piping Failure Experience & $3-28-69(F)$ \\
\hline 217 & $\begin{array}{l}\text { A Review of Piping and Pressure Vessel } \\
\text { Code Design Criteria }\end{array}$ & $4-18-69(F)$ \\
\hline 220 & $\begin{array}{l}\text { A Review of Fabrication and Installation } \\
\text { Requirements for LMFBR Piping }\end{array}$ & $2-28-69$ \\
\hline 223 & $\begin{array}{l}\text { A Study of Heating and Insulation Methods } \\
\text { for LMFBR Sodium Piping }\end{array}$ & $2-28-69$ \\
\hline 228 & A Review of LMFBR Piping Materials & $4-3-69$ \\
\hline 231 & A Study of LMFBR System Interfaces & $3-28-69$ \\
\hline 234 & $\begin{array}{l}\text { A Study of Scale Model Testing Methods } \\
\text { Applicable to LMFBR Piping Design }\end{array}$ & $5-6-69$ \\
\hline 237 & $\begin{array}{l}\text { A Study of Dynamic Analysis Methods } \\
\text { as Related to LMFBR Piping Systems }\end{array}$ & $5-14-69(F)$ \\
\hline 240 & $\begin{array}{l}\text { A Study of Instability Analysis Methods } \\
\text { as Related to LMFBR Piping Systems }\end{array}$ & $2-13-69$ \\
\hline 243 & $\begin{array}{l}\text { A Review of In-Service Surveillance } \\
\text { Methods Applicable to Liquid Sodium Piping }\end{array}$ & (May 1969) \\
\hline
\end{tabular}


TABLE OF CONTENTS

Nomenclature . . . . . . . . . . . . . 5

1. INTRODUCTION . . . . . . . . . . . . . . 1-1

2. GENERAL DISCUSSION .............. . . 2-1

2.1 Statement of the Problem ............ $2-1$

2.2 Design of a Piping System for Dynamic Loading . . . . 2-4

3. DYNAMIC MODEL OF A THREE-DIMENSIONAL

ELASTIC SYSTEM . . . . . . . . . . . . . . . 3-1

4. APPLICABILITY OF STATIC STRUCTURAL

ANALYSIS METHODS TO THE EVALUATION OF

SYSTEM DYNAMIC RESPONSE . . . . . . . . . . . . 4-1

4.1 Matrix Displacement Method - Stiffness Matrix . . . 4-3

4.2 Matrix Force Method - Flexibility Matrix . . . . . 4-6

4.3 Discussion . . . . . . . . . . . . . 4-11

5. CONSISTENT MASS MATRIX . . . . . . . . . 5-1

6. EIGENVALUES AND EIGENVECTORS (NATURAL

FREQUENCIES AND MODE SHAPES) . . . . . . . . 6-1

7. MODAL DAMPING MATRIX ........... . . 7-1

8. FORCING FUNCTION VECTOR . . . . . . . . . . 8-1 $_{8-1}$

8.2 Steady-State Forcing Functions . . . . . . . . 8-2

8.2.1 Steady Running of Pumps 8-5

8.2.2 Entrapped Gases

8-6 
8. 3 Transient Forcing Functions . . . . . . . . 8-6

8.3.1 Waterhammer . . . . . . . . . . 8-7

8.3. 2 Momentum Excitation . . . . . . . 8-9

8.3.3 Pump Starting . . . . . . . . . . . . 8-11

8. 4 Seismic Forcing Functions . . . . . . . . 8-12

8.4.1 Background . . . . . . . . . . . . . 8-12

8. 4. 2 Average Response Spectra (Housner's

Deterministic Method) . . . . . . . . . 8-14

8.4.3 Maximum Response Spectra (Newmark's

Det erministic Method) . . . . . . . . 8-17

8. 4. 4 Stationary Process With Specified Power
Spectral Density (PSD) Function. . . . . 8-22

8.4.5 Nonstationary Process With Filtered or

Specified Power Spectral Density Function . . 8-25

8. 4. 6 Nonstationary Process With Superposition

of Waves. . . . . . . . . . . . . . 8-27

9. METHODS OF SOLUTION . . . . . . . . . . . 9-1

9. 1 Steady-State Problems . . . . . . . . . . . 9-1

9.1.1 Sinusoidal Vibration . . . . . . . . . . 9-1

9.1.2 RMS Responses of Stationary Random

9. 1.3 RMS Response of $\{\mathrm{s}\}$. . . . . . . . 9-4

9. 2 Transient Problems . . . . . . . . . . . 9-5

9. 2.1 Normal Mode Method . . . . . . . . 9-5

9. 2.2 Numerical Time-Step Integration . . . . . 9-7

10. DIGITAL COMPUTER PROGRAMS . . . . . . 10-1

10.1 COSMIC Program Number MFS-2226 . . . . . 10-1

10. 2 COSMIC Program Number NPO-10129 . . . . . 10-3

10. 3 IBM Service Bureau Corporation . . . . . . 10-3

10.4 FIRL Program LUMS . . . . . . . . . 10-5

10.5 FIRL Program DRAS . . . . . . . . 10-6

10. 6 FIRL Program PIPSYS . . . . . . . . . 10-7

10.7 FIRL Program GENSHL . . . . . . . . . 10-9

10.8 Program CTAC-MODE . . . . . . . . . . . 10-10

10.9 AVCO Computer Program No. 1520 . . . . . 10-11

10.10 AVCO Computer Program No. 1536C . . . . . 10-12

10.11 AVCO Computer Program No. 1384 . . . . . 10-12

10.12 AVCO Computer Program No. 2607 . . . . . . 10-13

10.13 AVCO Computer Program No. 2680A, B, C, and Aerospace Computer Program DRASTIC . . . . 10-13

10.14 Electric Boat Division (General Dynamics)

Computer Program GENSAM. . . . . . . . 10-14

10.15 Computer Program STARDYNE . . . . . . 10-14 
11. CONCLUSIONS • • • • • . . . . • . • . • . 11-1

12. REFERENCES . . . . . . . . . . . . 12-1

APPENDIX A - STIFFNESS MATRICES FOR VARIOUS BEAM MEMBER TYPES . . . . . . . . A-1

APPENDIX B - DERIVATION OF PLATE BENDING STIFFNESS MATRIX . . . . . . . . B-1

APPENDIX C - COMPUTATIONS OF EIGENVALUES AND EIGENVEC TORS OF $[\mathrm{M}]^{-1}[\mathrm{~K}][\phi]=[\phi][\Lambda]$ USING ONLY SYMMETRIC MATRICES . . . C 1 


\section{FIGURES}

2. 1 Relationships Between Various Elements Involved in Computation of the System Dynamic Response, and Potential Choices in Modeling Representation and Solution . . . . . . . . . . . . 2-3

4.1 Typical Pin-Jointed Truss Structure. . . . . . . 4-10

4.2 Internal Forces in Members of Truss . . . . . . 4-10

5.1 Uniform Beam Segment . . . . . . . . . . 5-3

5. 2 Displacements and Inertial Loads for Translation Coordinate of Uniform Beam Segment . . . . . 5-4

5. 3 Displacements and Inertial Loads for Rotation Coordinate of Uniform Beam Segment . . . . . 5-5

8. 1 Cantilever Stepped Beam Structure . . . . . . 8-3

8. 2 Velocity of Sound in Liquid Sodium . . . . . . 8-8

8.3 Expansion Loop With Elbows . . . . . . . . 8-10

8.4 Expansion Loop With Ball Joints . . . . . . . . 8-10

8.5 Average Response Spectra for Earthquake Ground

Motion of the Intensity Recorded at El Centro, California, 1940 . . . . . . . . . . . . . 8-16

8. 6 Smoothed Tripartite Logarithmic Response Spectrum for $0.33 \mathrm{~g}$ Earthquake, 2\% Critical Damping . . . . 8-21

8. 7 Schematic Block Diagram Showing Nondeterministic Procedure to Obtain Artificial Earthquakes and Average Response Spectra . . . . . . . . . . 8-23

8. 8 Variations and Confidence Limits for Average Velocity Spectra for 50 Artificial Earthquakes,

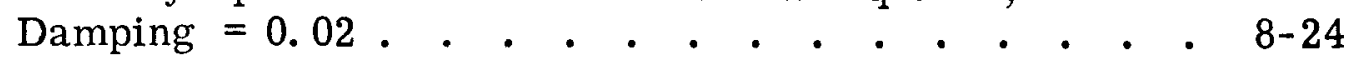

8. 9 Normalized Response Spectra of El Centro 1940 Earthquake. . . . . . . . . . . . . . 8-28

\section{TABLES}

TABLE 8.1 Relative Values of Maximum Ground Acceleration, Velocity and Displacement . . . 8-19

$\begin{array}{ll}\text { TABLE 8.2 } & \begin{array}{l}\text { Relative Values of Spectrum } \\ \text { Amplification Factors . . . . . . . . . } 8-20\end{array}\end{array}$ 
NOMENC LATURE

$\begin{array}{ll}\text { e } & \text { Base of natural logarithms }=2.71828 \\ \mathrm{E} & \text { Young's modulus } \\ \mathrm{E} & \text { Error, defined in Eq. } 9.23 \\ \mathrm{f} & \text { Frequency }=2 \pi \omega(\mathrm{cps}) \\ \mathrm{h} & \text { Time step defined in Eq. } 9.21 \\ \mathrm{I} & \text { Moment of inertia } \\ \mathrm{i} & \sqrt{-1} \\ \mathrm{k}_{\mathrm{ij}} & \text { Stiffness matrix elements, } \mathrm{i}=1, \ldots, \mathrm{n} ; \mathrm{j}=1, \ldots, \mathrm{n} \\ \mathrm{m}_{\mathrm{ij}} & \text { Mass matrix elements, } \mathrm{i}=1, \ldots, \mathrm{n} ; \mathrm{j}=1, \ldots, \mathrm{n} \\ \mathrm{m}(\mathrm{x}, \mathrm{y}, \mathrm{z}) & \text { Mass per unit volume (mass density) } \\ \mathrm{n} & \text { Number of nodes, degrees of freedom or order of matrix } \\ \mathrm{p} & \text { Damped natural frequency } \\ \mathrm{q} & \text { Generalized displacement (coordinate) } \\ \mathrm{R}_{\mathrm{j}} & \text { Mean square value of }\{\mathrm{s}\} \text { defined in Eq. } 9.8 \\ \mathrm{R}_{\mathrm{i}} & \text { Relative error, defined in Eq. 9.24 } \\ \mathrm{r} & \text { Constant } \\ \mathrm{s} & \text { Constant, or indication of direction parallel to } \mathrm{x}, \mathrm{y}, \mathrm{z} \text { axes, } \\ & \text { (see Eq. 8.1) }\end{array}$


$\mathrm{t}$

U Internal strain energy

$\mathrm{U}^{*}$

$\mathrm{U}_{0}$

V

y

$\alpha$

$\beta$

$\gamma$

$\sigma$

$\epsilon$

$\pi_{\mathrm{p}}$

$\pi_{\mathrm{c}}$

$\mathrm{S}_{\mathrm{E}}{ }^{(\mathrm{f})}$

$\mathrm{T}(\omega)$

$\omega$

$\xi$

Time

Volume

Undetermined coefficients

Undetermined coefficients

Displacement functions

Stress

Strain

Potential energy

Complementary energy

Power spectral density

Complementary strain energy

Complementary strain energy density function

Normalizing coordinate defined by Eq. 6.13

Complex frequency response function, obtained from the homogeneous solution of the damped equation of motion

Natural frequency or circular frequency (radians/sec)

Ratio of the actual amount of viscous damping to the critical amount

Matrix Notations:

[] Matrix

\{\} Column matrix (vector)

[」 Row matrix (vector)

[]$^{\mathrm{T}} \quad$ Transpose of matrix

[]$^{-1} \quad$ Inverse of matrix 
[- ] Diagonal matrix

[C] Viscous damping matrix

[f] Flexibility matrix

$\{F(t)\} \quad$ Forcing function vector

[K] Stiffness matrix

[M] Inertia matrix, mass and moments of inertia

$\{\gamma\} \quad$ Phase angle vector, defined in Eq. 9.1

$\{\ddot{q}\} \quad$ Generalized acceleration vector

$\{\dot{q}\} \quad$ Generalized velocity vector

$\{q\} \quad$ Generalized displacement vector

$\{Q\} \quad$ Generalized forcing function vector

$\{\mathrm{u}\} \quad$ Displacement of structural element

[ $\Lambda$ Eigenvalues

$[\phi] \quad$ Eigenfunctions

$\{\eta\},\{\beta\}$, $\left\{\alpha_{\mathbf{j}}\right\},\left\{\mathrm{R}_{1}\right\}$, $\left\{\mathrm{R}_{2}\right\},\left\{\mathrm{R}_{3}\right\}$

Vectors defined in Eqs.9.2 through 9.6 $\left\{\mathrm{R}_{4}\right\},\left\{\mathrm{R}_{5}\right\}$ $\{\mathbf{s}\},[\mathrm{a}]$, $[\mathrm{b}],[\mathrm{d}]$,

Vector and matrices defined in Eq. 9.10 


\section{INTRODUCTION}

C.F。Braun \& Co. with United Nuclear Corporation as a major subcontractor has been awarded a contract* by the United States Atomic Energy Commission for the development and verification of a Piping Design Guide for sodium-cooled fast breeder reactor power plants (LMFBR). The work is a Priority 1 Task under the LMFBR Program Plant prepared for the USAEC Division of Reactor Development and Technology (RDT) by the LMFBR Program Office, Argonne National Laboratory. It is identified in the Program Plan as Task 3-8.2, Development of Design Technology for Piping.

This Technical Report critically reviews methods of dynamic analysis as related to LMFBR piping systems, with an aim toward selecting those procedures and analytical methods most suitable for performing dynamic analyses of LMFBR piping systems.

A review procedure has been established to insure coordination of interdependent studies currently being performed under this and other task areas of the LMFBR Program Plan. Under the review procedure, the Liquid Metal Engineering Center (LMEC) is the coordinating agency. Technical Reports prepared by Braun under this contract will be distributed by LMEC to appropriate Review Agencies designated by USAEC.

*AT(04-3)-781, AEC San Francisco Operations Office (SAN). †Liquid Metal Fast Breeder Reactor Program Plan, LMFBR Program Office, Argonne National Laboratory - AEC R\&D Report, Reactor Technology, WASH-1101 (Aug. 1968). 


\section{GENERAL DISCUSSION}

The objective of this study is to survey the existing methods for computation of the deflection responses of LMFBR sodium piping systems under the influence of transient and steady-state time-dependent forcing functions such as arising from earthquakes, hydraulic shocks (sodium hammer), flow-induced vibration, mechanical vibration of connected equipment (e.g., pumps), etc.

This study is to form the basis for selecting and developing dynamic analysis procedures for incorporation into the LMFBR Piping Design Guide.

\section{1 STATEMENT OF THE PROBLEM}

Continuous piping systems which have an infinite number of degrees of freedom are analyzed approximately by modeling the continuous system into a discrete framework consisting of a finite number of elastic/inelastic, straight/curved, beam/shell elements. The elastic and dynamic properties (dynamic properties include the inertial and damping properties) of these simple components can be readily expressed in matrix forms. These component matrices are considered as building blocks that, when fitted together according to a set of predetermined rules, provide the static and dynamic properties of the entire system. The matrix formulation of these rules, including usage of transformation matrices and Boolean matrices, are readily adaptable to digital computation.

The dynamic model of the piping system, using matrix methods of linear-elastic structural analysis, may be represented by a set or sets of equations of motion: 
$[\mathrm{M}]\{\ddot{\mathrm{q}}\}+[\mathrm{C}]\{\dot{\mathrm{q}}\}+[\mathrm{K}]\{\mathfrak{q}\}=\{\mathrm{F}(\mathrm{t})\}$.

$[\mathrm{M}],[\mathrm{C}],[\mathrm{K}]$ represent the inertia, damping, and stiffness matrix in generalized coordinates, respectively. $\{\ddot{q}\},\{\dot{q}\},\{q\}$ are response vectors in generalized acceleration, velocity, and displacement, respectively. $\{\mathrm{F}(\mathrm{t})\}$, the forcing function vector, can be either transient or stationary.

The problem is analyzed approximately by modeling the continuous piping system by a discrete beam structure in three-dimensional space, with many intermittent rigid and elastic supports. It can be sectionalized between the chosen supports to provide a set or sets of equations of motion. The stiffness matrix, [K], can be obtained directly from the static stress analysis by inverting the flexibility matrix (based upon lumped parameter model of beams). In general, each node possesses six degrees of freedom (three translational and three rotational) represented in the chosen generalized coordinates. The inertia matrix $[M]$ includes the inertia (mass and moments of inertia with respect to the three chosen coordinates) of the piping, insulation, other inertia permanently imposed upon the piping, plus the inertia of liquid metal (at operation).

The following diagram (Fig. 2.1) illustrates the relationships between various elements involved in the computation of the system dynamic response, and potential choices in modeling representation and solution.

From a practical design standpoint it appears that the computation of the dynamic response of a piping system makes the use of a digital computer program mandatory, and this study has emphasized this approach. The scope of present study will be limited to a time-invariant, linear elastic structural model, with the reservation that if a localized high-strain region is found in the linear elastic model, the computation of responses in the inelastic range can be followed (such as usage of bilinear analysis) by using a refined model in subsequent runs. The merits in constructing the elastic model for dynamic analysis by either the Matrix Force Method (piping flexibility analysis) or the Matrix Displacement Method (piping stiffness analysis) will be fully discussed in the following sections. Current techniques on the idealization of inertia and damping matrices will be discussed. The method and its applicability of known computation procedures for both the steady-state and transient responses will be reviewed. 


\section{Excitations $\{\boldsymbol{F}(\mathrm{t})\}$}

Stationary/Transient

Deterministic/Random

Forcing function/

Displacement function
2. Equations of Motion of Piping Structural Model

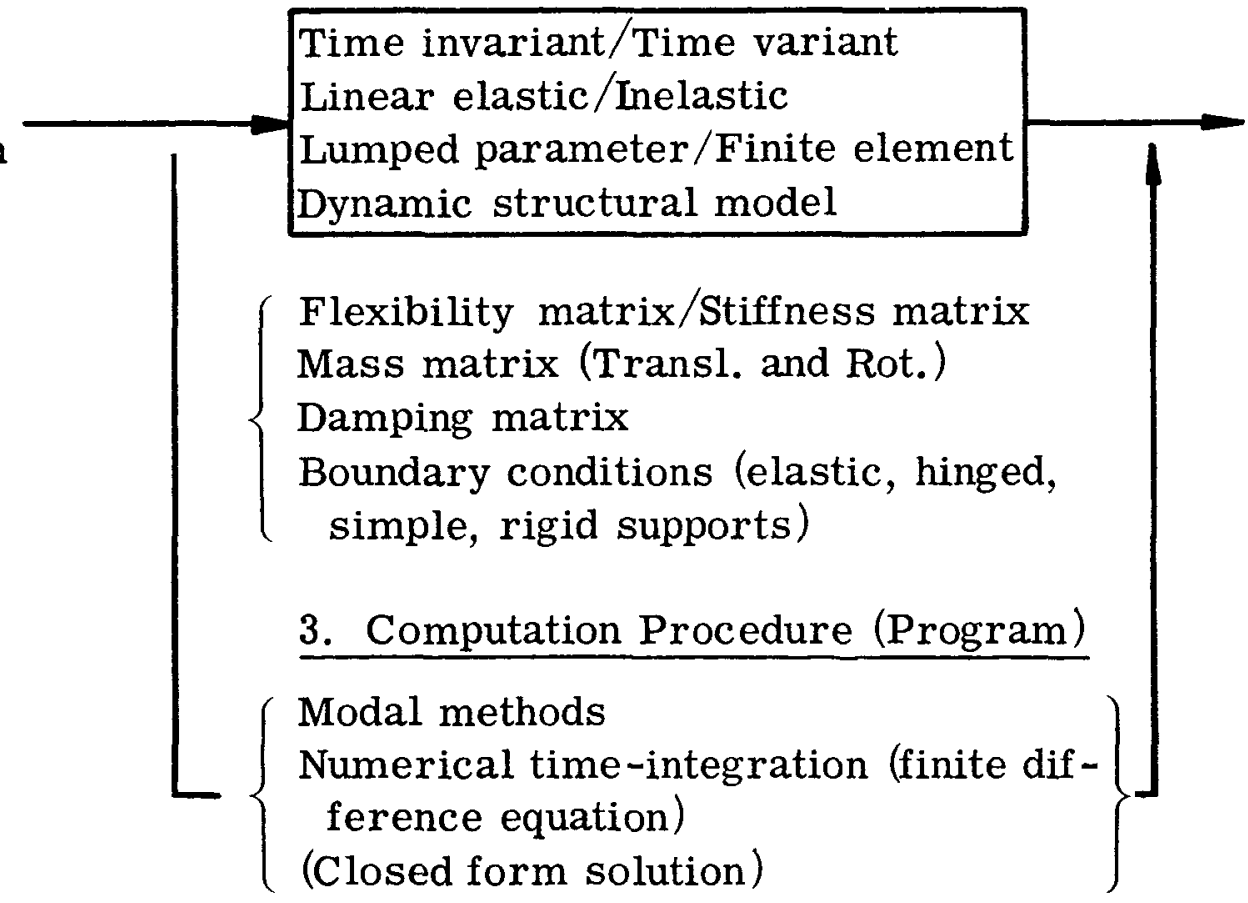

4. Responses $\{\gamma(\mathrm{t})\}$

Relative displacement/ Relative acceleration Stress/Strain

Fig. 2.1 - Relationships between Various Elements Involved in Computation of the System Dynamic Response, and Potential Choices in Modeling Representation and Solution 


\subsection{DESIGN OF A PIPING SYSTEM FOR DYNAMIC LOADING}

From a dynamics standpoint, the first step in the design of a piping system is to determine the undamped system natural frequencies by computing the eigenvalues of the undamped homogeneous equation

$$
[\mathrm{M}]\{\ddot{q}\}+[\mathrm{K}]\{\mathfrak{q}\}=0 .
$$

This permits optimizing the piping supports to eliminate any natural frequencies close to excitation frequencies which may be present in the system, thereby reducing the response amplitude. The second step then will be to calculate the dynamic responses of this optimized design due to both transient shocks and stationary vibrations. To calculate the steady-state responses due to either sinusoidal or random vibration, the damping matrix [C] is obtained by using a modal damping method, to be used in conjunction with the procedure described in Section 9.1. The transient responses due to shocks can be computed by the procedures described in Section 9.2. 


\section{DYNAMIC MODEL OF A THREE-DIMENSIONAL ELASTIC SYSTEM}

For the purpose of obtaining the dynamic responses of a continuous system, which has an infinite number of degrees of freedom, the approximate method is to represent the deformation by a finite number of discrete generalized displacements (coordinates) $\mathrm{q}_{1}, \mathrm{q}_{2} \cdots \cdots \mathrm{q}_{\mathrm{n}}$ of various parts of the continuous structure. Physically, it can be visualized that the piping system is a three-dimensional framework of a finite number of elastically coupled beam/shell elements.

If small displacements are assumed, the applicable form of Lagrange' equation for an undamped system is as follows:

$$
\frac{\mathrm{d}}{\mathrm{dt}}\left(\frac{\partial \mathrm{KE}}{\partial \dot{q}_{\mathrm{i}}}\right)=\frac{\partial \mathrm{KE}}{\partial \mathrm{q}_{\mathrm{i}}}+\frac{\partial \mathrm{PE}}{\partial \mathrm{q}_{\mathrm{i}}}=\mathrm{Q}_{\mathrm{i}} \quad(\mathrm{i}=1,2, \ldots, \mathrm{n})
$$

where $\mathrm{PE}=$ potential energy

$$
\begin{aligned}
\mathrm{KE} & =\text { kinetic energy } \\
\dot{\mathrm{q}}_{\mathrm{i}} & =\frac{\mathrm{dq}}{\mathrm{dt}} \\
\mathrm{t} & =\text { time } \\
\mathrm{Q}_{\mathrm{i}} & =\text { forcing function (steady state or transient) }
\end{aligned}
$$

In the Rayleigh-Ritz approach to natural mode analysis, ${ }^{1}$ the deformation of the system is described by a set of $n$ independent functions $\gamma_{\mathbf{i}}(\mathrm{x}, \mathrm{y}, \mathrm{z})$, so that the total displacement is represented by: 


$$
d(x, y, z, t)=\sum_{i=1}^{n} \gamma_{i}(x, y, z) q_{i}(t)
$$

where the function $d(x, y, z, t)$ is the total displacement vector composed of the superimposed component vectors $\gamma_{i}(x, y, z)$ with time variant amplitudes $q_{i}(t)$.

In a linear system, the potential energy $\mathrm{PE}$ and kinetic energy $\mathrm{KE}$ are expressed as:

$$
\begin{aligned}
& \mathrm{PE}=\frac{1}{2} \sum_{i=1}^{\mathrm{n}} \sum_{j=1}^{n} \mathrm{k}_{\mathrm{ij}} \mathrm{q}_{\mathrm{i}} \mathrm{q}_{\mathrm{j}} \\
& \mathrm{KE}=\frac{1}{2} \sum_{\mathrm{i}=1}^{n} \sum_{j=1}^{n} \mathrm{~m}_{\mathrm{ij}} \dot{\mathrm{q}}_{\mathrm{i}} \dot{\mathrm{q}}_{j}
\end{aligned}
$$

where $\mathrm{k}_{\mathrm{ij}}$ = elastic restraining force (generalized) acting at coordinate $i$ associated with a unit displacement of coordinate $j$

$\mathrm{m}_{\mathrm{ij}}=$ mass inertia force (generalized) acting at coordinate $i$ associated with a unit acceleration of coordinate $\mathbf{j}$.

The coefficients $k_{i j}$ are obtained from a space integral over the system of the product of the stress $\sigma_{i}$ and strain $\epsilon_{j}$ associated with the displacement functions $\gamma_{i}$ and $\gamma_{j}$.

Thus:

$$
\mathrm{k}_{\mathrm{ij}}=\int_{\mathrm{V}} \sigma_{\mathrm{i}}(\mathrm{x}, \mathrm{y}, \mathrm{z}) \epsilon_{\mathrm{j}}(\mathrm{x}, \mathrm{y}, \mathrm{z}) \mathrm{dV}
$$

The coefficients $m_{i j}$ are obtained from a space integral of the product of mass per unit volume $\mathrm{m}(\mathrm{x}, \mathrm{y}, \mathrm{z})$ associated with the displacement functions $\gamma_{\mathrm{i}}$ and $\gamma_{\mathrm{j}}$.

Thus:

$$
m_{i j}=\int_{V} m(x, y, z) \gamma_{i}(x, y, z) \gamma_{j}(x, y, z) d V
$$


Substituting Eqs. 3.3 and 3.4 into Eq. 3.1 yields the undamped equation of motion in matrix form:*

$$
\left[\mathrm{m}_{\mathrm{ij}}\right]\left\{\ddot{\mathrm{q}}_{\mathrm{j}}\right\}+\left[\mathrm{k}_{\mathrm{ij}}\right]\left\{\mathrm{q}_{\mathrm{j}}\right\}=\left\{\mathrm{Q}_{\mathbf{i}}\right\}
$$

The stiffness matrix $\left[\mathrm{k}_{\mathrm{ij}}\right]$ of a constrained system (that is, boundary conditions restraining any rigid body rotation or translation are implied in the matrix) is a square, symmetric, positive-definite matrix. Inversion of $\left[k_{i j}\right]$ is $\left[k_{i j}\right]^{-1}=\left[f_{i j}\right]$, the flexibility matrix of the system. Homogeneous solution of Eq. 3.7 yields the undamped natural frequencies and normal mode shapes. These are predominant factors in subsequent modal analysis and determination of the modal damping matrix in Sections 6 and 7.

Physically, all structural materials do not behave in a perfectly elastic manner, even at very low stresses (inelasticity is always present under all types of loading). In all cases, the structural materials dissipate energy under cyclic load. The cyclic load-deformation (or stressstrain) curve is not a single valued function but forms a hysteresis loop. The damping energy dissipated is proportional to the area of hysteresis loop. Structural damping is a complicated viscoelastic phenomenon even for a linear system, and is still under research and development. In the present state of the art, the approach to simulate the viscoelasticity of structural damping in dynamic analysis is limited almost exclusively to the usage of the Voigt-type biparameter model (linear viscosity or dashpot damping $).{ }^{2}$ Continued use of this simple model is a result of both the lack of proven experimental material data for the more accurate general linear viscoelastic model (for $\mathrm{m}$ Voigt units in series having $\mathrm{m}$ relaxation times), and the difficulty in constructing a dynamic model for computa. tional purposes in a complicated system. The damped dynamic structural model is thus approximated as follows:

$$
\left[\mathrm{m}_{\mathrm{ij}}\right]\left\{\ddot{q}_{\mathbf{j}}\right\}+\left[\mathrm{C}_{\mathrm{ij}}\right]\left\{\dot{q}_{\mathrm{j}}\right\}+\left[\mathrm{k}_{\mathrm{ij}}\right]\left\{\mathrm{q}_{\mathbf{j}}\right\}=\left\{\mathrm{Q}_{\mathbf{i}}\right\}
$$

$$
\begin{array}{ll}
\text { "Matrix Notation: } & {[]=\text { matrix }} \\
& \{\}=\text { column matrix (vector) } \\
\lfloor]=\text { row matrix (vector) } \\
{[]^{\mathrm{T}}=\text { transpose of matrix }} \\
{[]^{-1}=\text { inverse of matrix }}
\end{array}
$$


where $\left[\mathrm{C}_{\mathrm{ij}}\right]=$ viscous damping matrix.

Eq. 3.8 is the damped equation of motion, and its homogeneous solution leads to the complex frequency response function $\mathrm{T}(\omega)$. Eq. 3.8 is used predominantly to evaluate the dynamic responses due to steadystate excitations (sinusoidal and random vibrations) discribed in Section 9.

Detailed discussion and definitions of the parameters in Eqs. 3.7 and 3.8 and their solutions are included in following sections. 


\section{APPLICABILITY OF STATIC STRUCTURAL ANALYSIS METHODS TO THE EVALUATION OF SYSTEM DYNAMIC RESPONSE}

In the evaluation of system dynamic responses resulting from a time-dependent force vector, static structural analysis methods which solve for the static responses at component nodes of a constrained system (composed of discrete elements of beams and shells in a three-dimensional array) are directly applicable to obtain either the stiffness matrix $\left[k_{i j}\right]$ or the flexibility matrix $\left[f_{i j}\right]$.

There are two basic approaches to solving a stress analysis problem of a complex redundant structure:

1. Matrix Displacement Method (or Compatibility Model) Based upon the principle of minimum potential energy $\left(\pi_{\mathrm{p}}\right)$ :

$$
\delta \pi_{\mathrm{p}}=0 \rightarrow \frac{\partial \pi_{\mathrm{p}}}{\partial \mathrm{q}_{\mathrm{i}}}=0 \rightarrow\left[\mathrm{k}_{\mathrm{ij}}\right]\left\{\mathrm{q}_{\mathrm{j}}\right\}=\left\{\mathbf{Q}_{\mathrm{i}}\right\}
$$

Early effort in the use of this method was by Turner, Clough, Martin, and Topp in $1956 .{ }^{3}$ Recent development of the finite element displacement method represents a further evolution of this approach.

2. Matrix Force Method (or Equilibrium Model) - Based upon the principle of minimum complementary energy $\left(\pi_{\mathrm{c}}\right)$ :

$$
\delta \pi_{c}=0 \rightarrow \frac{\partial \pi_{c}}{\partial Q_{i}}=0 \rightarrow\left[f_{i j}\right]\left\{Q_{j}\right\}=\left\{q_{i}\right\}
$$


This approach has been used extensively for trusswork, piping system, and earlier aircraft structure analysis (Castigliano's Theorem, Dummy Load Theorem, etc. ). ${ }^{4-6}$

Both methods and their application to dynamic analysis will be discussed further in Sections 4.1, 4. 2, and 4.3.

There are other hybrid methods for finite element analysis such as the following:

1. Methods using an assumed stress distribution in each element, ${ }^{7,8}$

2. Methods using assumed continuous displacements in each element, ${ }^{9}$ and

3. Methods using Reissner's variational principle. ${ }^{10,11}$

These hybrid methods were developed to illustrate various applicable disciplines within the variational principle of structural mechanics. The examples used are solid continuums of simple geometrical shapes, such as beams and cylindrical shells. Industry has not yet adapted and developed these methods into finite element static and/or dynamic structural analysis computer programs for complex structures. Therefore, applicability of the hybrid methods to LMFBR piping system cannot be evaluated at present time.

In static stress analysis, the constitutive matrix equation is either

$$
\left[k_{i j}\right]\left\{q_{j}\right\}=\left\{Q_{i}\right\}
$$

or

$$
\left[\mathrm{f}_{\mathrm{ij}}\right]\left\{\mathbf{Q}_{\mathbf{j}}\right\}=\left\{\mathrm{q}_{\mathbf{i}}\right\}
$$

where $\left\{Q_{i}\right\}$ is a constant. By the techniques of matrix manipulation (such as diagonalization), a high-speed digital computer can solve up to 8000 such simultaneous linear equations without difficulty. Whereas, in dynamic analysis, the constitutive matrix equation is a second-order linear or nonlinear differential equation (see Eqs. 3.7 and 3.8 in Section 3$)$, where $\left\{Q_{i}\right\}$ can be either $\left\{Q_{i}(t)\right\},\left\{Q_{i}(q, t)\right\}$ or $\left\{Q_{i}(q, \dot{q}, t)\right\}$.

Based upon a survey of the existing state of the art in digital computer programs, it appears that the limiting number of degrees of freedom for dynamic analysis is about 200, if a convergence check on accuracy of solution is imposed. If no convergence check on the accuracy of solution is imposed, problems up to 500 degrees of freedom can be solved. With consideration of the possible truncation and round-off errors, economy of computer time, and computer memory storage capacity limitation, it is apparent that for a given piping system, a dynamic model of discrete elements cannot be refined to the same degree as in the case for a detailed static stress analysis. In general, accumulated round-off and 
truncation errors reflected in the dynamic responses of a system by a digital computer program are dependent upon the degrees of freedom, the "condition" of the matrix equation of motion (such as closeness of spreadout of eigenvalues and eigenfunctions), and the mathematical procedures defined by the computer program. Error analysis of the dynamic responses of a complex structure is sometimes a built-in feature of the computer program. An "ill-conditioned" input of matrix equations of motion of large numbers of freedom may result a nonconvergent solution. Therefore, judgment by the engineer to choose the optimized location and number of nodal points (sometimes by trial and error) in order to represent the predominant dynamic modes of system is required.

\subsection{MATRIX DISPLACEMENT METHOD - STIFFNESS MATRIX}

The basic steps in static stiffness and deflection analysis in a complex structure are:

1. The structure is replaced by an equivalent idealized structural model consisting of basic structural elements that are elastically coupled to each other at selected nodal points. For a piping system in three-dimensional space, these basic structural elements are either beams or shells, and each node has six degrees of freedom.

2. Element stiffness matrices are either known or determined for each basic structural unit appearing in the idealized structure.

3. The overall stiffness matrix is obtained by summing these element stiffness matrices. In the general case, this matrix will be of the order $6 n \times 6 n$, where $n$ equals the number of nodes. The stiffness matrix so developed will be singular.

4. Desired support conditions are imposed by striking out columns and corresponding rows, in the stiffness matrix, for which zero displacements have been specified. This reduces the order of the stiffness matrix and renders it nonsingular.

5. For any given set of external forces $\left\{Q_{i}\right\}$ at the nodes, matrix calculations of $\left[\mathrm{k}_{\mathrm{ij}}\right]\left\{\mathrm{q}_{\mathrm{j}}\right\}=\left\{\mathrm{Q}_{\mathbf{i}}\right\}$ applied to the stiffness matrix $\left[\mathrm{k}_{\mathrm{ij}}\right]$ then yield all components of node displacement $\left\{q_{j}\right\}$ plus the external reactions.

6. Forces, stresses, and strains in the internal members are found by applying the appropriate force-deflection and forcestress-strain relations.

The primary function of the analyst is to provide the information required in steps 1 and 2 above. Steps 3 through 6 are essentially 
matrix manipulations which are adaptable to automatic programming and computation by use of high-speed digital computers.

The development of element and overall stiffness matrices, based upon the principle of minimum potential energy $\left(\pi_{\mathrm{p}}\right)$, is as follows:

First, the displacement of a structural element $\{u(x, y, z)\}$ is expressed in terms of $\mathrm{n}$ undetermined coefficients $\alpha_{1}, \alpha_{2}, \ldots, \alpha_{\mathrm{n}}$, where $\mathrm{n}$ is the same as the number of generalized displacements of the structural elements. $t$ Thus,

$$
\{\mathbf{u}\}=[\mathbf{A}]\{\alpha\}
$$

where the terms of matrix [A] are functions of the coordinates $\mathrm{x}, \mathrm{y}$, and z. From Eq. 4.3, one can also express the $n$ generalized nodal displacements $\{q\}$ in terms of the undetermined coefficients $\{\alpha\}$ :

$$
\begin{aligned}
& \{\mathrm{q}\}=[\mathrm{B}]\{\alpha\} \\
& (\mathrm{n} \times 1) \quad(\mathrm{n} \times \mathrm{n})(\mathrm{n} \times 1)
\end{aligned}
$$

and solve for $\{\alpha\}$,

$$
\begin{aligned}
& \{\alpha\}=[\mathrm{B}]^{-1}\{\mathrm{q}\} \\
& \{\mathrm{u}\}=[\mathrm{A}][\mathrm{B}]^{-1}\{\mathrm{q}\} .
\end{aligned}
$$

By using the strain-displacement relation, the strain distribution can be written as:

$$
\{\epsilon\}=[\mathrm{W}][\alpha]=[\mathrm{W}][\mathrm{B}]^{-1}\{\mathrm{q}\}
$$

and when the stress-strain relation:

$$
\{\sigma\}=[\mathrm{E}]\{\epsilon\}
$$

$\lceil$ In general, there can be more than $\mathrm{n}$ undetermined coefficients $\{\alpha\}$ for a highly refined assumed displacement function. ${ }^{12}$ For the purpose of derivation, we limit $[A]$ to be an $(n \times n)$ square matrix. 
is introduced, the internal strain energy can be expressed as:

$$
\begin{aligned}
\mathrm{U}_{\text {element }} & =\frac{1}{2} \int_{\mathrm{V}}\lfloor\epsilon][\mathrm{E}]\{\epsilon\} \mathrm{dV} \\
& =\frac{1}{2}\lfloor\mathrm{q}\rfloor \underbrace{\left(\int_{\mathrm{V}}\left[\mathrm{B}^{-1}\right]^{\mathrm{T}}[\mathrm{W}]^{\mathrm{T}}[\mathrm{E}][\mathrm{W}]\left[\mathrm{B}^{-1}\right] \mathrm{dV}\right)}_{[\mathrm{k}]}\{\mathrm{q}\} \\
& =\frac{1}{2}\lfloor\mathrm{q}\rfloor[\mathrm{k}]\{\mathrm{q}\}
\end{aligned}
$$

and

$$
\mathrm{U}_{\text {structure }}=\sum \mathrm{U}_{\text {element }}=\frac{1}{2}\lfloor\mathrm{q}\rfloor[\mathrm{K}]\{\mathrm{q}\}
$$

where

$$
K_{i j}=\sum_{i=1}^{n_{1}} k_{i j}
$$

Work done due to external loading, which includes both tractions and body forces, is:

$$
\text { Work }=\lfloor\mathbf{Q}\rfloor\{q\}=\lfloor q\rfloor\{\mathbf{Q}\}
$$

where $\{Q\}=$ generalized force for the entire structure. $\uparrow$ Therefore,

$$
\text { Potential energy }=\pi_{p}=\frac{1}{2}\lfloor q\rfloor[K]\{q\}-\lfloor q\rfloor\{Q\}
$$

Applying the principle of minimum potential energy $\delta \pi_{\mathrm{p}}=0$, $\partial \pi_{\mathrm{p}} / \partial \mathrm{q}_{\mathrm{n}}=0$ to Eq. 4.13 , yields:

†Generalized force $\{Q\}$ is to be consistent with the assumed displacement function, to be determined by principle of virtual work. 


$$
[\mathbf{K}]\{\mathbf{q}\}=\{\mathbf{Q}\}
$$

The subject of compiling and optimizing element stiffness matrices, by using various forms of displacement functions that are best suitable for each computer code, has been under continuous development in recent years. The element stiffness matrices include simple beam, thin plate and shell of revolution, thick shell and solid of revolution, general shell, and three-dimensional tetrahedra. ${ }^{3-18}$ For a piping system, the predominant approach is to use beam elements to idealize the piping in three-dimensional space. For detailed static stress analysis, such as at tee-connections, the techniques of using general shell elements and shells of revolution elements are employed. For dynamic analysis, specifically limited by the number of nodes in a "computable" idealized system as described earlier in Section 4, the beam element idealization that can represent a complicated piping system by a framework of a few long beam elements appears to be the feasible and logical choice. The beam stiffness matrices under different boundary conditions are included in Appendix A. ${ }^{55}$ For illustrative purposes, the stiffness matrix of a square plate finite element for a plane stress problem is shown in Appendix B.

\subsection{MATRIX FORCE METHOD - FLEXIBILITY MATRIX}

The basic steps in static flexibility and load analysis in a complex structure are:

1. The structure to be analyzed is broken down into an idealized model composed of beams, shells, etc.

2. The internal load distribution required to put each member and member joint into equilibrium is assigned to the structure. The redundancy is selected to allow a statically determinant structure.

3. Each member and joint is placed into equilibrium by a set of equilibrium equations (in general, six degrees of freedom at each joint), which are written so as to equate the statically determined loads to the applied loads and redundants.

4. The flexibilities $\left[f_{i j}\right]$ of each member are determined.

5. Solve first the statically determined loads in terms of the applied loads and redundants. 
6. Solve next the redundants in terms of the applied loads.

7. Obtain then the solution of all internal loads in terms of applied loads $\left\{Q_{j}\right\}$. Then, from the equation $\left[\mathrm{f}_{\mathrm{ij}}\right]\left\{\mathbf{Q}_{\mathrm{j}}\right\}=\left\{\mathrm{q}_{\mathrm{j}}\right\}$, find the deflections $\left\{q_{i}\right\}$ under the applied loads. Stresses and strains can be directly found in the displacement-strain equations.

Steps 1 through 3 are the information provided by the engineer, while Steps 4 through 7 are stored information incorporated in digital computer programs.

The matrix force method is based upon the principle of minimum complementary energy $\pi_{c}$ described as follows.

Express first the stress $\{\sigma\}$ of a structural element in terms of $j$ undetermined coefficients $\beta_{1}, \beta_{2}, \ldots, \beta_{\mathrm{j}}$ :

$$
\{\sigma\}=[\overline{\mathbf{A}}]\{\beta\}
$$

Then express the internal forces $\left\{Q_{\mathbf{i}}\right\}$ as:

$$
\begin{aligned}
& \{\mathbf{Q}\}=[\overline{\mathrm{B}}] \quad\{\beta\} \\
& (\mathrm{i} \times 1)(\mathrm{i} \times \mathrm{j})(\mathrm{j} \times 1)
\end{aligned}
$$

where $\mathrm{i}>\mathrm{j}$.

Write $\{Q\}$ into two parts:

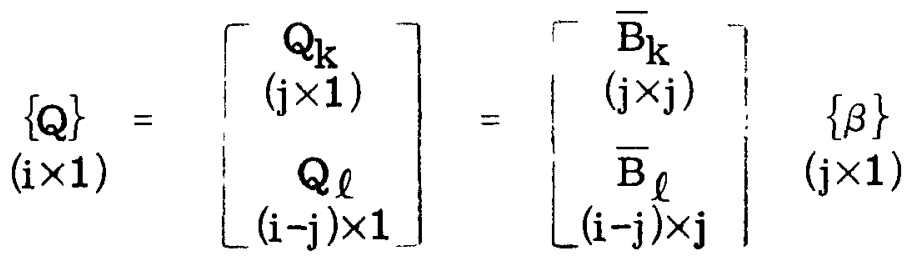

Make a choice of redundant loads, such that $\left\{Q_{\ell}\right\}$ becomes a function of $\mathbf{Q}_{\mathrm{k}}$ 's, with all $\mathbf{Q}_{\mathrm{k}}$ 's independent. Proceed to solve for $\{\beta\}$ :

$$
\{\beta\}=\left[\overline{\mathrm{B}}_{\mathbf{k}}\right]^{-1}\left\{\mathbf{Q}_{\mathbf{k}}\right\}
$$


yields

$$
\{\sigma\}=[\overline{\mathrm{A}}]\left[\overline{\mathrm{B}}_{\mathrm{k}}\right]^{-1}\left\{\mathrm{Q}_{\mathbf{k}}\right\}
$$

From stress-strain relation, $\{\epsilon\}$ can be expressed as:

$$
\{\epsilon\}=[C]\{\sigma\}
$$

The complementary strain energy $U^{*}$ is:

$$
\mathrm{U}_{\text {element }}^{*}=\frac{1}{2} \int_{\mathrm{V}}\lfloor\sigma\rfloor[\mathrm{C}]\{\sigma\} \mathrm{dV}=\frac{1}{2}\left\lfloor\mathrm{Q}_{\mathrm{k}}\right\rfloor[\mathrm{f}]\left\{\mathrm{Q}_{\mathrm{k}}\right\}
$$

where $[\mathrm{f}]=$ the flexibility matrix of the element.

$$
\mathrm{U}_{\text {structure }}^{*}=\frac{1}{2}\lfloor\mathrm{Q}\rfloor[\mathrm{F}]\{\mathrm{Q}\}
$$

Therefore,

$$
\text { Complementary energy }=\pi_{c}=U^{*}-\lfloor Q\rfloor\{q\}
$$

Applying the principle of minimum complementary energy $\delta \pi_{\mathrm{c}}=0$, $\partial \pi_{c} / \partial Q_{n}=0$ to Eqs. 4.22 and 4.23 yields

$$
[\mathrm{F}]\{\mathrm{Q}\}=\{\mathrm{q}\} \text {. }
$$

It is to be noted that the steps in Eqs. 4.17 and 4.18, involving the choice of the redundant quantity, $Q$, are critical and are subject to the judgment of the engineer. The solution of the problem can be an illconditioned one if the choice is poor.

By comparing Eq. 4.14 in Section 4.1 and Eq. 4.24 in Section 4.2, it is evident the relations $[\mathrm{F}]=[\mathrm{K}]^{-1}$ and $[\mathrm{F}]^{-1}=[\mathrm{K}]$ are true for a constrained system (that is, $[\mathrm{K}]$ or $[\mathrm{F}]$ are definite positive).

An example to illustrate the principle of minimum complementary energy (Castigliano's theorem of least work) applying to analysis of a 
redundant pin-jointed truss structure is shown as follows:

- Given: Cross-sectional area (see Fig. 4.1):

Members $\mathrm{AB}, \mathrm{BC}, \mathrm{CD}=\mathrm{S}$

Members DB, AC $=\sqrt{2} \mathrm{~S}$

$\mathrm{E}=$ Young's modulus.

- Find: Internal forces in members of truss.

- Solution: The complementary strain energy density function $U_{0}$ of a linear elastic structure is: ${ }^{15}$

$$
\begin{aligned}
\mathrm{U}_{0} & =\frac{1}{2 \mathrm{E}}\left[(1+\nu) \sigma_{\mathrm{ij}} \sigma_{\mathrm{ij}}-\nu \sigma_{\ell \ell} \sigma_{\mathrm{kk}}\right] \\
& =\frac{1}{2 \mathrm{E}}\left[\sigma_{\mathrm{x}}^{2}+\sigma_{\mathrm{y}}^{2}+\sigma_{\mathrm{z}}^{2}-2 \nu\left(\sigma_{\mathrm{x}} \sigma_{\mathrm{y}}+\sigma_{\mathrm{y}} \sigma_{\mathrm{z}}+\sigma_{\mathrm{z}} \sigma_{\mathrm{x}}\right)+2(1+\nu)\left(\tau_{\mathrm{xy}}^{2}+\tau_{\mathrm{yz}}^{2}+\tau_{\mathrm{zx}}^{2}\right)\right] \\
\mathrm{U}^{*} & =\text { complementary strain energy }=j_{\mathrm{V}} \mathrm{U}_{0} \mathrm{dV}
\end{aligned}
$$

For the truss structure containing one-dimensional beam elements, the complementary strain energy is:

$$
\mathrm{U}^{*}=\sum \frac{\sigma_{\mathrm{X}}^{2} \mathrm{AL}}{2 \mathrm{E}}=\sum \frac{\mathrm{F}^{2} \mathrm{~L}}{2 \mathrm{AE}}
$$

where $\mathrm{A}=$ cross-sectional area of beam element

$\mathrm{L}=$ length of beam element

$\mathrm{F}=$ load in beam element.

Choose the redundant member as element AC. This member is conceived to be removed and replaced by its tension $X=F_{A C}$ (see Fig. 4.2). By static equilibrium at joints $A, C, B$, and D, we can obtain the forces in the other members:

$$
\mathrm{F}_{\mathrm{AB}}=-\left(\frac{\mathrm{X}}{\sqrt{2}}+\mathrm{P}\right), \mathrm{F}_{\mathrm{BC}}=\frac{\mathrm{X}}{\sqrt{2}}, \mathrm{~F}_{\mathrm{CD}}=\frac{\mathrm{X}}{\sqrt{2}}, \mathrm{~F}_{\mathrm{BD}}=\sqrt{2} \mathrm{P}+\mathrm{X}
$$




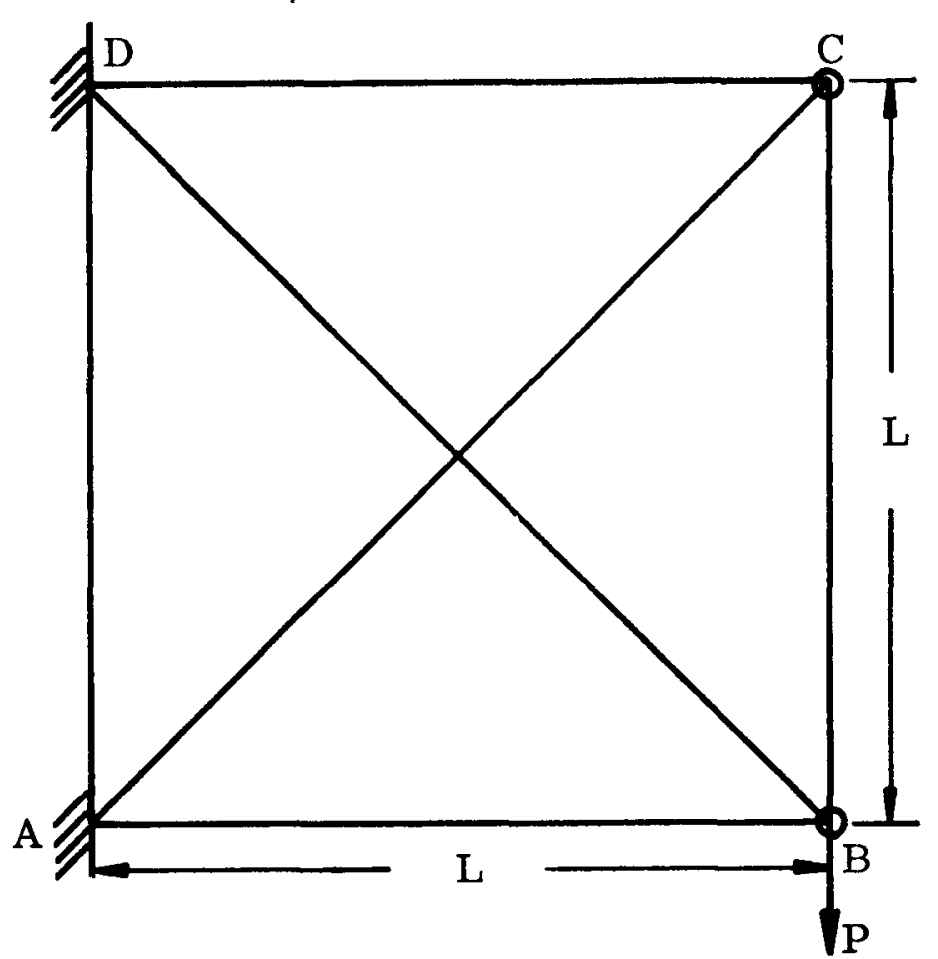

Fig. 4.1 - Typical Pin Jointed Truss Structure

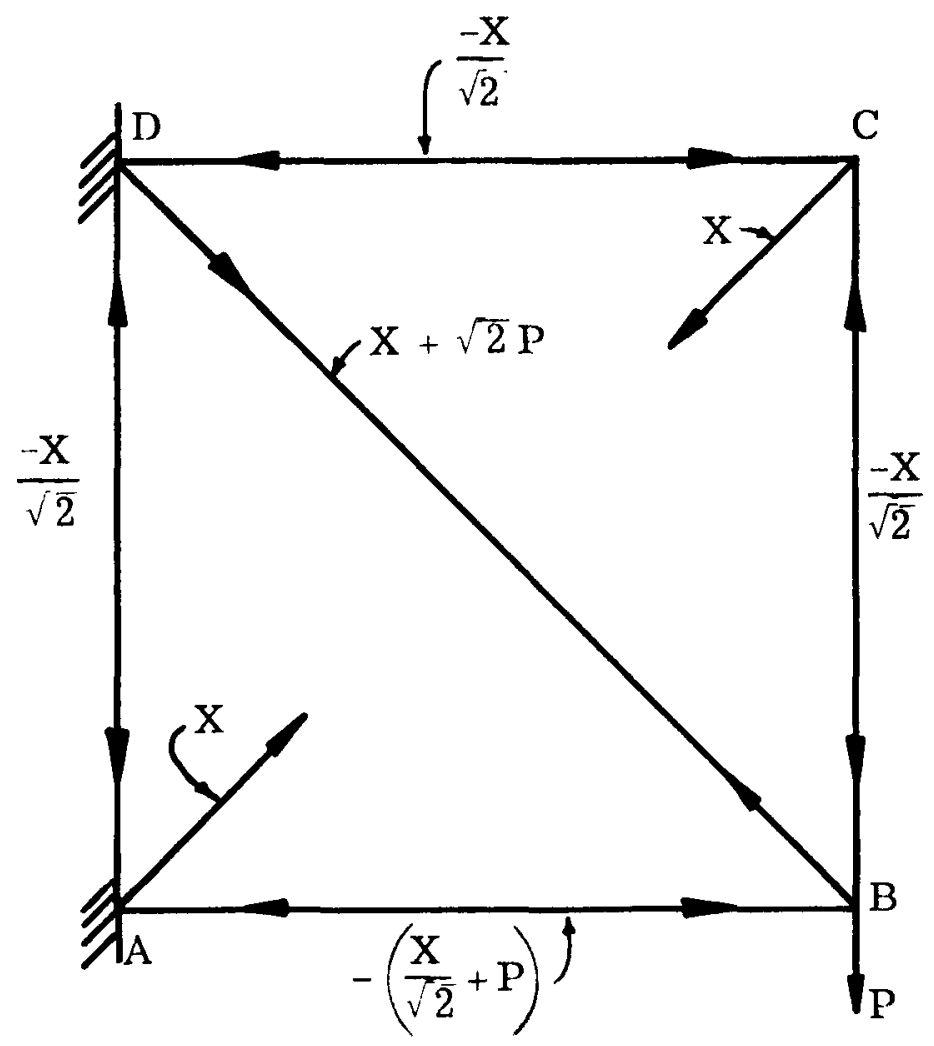

Fig. 4.2 - Internal Forces in Members of Truss 


$$
\begin{aligned}
U^{*}= & \frac{1}{2} \sum \frac{F^{2} L}{A E}=\frac{1}{2 E} \quad X^{2} \frac{\sqrt{2} \ell}{\sqrt{2} S}+\left(\frac{X}{\sqrt{2}}+P\right)^{2} \frac{\ell}{S}+\frac{X^{2}}{2} \frac{\ell}{S}+ \\
& \left.+\frac{X^{2}}{2} \frac{\ell}{S}+(\sqrt{2} P+X)^{2} \frac{\sqrt{2} \ell}{\sqrt{2} S}\right] \\
= & \frac{\ell}{2 E S}\left[3 P^{2}+3 \sqrt{2} P X+(7 / 2) X^{2}\right] \\
\delta U^{*}= & 0, \partial U^{*} / \partial X=0, \text { yields } \\
X= & \frac{-3 \sqrt{2}}{7} P=F_{A C}
\end{aligned}
$$

Therefore,

$$
\mathrm{F}_{\mathrm{DC}}=\frac{3}{7} \mathrm{P}, \mathrm{F}_{\mathrm{BC}}=\frac{3}{7} \mathrm{P}, \mathrm{F}_{\mathrm{BD}}=\frac{4 \sqrt{2}}{7} \mathrm{P}, \mathrm{F}_{\mathrm{AB}}=\frac{-4}{7} \mathrm{P}
$$

It is noted that the solution in this example is exact, serving the purpose for illustration only. For the applications of principle of minimum complementary energy to obtain approximate solutions of flexibilities of complex problems, such as the shear-lag problem of a stiffened panel or a plate bending problem, see References 7, 14, and 16. The piping flexibility analysis programs, such as the "Design of Piping Systems," of Kellogg Company (1952), "The Automatic Calculation of Forces and Deflections in Piping Systems," Peck, Strong, Meyer and Kalson (Trans. ASME Jan 1958), etc., are typical examples.

\subsection{DISCUSSION}

In a linear elastic system, the complementary energy $\pi_{c}$ is identical to the potential energy $\pi_{\mathrm{p}}$. The matrix force method based upon $\delta \pi_{\mathrm{c}}=0$ is a dual relation of the matrix displacement method based upon $\delta \pi_{\mathrm{p}}=0$. In reality, either the stiffness or flexibility matrix is only a direct byproduct of matrix displacement or force method, respectively, and they are interchangeable by the dual relation $[\mathrm{F}][\mathrm{K}]=[\mathrm{I}]$, where 
$[\mathrm{I}]=$ the identity matrix. The main difference between these two methods is that:

1. The matrix displacement method uses an assumed displacement function that assures displacement compatibility inside each element and along interelement boundaries. The resulting direct flexibility influence coefficient is a lower bound to the exact solution.

2. The matrix force method uses an assumed stress distribution function that assures stress equilibrium within each element and along interelement boundaries. The resulting direct flexibility influence coefficient is an upper bound to the exact solution.

Solutions of both methods have been proven to be convergent to the exact solution when the size of the elements is progressively reduced. ${ }^{17}$ Conceptually, the finite element method developed by either $\delta \pi_{\mathrm{p}}=0$ or $\delta \pi_{\mathrm{c}}=0$ can be considered as an improved technique of the Rayleigh-Ritz method. ${ }^{1}$ The Ritz method assumes either a displacement mode or a stress function extended over the entire structure. Whereas the finite element method uses an assumed displacement or stress function of the localized pattern - these patterns are overlapped to provide sufficient generalized displacements of the entire complex structure. This matrix formulation is readily adaptable for high-speed digital computer coding.

These me thods may be contrasted to the lumped parameter method, in which the deformation of a continuous structure is approximated by linear displacements at a finite number of discrete points. That is, the dynamic responses $\{\mathrm{q}(\mathrm{x}, \mathrm{y}, \mathrm{z}, \mathrm{t})\}=\{\mathrm{q}(\mathrm{t})\}$. The structure is divided into a number of rigid segments of beams or bars, and the mass of each segment is lumped at the nodal point with interconnecting weightless springs. Although this method approximates the exact solution, the approach does not concern continuum in reality as it has no displacement compatibility or stress equilibrium requirements. As a result, the mass matrix and the damping matrix are diagonal matrices in a lumped parameter model. The method of determination of nodal forces, acting on the lumped masses on a lumped parameter model from a distributed load on a structure, is again determined arbitrarily and is based upon the judgment of the engineer, whereas, in a finite element model, the con- 
sistent mass matrix and consistent nodal force are determined in consistence with the assumed displacement function by the principle of virtual work. ${ }^{18}$ The resultant eigenvalues and eigenvectors, by usage of the consistent mass matrix, have been proven to be more accurate than the lumped mass matrix for the same problem with an equal number of discrete elements. ${ }^{19}$ 


\section{CONSISTENT MASS MATRIX}

The formulation of the stiffness matrix for various types of structures has been discussed widely and is well documented. On the other hand, the mass matrix construction is usually accomplished by physical lumping of the structural mass at the nodal points. The resulting mass matrix becomes a trivial diagonal matrix and leads to a simple technique of formulation and solution; however, the computed natural mode frequencies and shapes may differ greatly from the exact solution of the problem.

The consistent mass matrix formulation is a more accurate technique by assuming structural acceleration distributions corresponding with point load deformations and providing for mass distribution. In Section 3, by using the Rayleigh-Ritz approach to natural mode analysis, we have prescribed the total displacement $d(x, y, z, t)$ of the structure as:

$$
\mathrm{d}(\mathrm{x}, \mathrm{y}, \mathrm{z}, \mathrm{t})=\sum_{\mathrm{i}=1}^{\mathrm{n}} \gamma_{\mathrm{i}}(\mathrm{x}, \mathrm{y}, \mathrm{z}) \mathrm{q}_{\mathrm{i}}(\mathrm{t})
$$

where $\gamma_{\mathrm{i}}(\mathrm{x}, \mathrm{y}, \mathrm{z})=$ assumed displacement functions.

This yields,

$$
m_{i j}=\int_{V} m(x, y, z) \gamma_{i}(x, y, z) \gamma_{j}(x, y, z) d V
$$


where $m_{i j}=$ mass inertia force (or moment) effective at coordinate $i$ resulting from a structural acceleration of magnitude $\gamma_{\mathrm{j}}(\mathrm{x}, \mathrm{y}, \mathrm{z})$ associated with the point acceleration $\ddot{\mathrm{q}}_{\mathrm{j}}=1$.

$\mathrm{m}(\mathrm{x}, \mathrm{y}, \mathrm{z})=$ mass density (mass/unit volume)

$$
\begin{aligned}
\gamma(\mathrm{x}, \mathrm{y}, \mathrm{z}) & =1 \text { at }\left(\mathrm{x}_{\mathrm{i}}, \mathrm{y}_{\mathbf{i}}, \mathrm{z}_{\mathrm{i}}\right) \\
& =0 \text { at }\left(\mathrm{x}_{\mathrm{j}}, \mathrm{y}_{\mathbf{j}}, \mathrm{z}_{\mathbf{j}}\right), \mathrm{i} \neq \mathrm{j} .
\end{aligned}
$$

The technique of constructing a consistent mass matrix is applied to the problem of determining the mass matrix of a uniform beam segment whose behavior is defined for shear loads, moments, and the corresponding displacements applied at each end of the segment. As illustrated in Fig.5.1, the segment of length $L$ has a constant bending stiffness EI, and a uniformly distributed mass $m$ per unit length.

A unit displacement of coordinate 1 of the segment will cause the distortion $\gamma_{1}(\mathrm{x})$ illustrated in Fig. 5.2(a). The corresponding inertial load $m \gamma_{1}(x)$ and reactions $m_{i_{1}}$ are illustrated in Fig. 5.2(b), as obtained using Eq.5.2. A unit displacement at coordinate 2 will cause the distortion $\gamma_{2}(\mathrm{x})$ illustrated in Fig. 5.3(a). The corresponding inertial reactions $m_{i 2}$ are illustrated in Fig. 5.3(b). For example,

$$
\mathrm{m}_{12}=\mathrm{m} \int_{0}^{\mathrm{L}} \gamma_{1}(\mathrm{x}) \gamma_{2}(\mathrm{x}) \mathrm{dx}=\frac{-11 \mathrm{~mL}^{2}}{210}
$$

and

$$
\mathrm{m}_{22}=\mathrm{m} \int_{0}^{\mathrm{L}} \gamma_{2}(\mathrm{x}) \gamma_{2}(\mathrm{x}) \mathrm{dx}=\frac{\mathrm{mL}^{3}}{105}
$$

Noting the symmetry of the segment, the coefficients for inertial loads due to unit accelerations at points 3 and 4 are readily inferred from those for unit accelerations at points 1 and 2. The complete as sembled mass matrix for the beam segment is thus: 


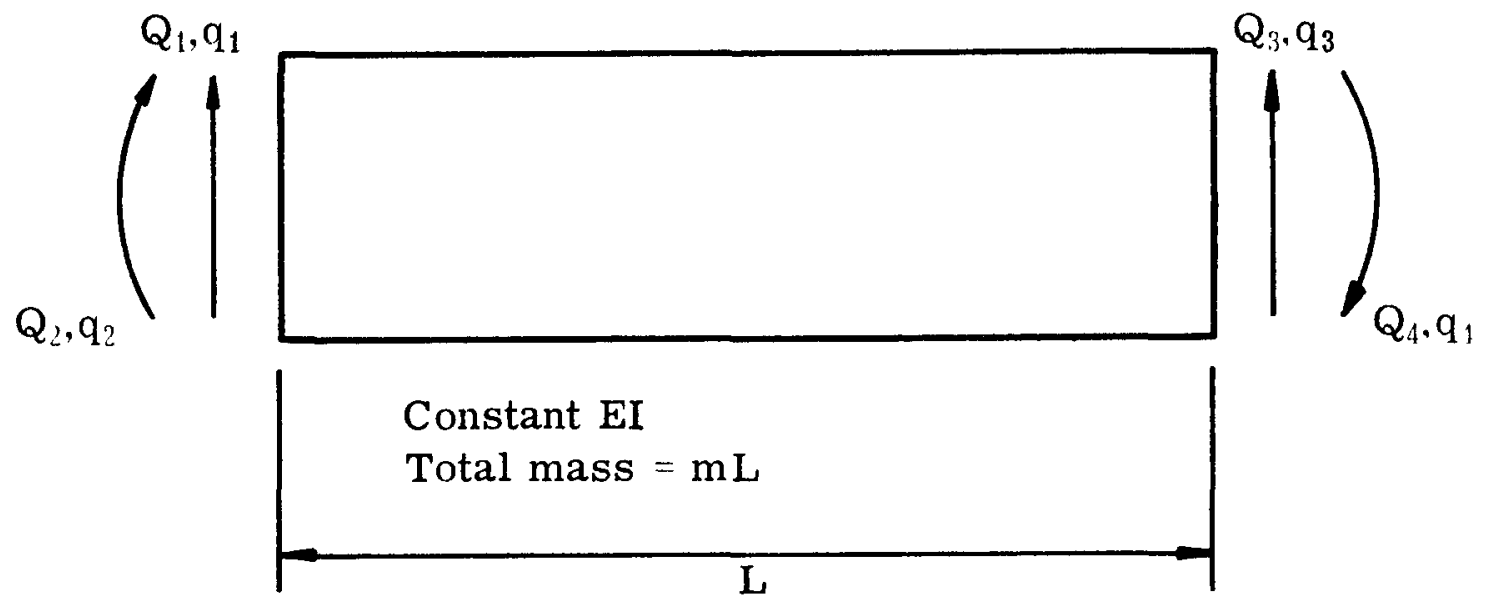

Fig. 5.1 - Uniform Beam Segment 


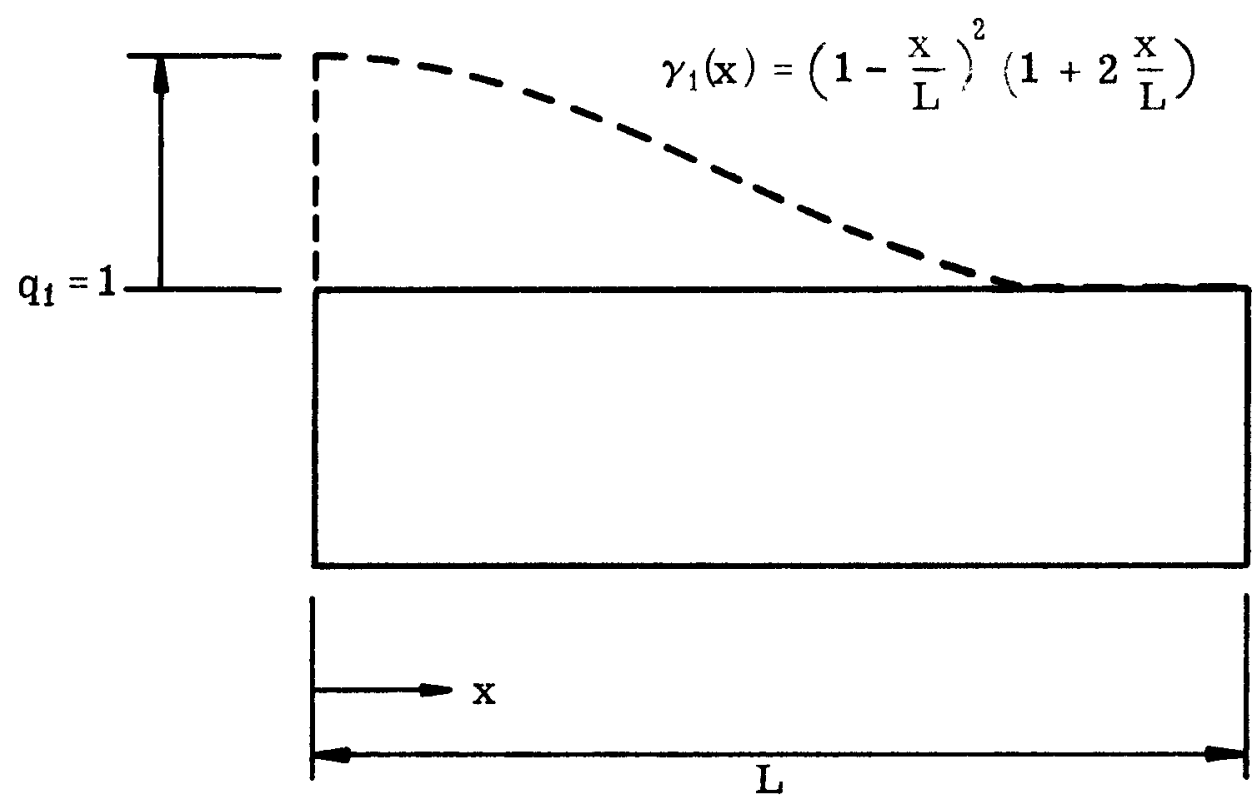

a. Static Displacement

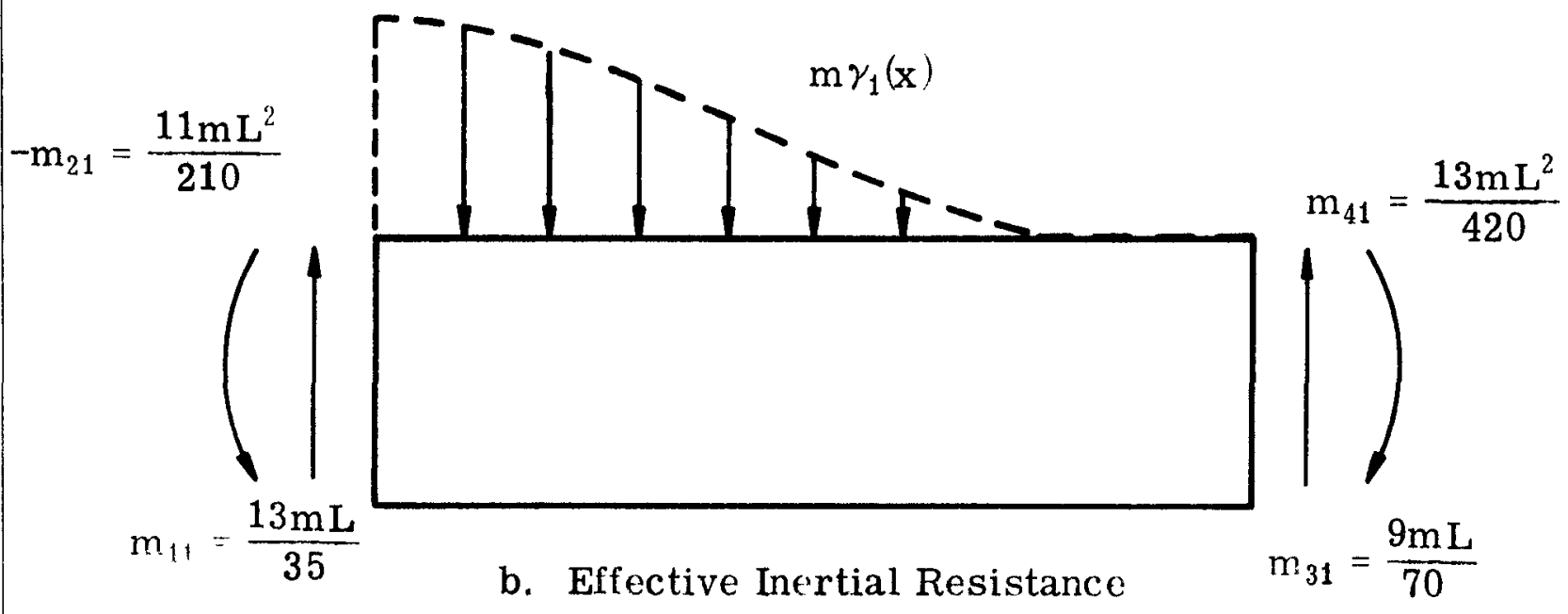

Fig. 5.2-Displacements and Inertial Loads for Translation Coordinate of Uniform Beam Segment 


$$
\left[\begin{array}{l}
Q_{1} \\
Q_{2} \\
Q_{3} \\
Q_{4}
\end{array}\right]=\frac{m L}{420}\left[\begin{array}{cccc}
156 & -22 \mathrm{~L} & 54 & 13 \mathrm{~L} \\
-22 \mathrm{~L} & 4 \mathrm{~L}^{2} & -13 \mathrm{~L} & -3 \mathrm{~L}^{2} \\
54 & -13 \mathrm{~L} & 156 & 22 \mathrm{~L} \\
131 & -3 \mathrm{~L}^{2} & 22 \mathrm{~L} & 4 \mathrm{~L}^{2}
\end{array}\right]\left[\begin{array}{c}
\tilde{\mathrm{q}}_{1} \\
\ddot{\mathrm{q}}_{2} \\
\stackrel{\mathrm{q}}{3}_{3} \\
\ddot{\mathrm{q}}_{4}
\end{array}\right]
$$

The corresponding stiffness for the beam segment ${ }^{4}$ is as follows:

$$
\left.\left[\begin{array}{l}
\mathrm{Q}_{1} \\
\mathrm{Q}_{2} \\
\mathrm{Q}_{3} \\
\mathrm{Q}_{4}
\end{array}\right]=\frac{2 \mathrm{EI}}{\mathrm{L}^{3}}: \begin{array}{cccc}
6 & -3 \mathrm{~L} & -6 & -3 \mathrm{~L} \\
-6 & 2 \mathrm{~L}^{2} & 3 \mathrm{~L} & \mathrm{~L}^{2} \\
-3 \mathrm{~L} & \mathrm{~L}^{2} & 6 & 3 \mathrm{~L} \\
\mathrm{q}_{2} \\
\mathrm{q}_{3} \\
\mathrm{q}_{4}
\end{array}\right]
$$




\section{EIGENVALUES AND EIGENVECTORS (NATURAL FREQUENCIES AND MODE SHAPES)}

The solution of the eigenvalue problem representing an undamped discrete structural model of a piping system is an essential step in computing the transient and steady-state dynamic responses of the system. The results of modal analysis (eigenvalues and eigenvectors) have the following applicability:

1. The eigenvalues are close approximations to the true natural frequencies of a lightly damped system;

2. The eigenvalues and eigenvectors may be used to compute the transient response as described in the remainder of this section; and

3. The eigenvalues and eigenvectors may be used to compute the modal damping matrix of the system (see Section 7) for subsequent use in calculating the system dynamic responses under steady-state excitation.

The natural modes of free vibration of the undamped system of $n$ degrees of freedom described by

$$
[\mathrm{M}]\{\ddot{\mathbf{q}}\}+[\mathrm{K}]\{\mathfrak{q}\}=0
$$

may be obtained in the classical manner by assuming the displacement to be

$$
\left\{\mathbf{q}_{\mathbf{j}}(\mathrm{t})\right\}=\left\{\mathbf{q}_{\mathbf{j}}\right\} \mathrm{e}^{\mathrm{i} \omega t}
$$


thus,

$$
\left\{\ddot{q}_{j}(t)\right\}=-\omega^{2}\left\{q_{j}\right\} e^{i \omega t}
$$

Substituting into Eq. 6.1, we obtain

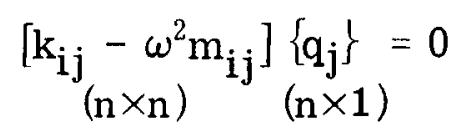

Since $\left\{q_{j}(x, y, z)\right\}$ is real and does not vanish, Eq. 6.2 becomes the standard eigenvalue problem of $[\mathbf{K}]\{\mathfrak{q}\}=\omega^{2}[\mathrm{M}]\{q\}$, or

$$
[\mathrm{M}]^{-1}[\mathrm{~K}]\{\mathbf{q}\}=\omega^{2}\{\mathbf{q}\}
$$

Eq. 6.2a can be solved for $n$ discrete eigenvalues $\omega_{1}^{2}<\omega_{2}^{2} \leqslant \ldots \leqslant \omega_{n}^{2}$ which approximates the eigenvalues of the real system. We can then proceed to solve the $n$ homogeneous solutions of $\left\{q_{i}\right\}$,

$$
\left\{q_{i}\right\}=\left\{\phi_{i}^{(r)}\right\} e^{i \omega_{r} t}, \quad \begin{aligned}
& r=1,2, \ldots, n \\
& i=1,2, \ldots, n
\end{aligned}
$$

where $\left\{\phi_{i}^{(r)}\right\}=$ mode shape or eigenvector for $\omega_{r}^{2}$.

Physically, there is a set of $n$ homogeneous solutions, and each of the solutions of $\left\{q_{i}\right\}$ represents a sinusoidal free vibration mode. Since each homogeneous solution satisfies Eq. 6.1 by using the $\mathrm{rth}^{\mathrm{t}}$ and $\mathrm{s}^{\text {th }}$ modes we have:

$$
\begin{aligned}
& \omega_{\mathrm{r}}^{2}[\mathrm{M}]\left\{\phi^{(\mathrm{r})}\right\}=[\mathrm{K}]\left\{\phi^{(\mathrm{r})}\right\} \\
& \omega_{\mathrm{S}}^{2}[\mathrm{M}]\left\{\phi^{(\mathrm{s})}\right\}=[\phi]\left\{\phi^{(\mathrm{s})}\right\}
\end{aligned}
$$

and $\left\lfloor\phi^{(\mathrm{s})}\right] \times(\mathrm{Eq}$. 6.4)

$$
\omega_{\mathrm{r}}^{2}\left\lfloor\phi^{(\mathrm{s})}\right\rfloor[\mathrm{M}]\left\{\phi^{(\mathrm{r})}\right\}=\left\lfloor\phi^{(\mathrm{s})}\right\rfloor[\mathrm{K}]\left\{\phi^{(\mathrm{r})}\right\}
$$


and $\lfloor\phi(\mathrm{r})\rfloor \times($ Eq. 6.5)

$$
\omega_{\mathrm{S}}^{2}\left\lfloor\phi^{(\mathrm{r})}\right\rfloor[\mathrm{M}]\left\{\phi^{(\mathrm{s})}\right\}=\left\lfloor\phi^{(\mathrm{r})}\right\rfloor[\mathrm{K}]\left\{\phi^{(\mathrm{s})}\right\}
$$

Transposing both sides of Eq. 6.6, and using the property that both [M] and $[\mathrm{K}]$ are symmetric, $[\mathrm{M}]^{\mathrm{T}}=[\mathrm{M}],[\mathrm{K}]^{\mathrm{T}}=[\mathrm{K}]$, Eq. 6.6 becomes

$$
\omega_{\mathrm{r}}^{2}\left\lfloor\phi^{(\mathbf{r})}\right\rfloor[\mathrm{M}]\left\{\phi^{(\mathbf{s})}\right\}=\left\lfloor\phi^{(\mathrm{r})}\right\rfloor[\mathrm{K}]\left\{\phi^{(\mathbf{s})}\right\}
$$

and Eq. 6.7 minus 6.8 yields

$$
\left(\omega_{\mathrm{S}}^{2}-\omega_{\mathrm{r}}^{2}\right)\left\lfloor\phi^{(\mathrm{r})}\right][\mathrm{M}]\left\{\phi^{(\mathrm{S})}\right\}=0
$$

Hence, if $r \neq s$,

$$
\left\lfloor\phi^{(\mathbf{r})}\right\rfloor[\mathbf{M}]\left\{\phi^{(\mathbf{s})}\right\}=0
$$

Eq. 6.10 is an "Orthogonality Relation"' between different modes $(r \neq s)$.

If matrix $[M]$ is diagonal (such as the case of the lumped parameter model), for $r=s$,

For $\mathrm{r}=\mathrm{s}\left\{\begin{array}{l}\left\lfloor\phi^{(\mathrm{r})}\right\rfloor[\mathrm{M}]\left\{\phi^{(\mathrm{r})}\right\}=\mathrm{m}_{\mathrm{r}} \\ \text { or }(\mathrm{r})\rfloor[\mathrm{M}]\left\{\phi^{(\mathrm{r})}\right\}=\delta_{\mathrm{rs}} \mathrm{m}_{\mathrm{r}}\end{array}\right\}$

In order to decouple the undamped equation of motion:

$$
[\mathrm{M}]\{\ddot{q}\}+[\mathrm{K}]\{\mathfrak{q}\}=\{\mathbf{F}\}
$$

where $\{\mathbf{F}\}=$ forcing function $=\{\mathbf{F}(\mathrm{t})\}$. We set

$$
\mathrm{q}_{\mathrm{i}}(\mathrm{t})=\sum_{\mathrm{r}=1}^{\mathrm{p}} \phi_{\mathrm{i}}^{(\mathrm{r})} \mathrm{y}_{\mathrm{r}}(\mathrm{t})
$$


or,

$$
\begin{aligned}
& \{\mathrm{q}\}=\left|\begin{array}{c}
\mathrm{q}_{1} \\
\mathrm{q}_{2} \\
\vdots \\
\mathrm{q}_{\mathrm{n}}
\end{array}\right|=\left[\begin{array}{l}
\phi_{1}^{(1)} \\
\cdot \\
\cdot \\
\phi_{\mathrm{n}}^{(1)}
\end{array}\right] \mathrm{y}_{1} \begin{array}{c}
\phi_{1}^{(2)} \\
\cdot \\
\dot{\phi}_{\mathrm{n}}^{(2)}
\end{array} \mid \mathrm{y}_{2}+\ldots+\left[\begin{array}{c}
\phi_{1}^{(\mathrm{n})} \\
\cdot \\
\cdot \\
\phi_{\mathrm{n}}(\mathrm{n})
\end{array}\right] \mathrm{y}_{\mathrm{n}}= \\
& =[\phi]\{y\}
\end{aligned}
$$

Substituting Eq. 6.14 into Eq. 6.12 yields,

$$
[\mathrm{M}][\phi]\{\ddot{\mathrm{y}}\}+[\mathrm{K}][\phi]\{\mathrm{y}\}=\{\mathrm{F}\}
$$

Multiplying Eq. 6.15 by transposition of $[\phi]$ gives:

$$
[\phi]^{\mathrm{T}}[\mathrm{M}][\phi]\{\ddot{\mathrm{y}}\}+[\phi]^{\mathrm{T}}[\mathrm{K}][\phi]\{\mathrm{y}\}=[\phi]^{\mathrm{T}}\{\mathrm{F}\}
$$

By orthogonality, only diagonal terms will be present for coefficients of $\ddot{\mathrm{y}}$ and $\mathrm{y}$ terms. The set of Eq. 6.16 reduces to:

$$
\left\{\begin{array}{c}
\mathrm{m}_{1} \ddot{\mathrm{y}}_{1}+\mathrm{m}_{1} \omega_{1}^{2} \mathrm{y}_{1}=\mathrm{Q}_{1} \\
\mathrm{~m}_{2} \ddot{\mathrm{y}}_{2}+\mathrm{m}_{2} \omega_{2}^{2} \mathrm{y}_{2}=\mathrm{Q}_{2} \\
\cdots \ldots \ldots \ldots \ldots \ldots \ldots \ldots \ldots \ldots \\
\mathrm{m}_{\mathrm{n}} \ddot{\mathrm{y}}_{\mathrm{n}}+\mathrm{m}_{\mathrm{n}} \omega_{\mathrm{n}}^{2} \mathrm{y}_{\mathrm{n}}=\mathrm{Q}_{\mathrm{n}}
\end{array}\right\}
$$

where

$$
\begin{aligned}
& \left.\mathrm{m}_{\mathrm{r}}=\mid \begin{array}{lll}
\left.\phi_{1}^{(\mathrm{r})} \ldots \phi_{\mathrm{n}}^{(\mathrm{r})}\right\rfloor[\mathrm{M}] & {\left[\begin{array}{c}
\phi_{1}^{(\mathrm{r})} \\
\vdots \\
\phi_{\mathrm{n}}^{(\mathrm{r})}
\end{array}\right]=\text { generalized mass of } \mathrm{r}^{\text {th }} \text { mode }} \\
\mathrm{Q}_{\mathrm{r}}=\left\lfloor\phi_{1}^{(\mathrm{r})} \ldots \phi_{\mathrm{n}}^{(\mathrm{r})}\right\rfloor & \vdots \\
\mathrm{F}_{1} \\
\mathrm{~F}_{\mathrm{n}}
\end{array}\right] \text { =generalized force of } \mathrm{r}^{\mathrm{th}} \text { mode }
\end{aligned}
$$


Eq. 6.17 is the uncoupled or normal equation of motion in normal coordinate $\mathrm{y}_{\mathrm{r}}(\mathrm{t})$.

In numerical computations, it is convenient to have the mode shapes $[\phi]$ be so scaled that

$$
[\phi]^{\mathrm{T}}[\mathrm{M}][\phi]=[\mathrm{I}]
$$

where $[I]=$ the identity matrix.

The mode shape which satisfies Eq. 6.18 is said to be normalized with respect to $[M]$. It can be shown also by direct substitution that for normalized mode shapes,

$$
[\phi]^{\mathrm{T}}[\mathrm{K}][\phi]=\left[\begin{array}{ccc}
\omega_{1}^{2} & & \\
& \omega_{2}^{2} & \\
& \ddots & \\
& & \omega_{\mathrm{n}}^{2}
\end{array}\right] \equiv[\Lambda]
$$

where $[\Lambda]$ is a diagonal matrix of eigenvalues.

It can be seen that the solution of Eq. 6.2a to obtain eigenvalues $[\Lambda]$ and eigenvectors $[\phi]$ is the key in modal analysis of a structural system. Although both matrices $[\mathrm{M}]$ and $[\mathrm{K}]$ are real symmetric, $[\mathrm{M}]^{-1}[\mathrm{~K}]$ is not symmetric in general, because $[\mathrm{M}]$ is not diagonal in general. Thus, to compute $[\Lambda]$ and $[\phi]$ directly from Eq. 6.2a would necessitate using an eigenvalue routine for a real general matrix as well as calculating $[\mathrm{M}]^{-1}$. The requirements of storage locations for a nonsymmetric matrix of order $\mathrm{n}$ is $\mathrm{n}^{2}$, while a symmetric matrix requires only $n(n+1) / 2$. By matrix manipulations, the present problem can be reduced to one which involves the finding of the eigenfunctions of two symmetric matrices. The procedure is described in Appendix C.

Applicable numerical methods of modal analysis are as follows: ${ }^{20-24}$

1. Power Method ${ }^{24,25}$ - an iterative method which leads directly to either the largest or smallest eigenvalue and its associated vector.

2. Jacobi Method ${ }^{20,21}$ - an iterative method which leads directly to all of the eigenvalues simultaneously. This is accomplished by 
a series of plane rotations which successfully annihilates off diagonal terms. The resulting diagonal matrix displays eigenvalues. The matrix of eigenvectors is formed from a combination of the transformation matrices.

3. Givens' Method $^{26}$ - a noniterative method for reducing a symmetric nondiagonal matrix to triple-diagonal form. It must be followed by other routines to find the eigenvalues and vectors.

4. Householder's Method ${ }^{27}$ - similar to Givens' Method, except it uses orthogonal transformations which are not plane rotations to reduce to triple-diagonal form. The advantage of Householder's Method over Givens' Method is that it requires less computer steps, and is thus more accurate and economical of time.

5. FAMOUS Computer Program ${ }^{30}$ - uses Householder's Method for triple-diagonalizing a real, symmetric matrix, Ortega's Method $^{28}$ for extracting the eigenvalues, and Wilkinson's Meth$\mathrm{od}^{29}$ for forming the eigenvectors. (Capacity $=100 \times 100$ matri ces.)

6. HOUSE Computer Program ${ }^{31}$ - uses basically Householder's Method but is modified in the following steps:

a. The input symmetric matrix is reduced to a tridiagonal symmetric matrix.

b. A Sturm sequence is formed from the tridiagonal elements, and the eigenvalues of this tridiagonal matrix are computed by interval halving.

c. Using these computed eigenvalues and the tridiagonal matrix, the eigenvectors are found by the inverse power method.

d. These eigenvectors are transformed into the eigenvectors of the original matrix using the same transformations applied in Step a. (Capacity $=150 \times 150$ matrices.)

7. STIFF-EIG Computer Program (Jet Propulsion Laboratory and IBM Service Bureau Corp.) - uses Jacobi's Method (Capacity = $130 \times 130$ matrices.) 
8. LUMS Computer Program (Franklin Institute Research Laboratory)-method and capacity unknown.

9. GENSAM Computer Program (Electric Boat Division, General Dynamics) - method unknown. (Capacity $=165 \times 165$ matrices.)

10. NPO-10124 Computer Program (COSMIC) - (Capacity $=300 \times$ 300 matrices for lumped parameter model only).

11. CTAC Computer Program (Bettis Atomic Power Laboratory and Argonne Code Center) - uses flexibility matrix and iterative method. (Capacity $=60 \times 60$ matrices for lumped parameter only.)

In conclusion, considering all the factors involved (computer time and storage capacity, accuracy and convergence rate) in numerical computation of $[\phi]$ and $[\Lambda]$ of the eigenvalue problem

$$
[\mathrm{M}]^{-1}[\mathrm{~K}][\phi]=[\phi][\Lambda],
$$

the modified version of Householder's Method is recommended, especially for a fully populated $[M]$ matrix. 


\section{MODAL DAMPING MATRIX}

In a steady-state problem of mechanical vibration, the solution of responses is highly dependent on the system damping characteristics. As discussed previously in Section 3, the structural damping can be approximated by a viscous damping matrix [C], to be computed by the modal analysis method. The basic assumption in computing the modal damping matrix [C] is that the normal modes are not coupled by damping. This assumption is a close approximation to the true solution when the system is "lightly damped," which is defined here as a sys tem with a ratio of critical damping $\xi \leqslant 5 \%$ (from definition of viscous damping). In a single degree of freedom system, it can be shown that the damped natural frequency $p=\sqrt{1-\xi^{2}} \omega_{n}$ where $\omega_{n}=$ undamped natural frequency. For $\xi=0.05, p=0.994 \omega_{n}$. Therefore, the eigenvalues and eigenvectors for an undamped system are a reasonable approximation of those for a lightly damped system.

The viscous damped system may be described as follows:

$$
[\mathrm{M}]\{\ddot{\mathrm{q}}\}+[\mathrm{C}]\{\dot{\mathrm{q}}\}+[\mathrm{K}]\{\mathrm{q}\}=\{\mathrm{F}(\mathrm{t})\}
$$

The eigenvalues $[\Lambda]$ and normalized eigenvector $[\phi]$ of $\mathrm{M}^{-1} \mathrm{~K}$ for an undamped system are computed in the following well-known manner:

$$
[\mathrm{M}]^{-1}[\mathrm{~K}][\phi]=[\phi][\Lambda]
$$

with $[\phi]^{\mathrm{T}}[\phi]=[\mathrm{I}]$.

It can be shown by direct substitution that 


$$
\begin{aligned}
& {[\phi]^{\mathrm{T}}[\mathrm{M}][\phi]=[\mathrm{I}]} \\
& {[\phi]^{\mathrm{T}}[\mathrm{K}][\phi]=[\Lambda]}
\end{aligned}
$$

In order to decouple Eq.7.1, a transformation to normal coordinates is accomplished by substituting $\{q\}=[\phi]\{y\}$ into Eq. 7.1 which yields

$$
[\mathbf{M}][\phi]\{\ddot{\mathbf{y}}\}+[\mathrm{C}][\phi]\{\dot{\mathrm{y}}\}+[\mathrm{K}][\phi]\{\mathrm{y}\}=\{\mathbf{F}\}
$$

Pre-multiplying by $[\phi]^{\mathrm{T}}$ and using Eq. 7.3 yields:

$$
\{\ddot{\mathbf{y}}\}+[\phi]^{\mathrm{T}}[\mathbf{C}][\phi]\{\dot{\mathrm{y}}\}+\omega^{2}\{\mathrm{y}\}=[\phi]^{\mathrm{T}}\{\mathbf{F}\}
$$

Let $[\overline{\mathrm{C}}]=[\phi]^{\mathrm{T}}[\mathrm{C}][\phi]$ and assume $[\overline{\mathrm{C}}]$ is a diagonal matrix such that $\overline{\mathrm{C}}_{\mathrm{ii}}=2 \xi \omega_{\mathrm{i}}$, where $\omega_{\mathrm{i}}=\sqrt{\Lambda_{\mathrm{i}}}$ and $\xi$ is the estimated critical damping ratio.

Thus, $[\overline{\mathrm{C}}]=2 \xi[\sqrt{\Lambda}]$, and solving for [C] by pre-multiplying $[\overline{\mathrm{C}}]$ by $\left[\phi^{\mathrm{T}}\right]^{-1}$ and post-multiplying by $[\phi]^{-1}$ gives

$$
[C]=2 \xi\left[\phi^{T}\right]^{-1}[\sqrt{\Lambda}][\phi]^{-1}
$$

In general, $\mathrm{M}^{-1} \mathrm{~K}$ is not symmetric. Thus, to compute $\phi$ and $\Lambda$ directly from this product would necessitate using an eigenvalue routine for a real general matrix as well as calculating $\mathrm{M}^{-1}$. This approach was found to be unsatisfactory (see Reference 32, Section 4.1).

To avoid calculating $\left[\phi^{\mathrm{T}}\right]^{-1}$ and $[\phi]^{-1}$, Eq. 7.6 can be manipu lated in the following form which is more suitable for computation.

$$
[\mathrm{C}]=2 \xi[\mathrm{M}][\phi][\sqrt{\Lambda}][\phi]^{\mathrm{T}}[\mathrm{M}]
$$

Eq. 7.7 is the basic formulation of the modal damping matrix.

To show that Eqs. 7.6 and 7.7 are identical: from Eq. C.13 in Appendix C,

$$
[\phi]=\left[\psi \mu^{-1 / 2} \beta\right]
$$




$$
\begin{aligned}
& {[\phi]^{-1}=\left[\psi \mu^{-1 / 2} \beta\right]^{-1}=\beta^{-1} \mu^{1 / 2} \psi^{-1}=\beta^{\mathrm{T}} \mu^{1 / 2} \psi^{\mathrm{T}}} \\
& {\left[\phi^{\mathrm{T}}\right]^{-1}=\left[\beta^{\mathrm{T}} \mu^{-1 / 2} \psi^{\mathrm{T}}\right]^{-1}=\psi \mu^{1 / 2} \beta}
\end{aligned}
$$

Thus,

$$
\left[\phi^{\mathrm{T}}\right]^{-1}[\Lambda][\phi]^{-1}=\psi \mu^{1 / 2} \beta \Lambda^{1 / 2} \beta^{\mathrm{T}} \mu^{1 / 2} \psi^{\mathrm{T}}
$$

Also

$$
\mathbf{M} \phi \Lambda^{1 / 2} \phi^{\mathbf{T}} \mathbf{M}=\mathbf{M}\left[\psi \mu^{-1 / 2} \beta\right] \Lambda^{1 / 2}\left[\beta^{\mathbf{T}} \mu^{-1 / 2} \psi^{\mathbf{T}}\right] \mathbf{M}
$$

Substituting Eqs. 7.9 and 7.10 into Eq. 7.12 and utilizing the following relationships

$$
\begin{aligned}
\mathbf{M} \psi & =\psi \mu \\
\mathbf{M} & =\psi \mu \psi^{\mathbf{T}} \\
\mathbf{T}_{\psi} & =\mathbf{I}
\end{aligned}
$$

We obtain

$$
\begin{aligned}
\mathbf{M} \phi \Lambda^{1 / 2} \phi^{\mathbf{T}} \mathbf{M} & =\psi \mu \psi^{\mathbf{T}} \psi \mu^{-1 / 2} \beta \Lambda^{1 / 2} \beta^{\mathbf{T}} \mu^{-1 / 2} \psi^{\mathbf{T}} \psi \mu \psi^{\mathbf{T}} \\
& =\psi \mu^{1 / 2} \beta \Lambda^{1 / 2} \beta^{\mathbf{T}} \mu^{1 / 2} \psi^{\mathbf{T}} \\
& =\left[\phi^{\mathbf{T}}\right]^{-1}\left[\Lambda^{1 / 2}\right][\phi]^{-1} \quad \text { (Q.E.D) }
\end{aligned}
$$

Determination of the damping coefficient to be used in the dynamic analysis is one of the most important, and difficult, steps in the analysis. There are relatively little applicable test data to support an accurate estimate of the true damping of the components of a nuclear reactor plant. Most available test results are based on very small amplitude distortions, and the results probably do not accurately reflect the damping that might be expected for the large amplitude motions, such as a severe earthquake. And yet, very small changes in assumed damping may significantly change the calculated response of a structural sys - 
tem. It is apparent, therefore, that a considerable effort is required in the research field to provide test data that will minimize the uncertainties in the currently used damping values.

The damping values currently used in the dynamic analysis of reactor plants are generally only approximations of the total energy loss in the vibrating system.

The following table ${ }^{38}$ summarizes the damping values presently considered to be conservative.

Percent

Item Critical Damping

Containment structure and all internal concrete structures (see Structures Rocking)

Conventionally reinforced concrete struc tures above ground, i.e., shear walls and rigid frames

Steel structures

Welded steel structures

Bolted or riveted steel structures

Piping systems (welded)

Structures founded on base material (rocking)
On rock c $>6000 \mathrm{fps}$
2.0
On firm soil $c \geqslant 2000 \mathrm{fps}$
5.0
On soft soil $c<2000$ fps
7.0

Higher limits may be used for higher energy dissipation limits, providing justification for use of these higher limits is available.

These values are currently being reviewed for incorporation into the "AEC Regulatory Criteria for Aseismic Design of Nuclear Power Plants." 


\section{FORCING FUNCTION VECTOR}

Based upon the source of excitation of the piping system, the dynamic forcing functions can be classified into the following categories:

1. External Excitation (Base-Motion-History Loads)

One source of excitation of the piping system is the structural environment. The system sees this excitation in the form of motion of its supports. This may be further categorized as:

- Stationary (steady-state) vibratory motions causing stationary forces at the nodes (support points) of the structure.

- Transient motions of the base, resulting in transient forces at the system nodes (which are elastically connected at the base). An example of transient external excitation is seismic ground motion (see Section 8.4).

2. Internal Excitation (Force-Time-History Loads)

Among the more prevalent sources of internal excitation are the action of connected equipment such as valves and pumps, and those resulting from the sodium flow. These excitations include:

a. Pressure variations caused by check valve action;

b. Steady action of pumps;

c. Pump starting;

d. Entrapped gas effects;

e. Flow instabilities caused by vortex formation;

f. Valve chatter.

g. Pump rotating stall

h. Steam generator tube leaks

These are discussed further in Sections 8. 2 and 8.3. 
As was the case with external excitations, the internal excitations can be further categorized as:

- Stationary sinusoidal or random vibrations causing steadystate types of locally distributed loads (see Section 8.2).

- Transient loads acting at particular locations in the system (see Section 8.3).

\subsection{CONSISTENT NODAL FORCE VECTOR}

Historically, in both static and dynamic analyses, the treatment of distributed loads has been usually subjected to the judgment and gross lumping techniques of analysts - resulting in inaccuracies in the displacement solution. In Reference 18, J. S. Archer demonstrated an "exact" formulation of the nodal loads for a lumped system (finite element). Application of this method to both static and vibration analyses has proven that this method is a close approximation to the exact solution for a continuous system. The method, which is based upon the principle of virtual work, yields the following formulations for concentrated nodal forces which are statically equivalent to the distributed loads and consistent with the assumed displacement function:

$$
Q_{i}=\sum_{S} p^{S}(x, y, z) \gamma_{i}^{S}(x, y, z) d V
$$

where $\mathrm{p}^{\mathrm{S}}(\mathrm{x}, \mathrm{y}, \mathrm{z})=$ body force and surface traction vector function

$$
\begin{aligned}
\gamma_{\mathrm{i}}^{\mathrm{S}}(\mathrm{x}, \mathrm{y}, \mathrm{z}) & =\text { displacement function } \\
\mathrm{s} & =\mathrm{u}, \mathrm{v}, \mathrm{w} \text { parallel to } \mathrm{x}, \mathrm{y}, \mathrm{z} \text { axes. }
\end{aligned}
$$

In the Appendix of Reference 18, complete listings of nodal loads for a beam element with linearly varying stiffness, mass, and rotational inertia, and distributed loads are tabulated.

An illustration of the principles involved in a static load-displacement situation is provided by determining the coordinate displacements of the stepped cantilever beam illustrated in Fig. 8.1 due to application of a linearly varying distributed load. The behavior of the system is defined by the translation and rotation at the three points shown, requiring a sixth-order matrix for specifying the characteristics of the system. The stiffness 


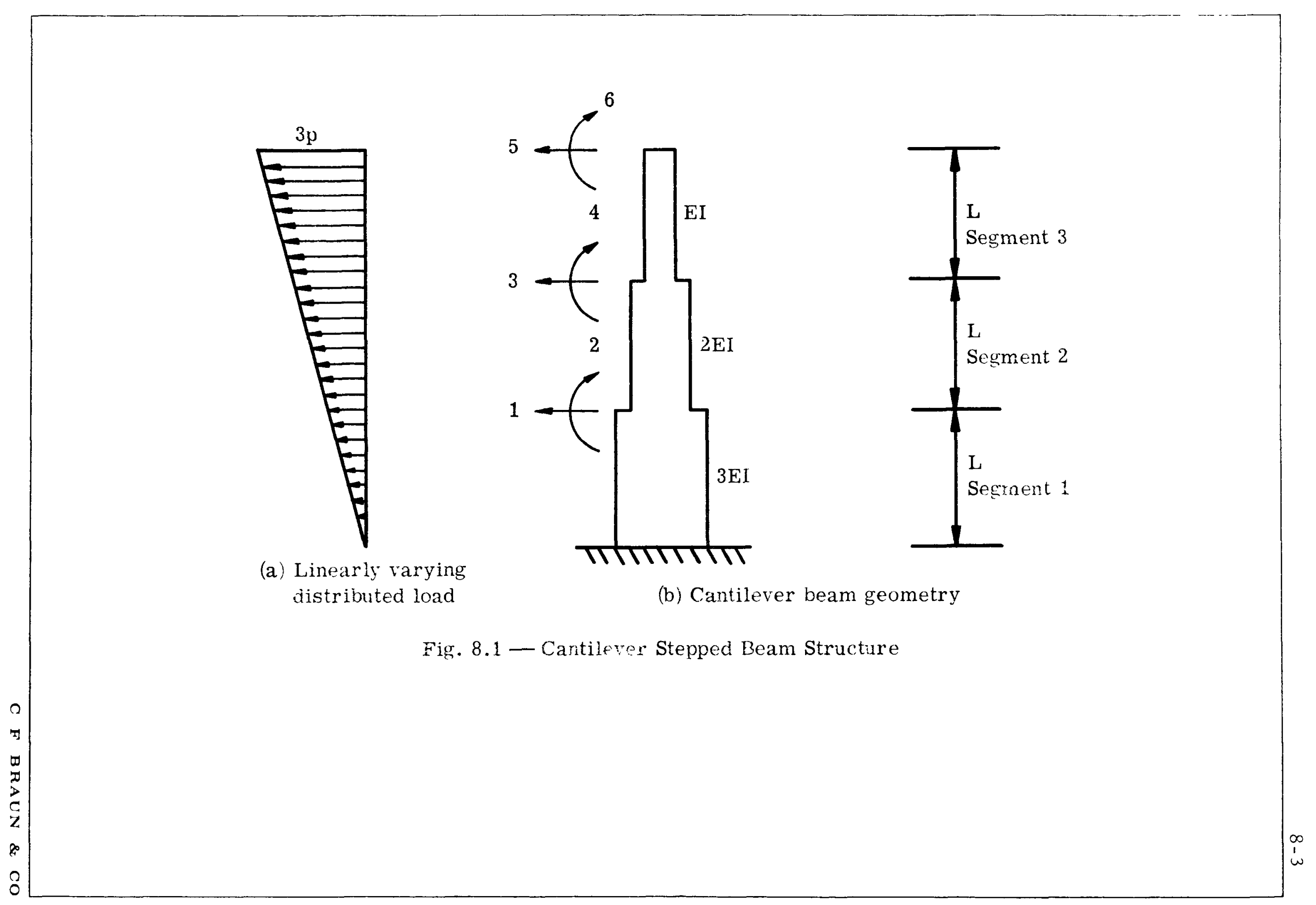


matrix is determined by superimposing the stiffnesses for each beam segment obtained by applying Eq. A2 given in the Appendix of Reference 18. Thus,

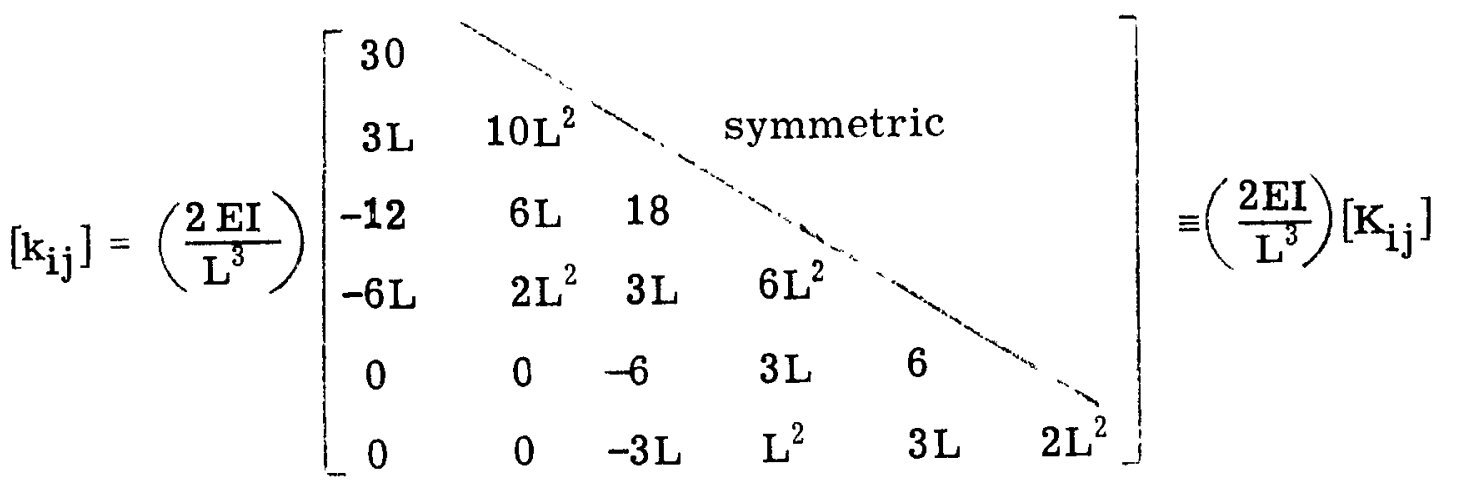

The load vector equivalent to the distributed load is determined by superimposing the load components for each beam segment obtained by applying Eq. A3 given in the Appendix of Reference 18. Thus,

$$
\left\{Q_{\dot{i}}\right\}=\mathrm{pL}\left\{\begin{array}{c}
7 / 20 \\
(1 / 20) \mathrm{L} \\
0 \\
0 \\
0 \\
0
\end{array}\right\}+\mathrm{pL}\left\{\begin{array}{c}
13 / 20 \\
-(7 / 60) \mathrm{L} \\
17 / 20 \\
(2 / 15) \mathrm{L} \\
0 \\
0
\end{array} \mid+\mathrm{pL}\left\{\begin{array}{c}
0 \\
0 \\
23 / 20 \\
-(1 / 5) \mathrm{L} \\
27 / 20 \\
(13 / 60) \mathrm{L}
\end{array}\right\}=\right.
$$

Segment 1

Segment 2

Segment 3

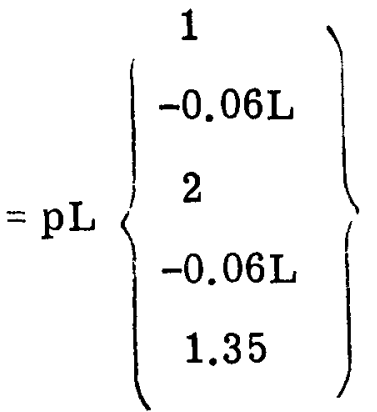


The static displacement of the structure is determined to be

$$
\left\{\mathrm{q}_{\mathrm{j}}\right\}=\left(\frac{\mathrm{L}^{3}}{2 \mathrm{EI}}\right)\left[\mathrm{K}_{\mathrm{ij}}\right]^{-1}\left\{\mathrm{Q}_{\mathrm{i}}\right\}=\left(\frac{\mathrm{pL}^{3}}{2 \mathrm{EI}}\right)\left\{\begin{array}{c}
2.506 \mathrm{~L} \\
-4.528 \\
8.750 \mathrm{~L} \\
-7.403 \\
16.836 \mathrm{~L} \\
-8.319
\end{array}\right\}
$$

By use of the moment-area theorem one readily may verify that the displacements given by Eq. 8.4 are consistent with the Timoshenko beam theory solution for the structure illustrated in Fig. 8.1.

\subsection{STEADY-STATE FORCING FUNCTIONS}

\subsubsection{Steady Running of Pumps}

A centrifugal pump may produce a component of alternating thrust having a fundamental frequency equal to the revolution frequency of the impeller due to the eccentricity of the impeller. In addition, there will be a higher frequency of fluid thrust alternation equal to the product of impeller revolution frequency and number of blades on the impeller. Since the disturbances due to the impeller blades will not be simple harmonic in wave form, there also will be disturbances whose frequencies are integral multiples of the product of revolution frequency and number of impeller blades. In the linear polyphase a-c electromagnetic pump, there are pulsations of thrust having a fundamental frequency equal to twice the a-c frequency, and there may be harmonics at integral multiples of the fundamental pulsation frequency.

In an impeller pump, the revolution frequency thrust pulsation and its harmonics except those proportional to the number of impeller blades is likely to be low enough to preclude excitation of excessive vibration. However, there may be excessive vibration of the piping at the pump revolution frequency if the pump is not well balanced and the attached piping is resonant to the pump revolution frequency. The pulsations at 
the frequency with which impeller blades pass a reference point may be a source of objectional noise, particularly if the fluid system resonates acoustically to the disturbance. The possibility of excessive piping vibration due to this source is small, because of the high frequencies, small excitations, and system damping inherent in high-frequency piping and fluid vibration.

\subsubsection{Entrapped Gases}

Entrapped gases in a liquid system will increase the risk of cavitation, because the gas pressure aids the vapor pressure of the fluid in expanding bubbles in regions of low liquid pressure, and because smaller drops in pressure will be able to expand bubbles into relatively large cavities. However, if cavitation is inevitable with or without entrapped gas, the presence of gas may be beneficial in reducing the intensity of local fluctuations in surface compressive and tensile stresses associated with the formation and collapse of cavities in the liquid, because of cushioning effects of the gas during recession of the bubbles. High vapor densities would provide similar cushioning to reduce collapse pressures and subsequent tensile stresses.

Entrapped gases are detrimental from the standpoint of noise, which results from the impact of the liquid on obstructions in the stream or on the confining walls of the system at branch connections, bends, etc. Local impact stresses similar to those associated with cavitation occur. These stresses are probably of much lower intensity than those with cavitation in a gas-free system, because the gas cushions the impact of the liquid, but they may be significant, particularly with respect to eroding protective corrosion product films.

\section{3 TRANSIENT FORCING FUNCTIONS}

Waterhammer takes place in a piping system whenever there is a change in the velocity of the fluid in the line. Of course, if the fluid in the line is liquid sodium, or some other liquid, the term waterhammer may seem to be inappropriate. The term, however, is so standard in the field of fluid mechanics, that it is retained in this report.

A transient velocity condition can be caused by the opening or closing of a valve, or by a change in the operation of a pump, or by other means. But regardless of the cause of the transient, a change in velocity means a corresponding change in momentum and a change in pressure. These two factors, momentum changes and pressure changes, lead to two separate categories of stress computations. The first of these is handled by classical procedure for waterhammer analysis. In general, these lead to a change in hoop stress. The second is treated as a solution to equation 3.8 in which the 
transient forcing function $\left\{Q_{i}\right\}$ is derived from the momentum changes of the fluid in the line. In general, this leads to a change in longitudinal stress. These two procedures are described below.

\subsubsection{Waterhammer}

In the solution of waterhammer problems, the pressure $(P)$, and the velocity $(V)$, are functions of time $(t)$, and distance $(x)$ measured along the axis of the pipe. Under the transient conditions of waterhammer, these are related by two simultaneous partial differential equations. These are

$$
\frac{\partial P}{\partial \mathbf{X}}+\rho \frac{\partial V}{\partial t}=0
$$

and

$$
\frac{\partial}{\partial t}+\rho S^{2} \frac{\partial V}{\partial x}=0
$$

In these, $\rho$ is the mass density of the fluid and $S$ is the speed of sound within the fluid in the pipe. Its value is

$$
S=\sqrt{\frac{E E^{\prime}}{\left(E^{\prime}+E d / T\right)}}
$$

in which $E$ is the bulk modulus of the fluid, $E^{\prime}$ is the modulus of elasticity of the pipe material, $d$ is the diameter of the pipe, and $T$ is the thickness of the pipe wall. Figure 8.2 indicates the velocity of sound in sodium based on the work of various investigators.

A general solution of these equations is

$$
P-P_{0}=\rho g[F(S t-x)+f(S t+x)]
$$

and

$$
V-V_{0}=\frac{g}{S}[F(S t-x)-f(S t+x)]
$$

In the expressions, $F$ and $f$ are arbitrary functions that must be established from boundary conditions, and $\mathrm{P}_{\mathrm{O}}$ and $\mathrm{V}_{\mathrm{O}}$ are initial values.

The functions $\mathrm{F}$ and $\mathrm{f}$ can be interpreted as the dimensionless form of pressure waves that travel unchanged in shape, with the speed of sound. $F$ moves in the direction of increasing values of $x$. It is the wave form that is generated by valve closure, or some other disturbance. The wave $f$ 


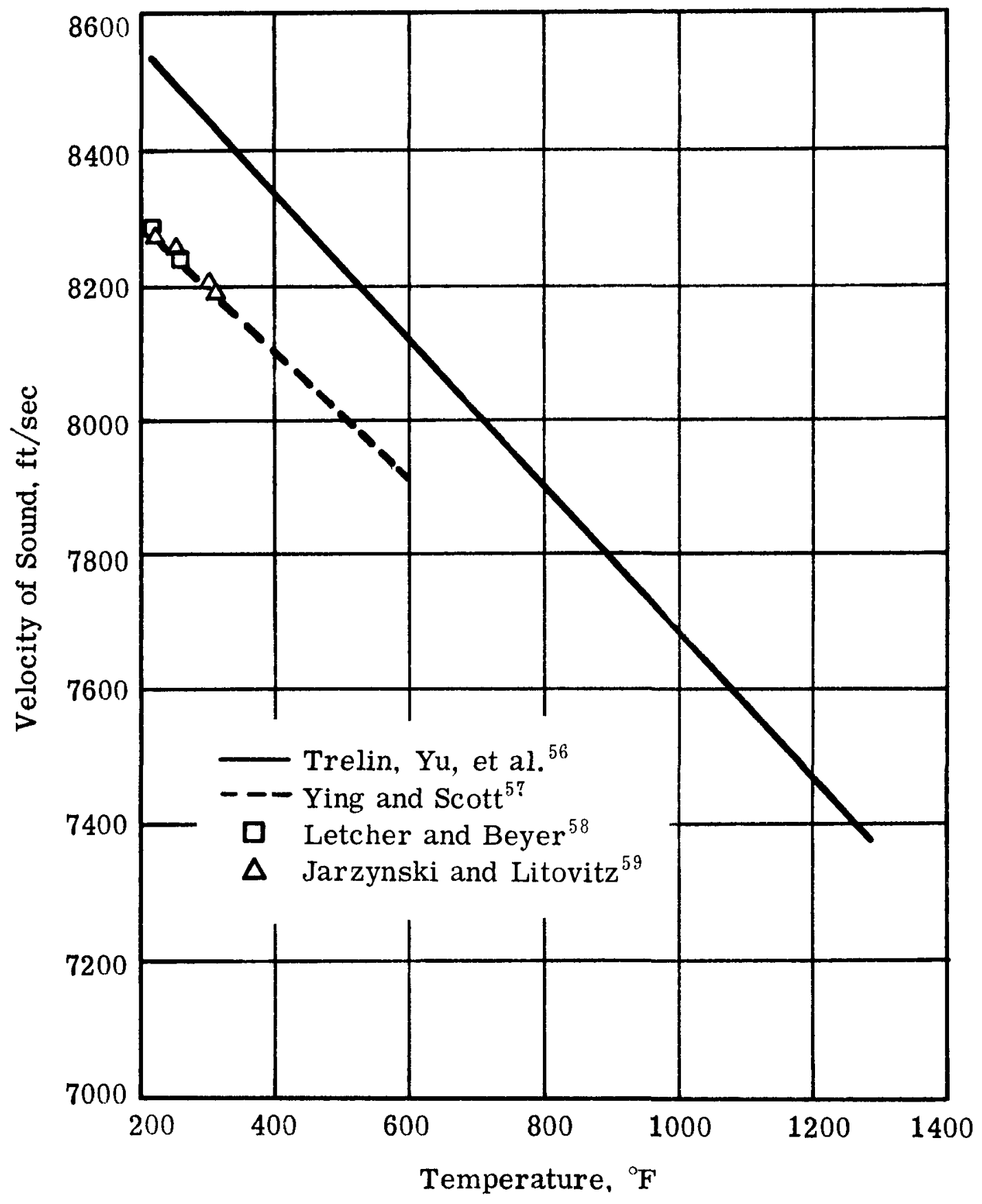

Fig. 8.2 - Velocity of Sound in Liquid Sodium 
moves in the opposite direction. In general, it has the same shape as $F$ and is formed by reflection.

An inspection of the general expression for $\mathrm{P}$ and $\mathrm{V}$ shows that, for times immediately following a velocity disturbance, $\mathrm{V}-\mathrm{V}_{\mathrm{O}}$ or $\Delta \mathrm{V}$, before a wave has been reflected, that is when $f$ equals zero,

$$
\mathbf{P}=-\rho \mathrm{S} \Delta \mathrm{V}
$$

Some numerical and graphical procedures for computing $\mathrm{P}$ and $\mathrm{V}$ are described in Reference 77. This reference also contains an extensive bibliography on this subject. The user of these and similar procedures must have some knowledge about the cause of the transients. If, for example, the transient is caused by the closing of a valve, he must know how long it takes to close the valve, and he must know or assume the velocity of the fluid in the line at the valve during the closing. He may assume for example, that the deceleration is linear, or perhaps sinusoidal, during the closure period.

In addition, the solutions to these problems require some knowledge of the extent and form of wave reflections that occur at tees, reducers, terminal points of the lines, and similar boundary points.

\subsubsection{Momentum Excitation}

Figure 8.3 shows a typical expansion loop in a piping system. This configuration has been selected to illustrate momentum excitation in piping systems. Figure 8.4 shows this same loop in an idealized form. For purposes of analysis, the four elbows have been replaced with ball and socket hinge joints that are frictionless, and offer no obstruction to the flow.

With the above assumptions, there can be no bending moment at the hinges, and it follows that there can be no shear in the vertical legs. There can be no horizontal forces acting on the horizontal run of the loop.

Consider this horizontal run of pipe, plus the liquid in the pipe as a free body, with no external horizontal restraining forces. If now there is a change in the momentum of the fluid, this change must be equal and opposite to the change in momentum of the pipe. This means that the pipe will move in a horizontal direction.

If, on the other hand, the pipe is restrained from moving by some external force $F(t)$, this force must be equal and opposite to the time rate of change of the momentum of the fluid. In other words,

$$
F(t)=-M
$$




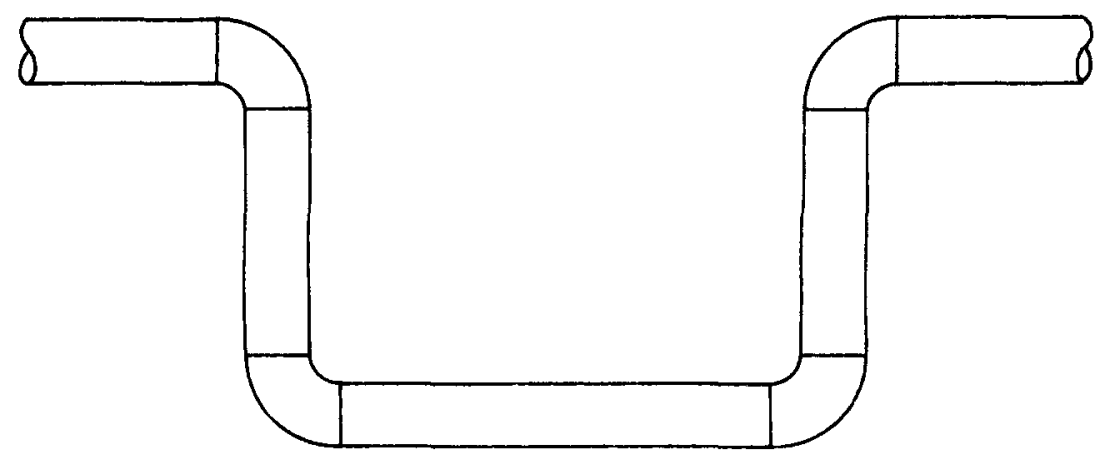

Fig. 8. 3 - Expansion Loop with Elbows

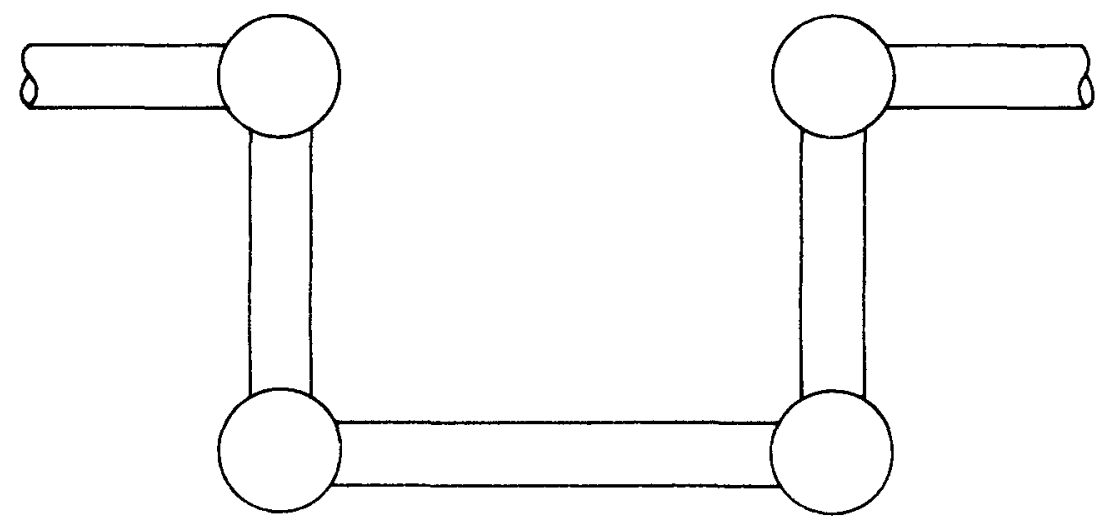

Fig. 8. 4 - Expansion Loop with Ball Joints 
This line of reasoning is equivalent to D'Alembert's Principle. And it means that we can treat piping systems subject to changing velocities as though each lineal segment of pipe were acted upon by a force that is equal to the rate of change of the momentum of the fluid in the pipe segment, and oppositely directed.

Thus, we have a basis for forming the forcing fuction vector $\left\{Q_{i}\right\}$ in equation 3.8. Each term in the vector is a time function that is equal to minus one times the rate of change of the momentum of the fluid in the pipe segment associated with the vector element.

Solutions to equation 3. 8 lead to an evaluation of stresses throughout the piping system as a function of time. And coexistent with these stresses will be the stresses produced by the pressure waves obtained from the waterhammer analysis.

This general procedure can be used to find the effects of opening and closing of valves, and changes in pump speed. It can also be used to estimate the effects of a large gas pocket that might be entrapped in the liquid, and forced to flow with the liquid at the same velocity as the liquid. Since the mass density of the gas is less than the mass density of the fluid, there will be an impulsive type change in the momentum of the fluid as the entrapped bubble moves from one section of the pipe to another.

\subsubsection{Pump Starting}

Starting of a pump against a closed valve may produce transient overpressure at the pump discharge. This has been demonstrated in KAPL tests on an electromagnetic induction pump. It was observed that the transient rise in discharge side pressure was about twice the steady-state rise in discharge pressure at the same applied voltage. This behavior is analogous to the case of a constant force applied suddenly to a mass suspended on a spring. This causes a $100 \%$ overshoot of deflection which dies out as a damped oscillation. In the case of the pump, the driving thrust was developed suddenly, causing a rapid acceleration of the fluid in the duct. The displacement of fluid in the duct compressed the fluid downstream of the pump and expanded fluid on the upstream side. When the fluid in the duct had been brought to rest, the kinetic energy previously acquired had been expended in producing compression and expansion of fluid on the discharge and inlet side relative to final steady-state conditions. Since the transient overpressure was about $100 \%$ of the steady-state increase in pressure, the behavior of the pump was similar to that of a simple spring-mass system. The compliance may have been localized in deformation of the valve stem seal bellows or of the inlet and outlet ducts of the pump. However, a similar overshoot in pressure would be expected even without local sources of compliance, if the pump thrust were fully developed in a time shorter than that for propagation of an acoustic wave from pump to closed valve. 


\section{4 SEISMIC FORCING FUNCTIONS}

\subsection{Background}

By definition, an earthquake is a dynamic displacement of the ground. Most earthquakes in USA are due to release of strain energy during slippage or breakage of a fault. The potential earthquake sources are known as fault lines, relatively concentrated "points" or arbitrarily shaped areas. In general, the maximum horizontal components of motion do not differ greatly in the various directions, but the vertical components of motion may be somewhat less than, or in some circumstances equal to or slightly greater than, the horizontal motions, depending upon whether the associated fault motions in the earthquake are primarily horizontal (strike-slip motions), or primarily vertical (thrust-fault motions).

The significance of faulting as an earthquake-generating mechanism was presented in the Elastic Rebound Theory developed by H. F. Reid ${ }^{33}$, and it has been widely accepted by American seismologists as the cause of nearly all the crustal-focus earthquakes. Housner has suggested that at a site a perpendicular distance $q$ from the fault, with average focal depth $=h$, and a fault length $=\mathrm{L}$, an earthquake can be treated as a point source if

$$
L<0.2 \sqrt{h^{2}+q^{2}}
$$

The Richter scale is the most common measurement of the magnitude of earthquakes. Empirical relationships (based upon statistical observations of several strong earthquakes) between earthquake magnitude and fault breakage length were developed initially by Tucker and later extended by Press. The relations recommended by Press are:

$$
\begin{aligned}
& M=5.65+0.98 \log _{10} L, \text { for } M>7.5 \\
& M=4.5+1.61 \log _{10} L, \text { for } M \leq 7.5
\end{aligned}
$$

where $\quad M=$ the magnitude of the earthquake on the Richter scale $\mathrm{L}=$ the length of the fault breakage in kilometers.

In order to specify the intensity of ground shaking in a particular site, we can use either the "Spectrum Intensity, " which is defined to be the area under the velocity response spectrum curve between 0.1 and $2.5 \mathrm{sec}$ natural period 40 , or the "Modified Mercalli Intensity Scale" which is a subjective measure of the degree of damage actually produced by an earthquake. Esteva and Rosenbleuth ${ }^{35}$ developed the following semitheoretical equations based on the statistical observations of many earthquakes. 


$$
\begin{aligned}
& m_{a}=2000 e^{0.8 M / d^{2}} \\
& m_{S}=0.3 d+0.02 e^{0.74 M}
\end{aligned}
$$

where $\quad \mathrm{m}_{\mathrm{a}}=$ expected maximum ground acceleration, $\mathrm{cm} \mathrm{sec}$

$$
\mathrm{m}_{\mathrm{S}}=\text { expected duration of earthquake, sec }
$$

$\mathrm{d}=$ epicentral distance in kilometers.

In the range of interest (for I $>4.0$ ), the intensity has the following dependence on magnitude $M$, and focal distance $R$

$$
I=c_{1}+c_{2} M-c_{3} \ln R
$$

in which $\ln$ denotes natural logarithm and $c_{i}, i=1,2,3$, are semiempirical constants which are a function of the site geology. For firm ground in southern California these constants are on the order of $8,1.5$, and 2.5, respectively.

The shock waves generated by earthquakes in both horizontal ( $\mathrm{P}$-waves) and vertical planes (S-waves) spread out in all directions from the epicenter, resulting in an earthquake motion whose characteristics are those of a nonstationary stochastic process considered for earthquake motion simulation are:

1. Expected maximum ground accelerations, $\mathrm{m}_{\mathrm{a}}$;

2. Expected duration of earthquake, $\mathrm{m}_{\mathrm{S}}$;

3. Time-variation in intensity of earthquake;

4. Time-variation in the frequency content of earthquake (caused by the variable attenuation rate of seismic waves).

Maximum ground acceleration $\mathrm{m}_{\mathrm{a}}$ and duration $\mathrm{m}_{\mathrm{s}}$ provide a handy set of upper bounds on intensity and duration. They do not provide sufficient information for determining structural response. Real earthquakes are known to be nonstationary random (or stochastic) processes. Examination of the statistical properties of recorded ground motion has led to the conclusion that duration, intensity and frequency content are the most significant characteristics of these data. Both intensity and frequency content are, in general, functions of time. 
There are two different approaches to the design of structures for seismic loadings. The first is the deterministic method (which was used exclusively until the early 1960's and is still used extensively today) which consists of the investigation of the response of structures to typical earthquake records, for example, Housner's average response spectra ${ }^{40}$ and Newmark's maximum response spectra ${ }^{44}$. The seismic provisions in the Uniform Building Code, which gives design lateral loads, are also deterministic $^{60}$, but its primary application should be limited only to secondary structures that are not essential to safe shutdown and isolation of LMFBR piping system during an earthquake ${ }^{44}$.

The second approach is the probabilistic method, which takes into account that earthquake motion is a random process, and that the maximum values of the excitation as well as those of the structural responses are statistical values. Due to the rapid development of knowledge in seismology, and the programs for obtaining instrumental records in recent years, earthquake motion can be better simulated and more realistic modeling techniques are being developed. They can be grouped into four major categories as follows:

1. Stationary, White Noise Process

2. Stationary Process with a Specified Power Spectral Density Function

3. Nonstationary Process with Filtered or Specified Power Spectral Density Function

4. Nonstationary Process with Superposition of Waves

The current trend of probabilistic earthquake modeling technique development is (1) from stationary to nonstationary; (2) from white noise to specified power spectral density functions; and (3) from random shock to superposition of sinusoidal waves or pulses occurring at random phase angles or times. Specifically, the white noise model is not only physically unsound, (it implies that the root mean square of the ensemble goes to infinity), but it also deviates from the observed properties of earthquake motion, hence it will not be discussed in this report.

Discussion of developed methods in both deterministic and probabilistic approach is presented in the following sections.

\subsubsection{Average Response Spectra (Housner's Deterministic Method)}

Response spectrum can be defined as a plot indicating the maximum response (maximum velocity, acceleration and/or displacement response) of single-degree-of-freedom, linear and damped systems to the given ground motion versus the undamped natural period of frequency for various fractions of critical damping. 
The basic assumption of deterministic method in earthquake motion simulation is that the well-recorded strong motion response such as the May 18, 1940, El Centro, Calif. earthquake, are typical of response spectra for nearly all types of ground motion. As a result, Housner constructed the "Average Response Spectra" 40 based upon the characteristics of earthquakes as follows:

1. The zero damping curve is marked by abrupt oscillations, which indicates that the response is very sensitive to small differences in periods of vibration. The introduction of damping makes the response much less sensitive to small changes of period.

2. The introduction of a small amount of damping causes a large reduction in the maximum response.

3. Spectrum curves for earthquakes of large magnitudes at moderate distances from the epicenter have similar shapes.

To obtain the average shape of the spectrum curve for strong ground motions, the spectra of the two horizontal components of each of the earthquakes listed below were averaged after first normalizing them so that the areas under the spectra for zero damping were equal to unity: El Centro, California, Dec. 30, 1934; El Centro, California, May 18, 1940; Olympia, Washington, Apr. 13, 1949; Tast, California, July 21, 1952.

The ordinates of the average spectrum curves are multiplied by the factors shown below to correspond to the respective ground motions.
Factor
1. El Centro, May 18, $1940 \ldots \ldots$. 2. 7
2. El Centro, Dec. 30, $1934 \ldots \ldots$.... 1.9
3. Olympia, Apr. 13, $1959 \ldots \ldots \ldots$... 1.9
4. Taft, July $21,1952 \ldots \ldots \ldots \ldots \ldots$. 1.6

The average velocity response spectra for earthquake ground motion of the intensity recorded at El Centro, Calif. (May 18, 1940) earthquake are shown in Fig. 8.5, which displays maximum acceleration, velocity, and displacement in a single graph of logarithmic scale.

From the spectrum curves it is possible to determine the maximum response of a single degree-of-freedom system as a function of natural period and the fraction of critical damping. The maximum response of a mode of vibration of a more complex system also can be determined by the modal method described in Section 8. For example, the seismic design analysis ${ }^{61}$ of Hanford Plutonium Recycle Test Reactor, is based upon the assumption that Hanford, Wash. is in Earthquake Zone 2 (El Centro, Calif. is in Zone 3). The average response spectrum as shown in Fig. 8.5, was used in the 


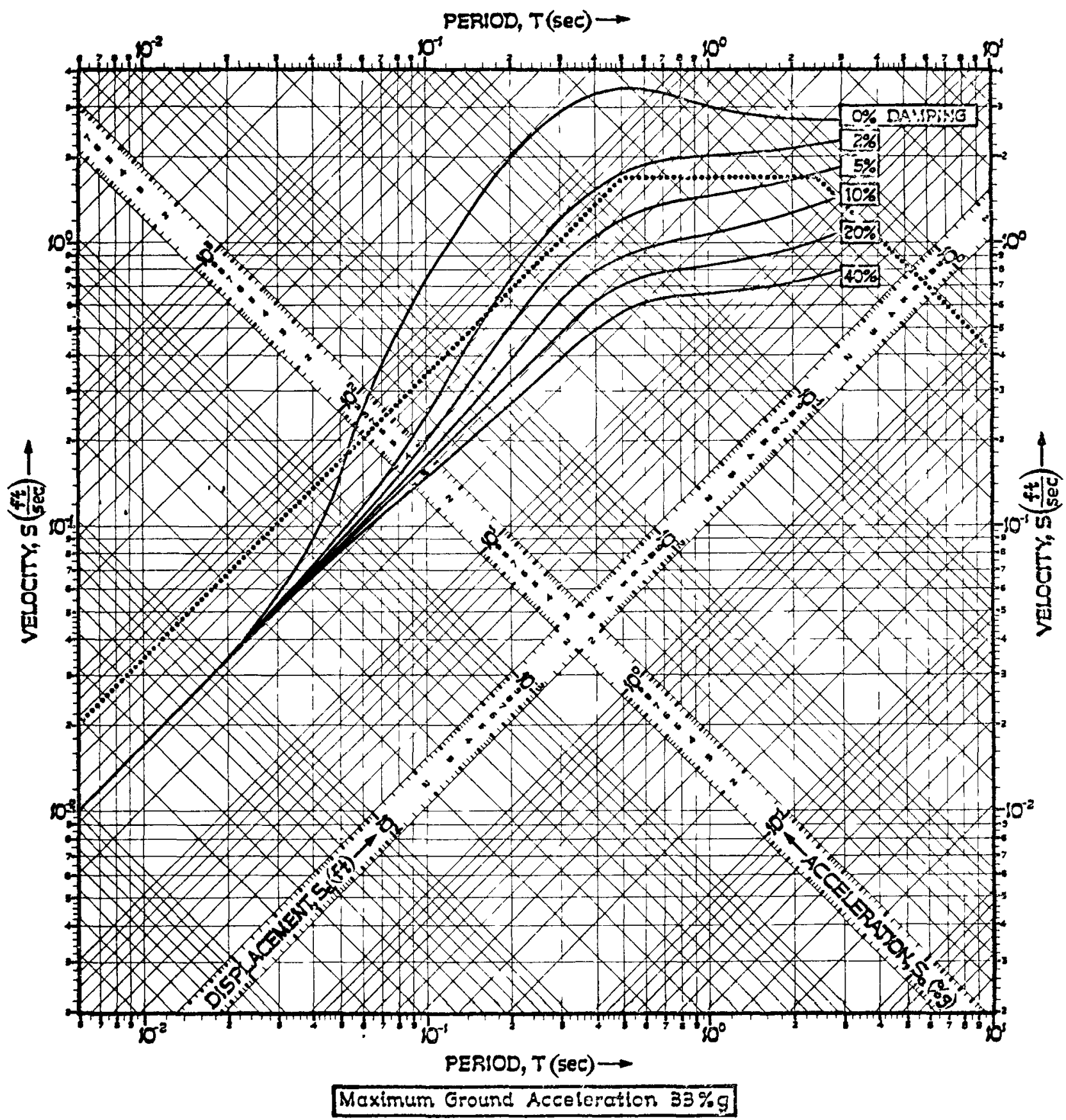

Converted to logarithmie plot from spectra th ILD 7024, "Witelear Reactors and Earthquakes" U. 5. Atomle Enargy Commisslom August 1563

Fig. 8.5 - Average Response Spectra for Earthquake Ground Motion of the Intensity Recorded at El Centro, California, 1940 
analysis, reduced to Zone 2 by using one-half of the El Centro maximum acceleration magnitudes.

\subsubsection{Maximum Response Spectra (Newmark's Deterministic Method)}

Newmark ${ }^{44}$ established that the design earthquake might be selected from available records and inferences from similar site conditions and geographical locations, as the "maximum earthquake" that has a reasonable change of occurring during the lifetime of the structure. For the design earthquake the structure should have a margin of safety sufficient to insure that its function will not be impaired. Values of the "maximum credible or extreme earthquake" have been suggested for the most hazardous regions of the world to correspond to accelerations as high as 1.0 gravity, velocities of 3 to $6 \mathrm{ft} / \mathrm{sec}$, and displacements of several feet, with relative displacements at active faults measured in feet to tens of feet.

As an approach to the problem where specific information is unavailable, the following is suggested based on a "standard" earthquake somewhat similar to the El Centro earthquake in terms of its ground motions, with the other earthquakes considered being stated in terms of the standard earthquake. The standard earthquake is assumed to have a maximum acceleration of $0.5 \mathrm{~g}$, a maximum ground velocity of $24 \mathrm{in}$. per sec., and a maximum displacement of $18 \mathrm{in.}$ This standard earthquake is approximately $50 \%$ greater in intensity than the El Centro earthquake. Other earthquakes with ground motion intensities proportional in value to the "standard" earthquake, are described in Table 8. 1.

It is justifiable to say that Newmark, based upon his observations of many strong earthquakes and his experiences in aseismic design, has intuitively established a maximum response spectra to be used as the seismic design criteria for nuclear reactors.

In the writer's opinion, it is a conservative (with safety margin included) and simple procedure to use, although it has oversimplified the complicated problems of (i) earthquake risk prediction; (ii) soil-foundation interaction; and (iii) earthquake motion as a stochastic process in reality.

The procedure is summarized as follows:

(1) Specify the maximum design earthquake. In no case should a maximum design earthquake be considered for the design of a nuclear reactor or associated facility for which the ground motion values are less than one-fifth of those given for the standard earthquake in Table 8.1. In other words, an earthquake of at least 10 percent "maximum credible ground acceleration" shall be used for every location for which a reactor will be designed. 
(2) The maximum values of ground acceleration, velocity, and displacement are sketched on the tripartite logarithmic chart shown in Fig. 8. 6. These plots give a polygonal curve representing the maximum ground motion values only.

(3) The response of components of structures and complete structures is then determined by amplifying the ground motion values to obtain response spectrum values, using the amplification factors for the various degrees of damping, as shown in Table 8.2. Values may be interpolated between those shown in this table by linear interpolation. An amplified response spectra for 2 percent damping, for an earthquake having a maximum ground acceleration of $0.33 \mathrm{~g}$, is shown in Fig. 8. 6 .

(4) The soil amplification factors are as follows:

Competent Rock. $\cdot \quad \cdot \quad \cdot \quad \cdot \quad \cdot 0.67$ Soft Rock or Firm Sediment . . . . 1.0

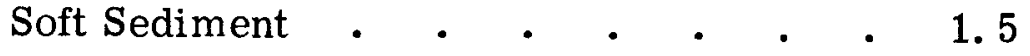

(5) In general, the vertical intensities can be taken as two-thirds of the horizontal where the fault motions are primarily horizontal, and equal to the horizontal where the fault motions involve large vertical components. 
TABLE 8.1 Relative Values of Maximum Ground Acceleration, Velocity and Displacement

\begin{tabular}{lccc}
\hline \multirow{2}{*}{ Condition } & \multicolumn{3}{c}{ Maximum Values of Ground Motion } \\
\cline { 2 - 4 } & $\begin{array}{c}\text { Acceleration } \\
\mathrm{g}\end{array}$ & $\begin{array}{c}\text { Velocity } \\
\text { in/sec }\end{array}$ & $\begin{array}{c}\text { Dispiacement* } \\
\text { in }\end{array}$ \\
\hline "Standard" Relative Values & 0.5 & 24 & 18 \\
Typical Maxima & & & \\
$\quad$ El Centro, 1940, Horizontal & 0.33 & 16 & 12 \\
El Centro, 1940, Vertical & 0.22 & 11 & 8 \\
$* *$ Minimum, Horizontal & 0.10 & 5 & 4 \\
$* *$ Minimum, Vertical & 0.07 & 3 & 3 \\
$\quad$ Very Intense Earthquake & 0.75 & 36 & 27 \\
\hline
\end{tabular}

* Transient motion not involving relative fault displacement

** Minimum values recommended for use in design of nuclear reactors in any region, even where earthquakes are not considered probable 
TABLE 8. 2 Relative Values of Spectrum Amplification Factors

\begin{tabular}{cccc}
\hline $\begin{array}{c}\text { Percent of Critical } \\
\text { Damping }\end{array}$ & \multicolumn{3}{c}{ Amplification Factor for } \\
\cline { 2 - 4 } & Acceleration & Velocity & Displacement \\
\hline 0 & 6.4 & 4.0 & 2.5 \\
0.5 & 5.8 & 3.6 & 2.2 \\
1 & 5.2 & 3.2 & 2.0 \\
2 & 4.3 & 2.8 & 1.8 \\
5 & 2.6 & 1.9 & 1.4 \\
7 & 1.9 & 1.5 & 1.2 \\
10 & 1.5 & 1.3 & 1.1 \\
20 & 1.2 & 1.1 & 1.0 \\
\hline
\end{tabular}

NOTE: See Fig. 8.6 for illustration of application of these amplification values 


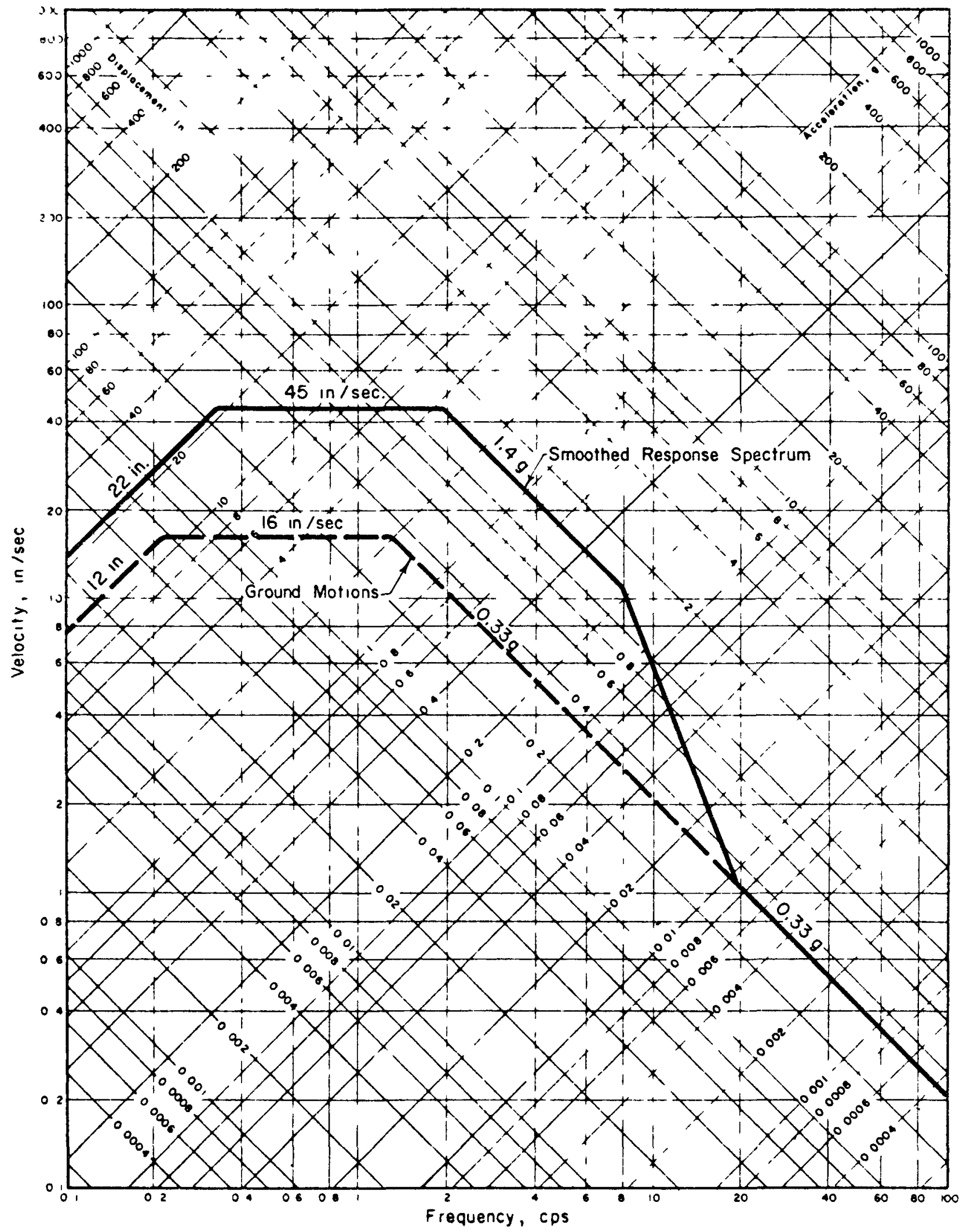

Fig. 8.6 - Smoothed Tripartite Logarithmic Response Spectrum for 0.33 -g Earthquake, 2\% Critical Damping 


\subsubsection{Stationary Process With Specified Power Spectral Density (PSD) Function}

In 1960, H. Tajimi suggested a power spectral density function for earthquakes ${ }^{42}$ based in part on K. Kanai's work ${ }^{43}$. This function is recognized to be more realistic than white noise and is highly recommended. It was adopted in 1964 by G. W. Housner and P. C. Jennings in their earthquake modeling ${ }^{41}$. They filtered a white noise with unit power density through a linear damped system to produce a stationary process with Tajimi's power spectral density function. The results fit Housner's "Average Response Spectra" except in zero and low damping.

In 1965, Arias and Laurent presented an earthquake model obtained by filtering a white noise input through a homogeneous, elastic, and damped single layer soil ${ }^{62}$.

In 1967, Liu and Penzien ${ }^{39,63}$ developed a model for earthquake simulation based on the method of Housner and Jennings, using a Gaussian, random process with Tajimi's power spectral density function. The procedure, which involves the generation of a number of artificial earthquakes through a random generator and linear-filtering process, as described in Fig. 8. 7, has been programmed by Blume Associates ${ }^{38}$ for digital computer use. Using the geological, seismological, and geophysical site data, the site characteristics can be approximately represented by a linear filter. The accelerograms can be obtained by passing through the filter a bandlimited, stationary Gaussian process. This procedure will produce a family of accelerogram records and the response spectra corresponding to these accelerograms can be averaged, this average spectra being used as the design spectra.

This procedure results in an average response spectra which tends to be reasonably "smooth" and continuous, and the family of artificial earthquakes can be used as the time-history input to determine the seismic response of structures. Figure 8.8 shows the average velocity response spectra for 50 records and the spectra variations and confidence limits.

This method, which is applicable to both linear and nonlinear structural models, can be considered as current "state-of-the-art" in the industry.

As demonstrated in the paper by Liu and Penzien ${ }^{63}$, stationary processes of short duration can be used quite effectively to establish the probabilistic peak response of both linear and nonlinear structural systems to strong motion earthquakesof a given intensity level. In the future, however, when the true dynamic characteristics of real structures become better known, damage is likely to be measured using various cumulative damage criteria, in which case it will become more important that appropriate nonstationary processes be developed for damage prediction studies. 


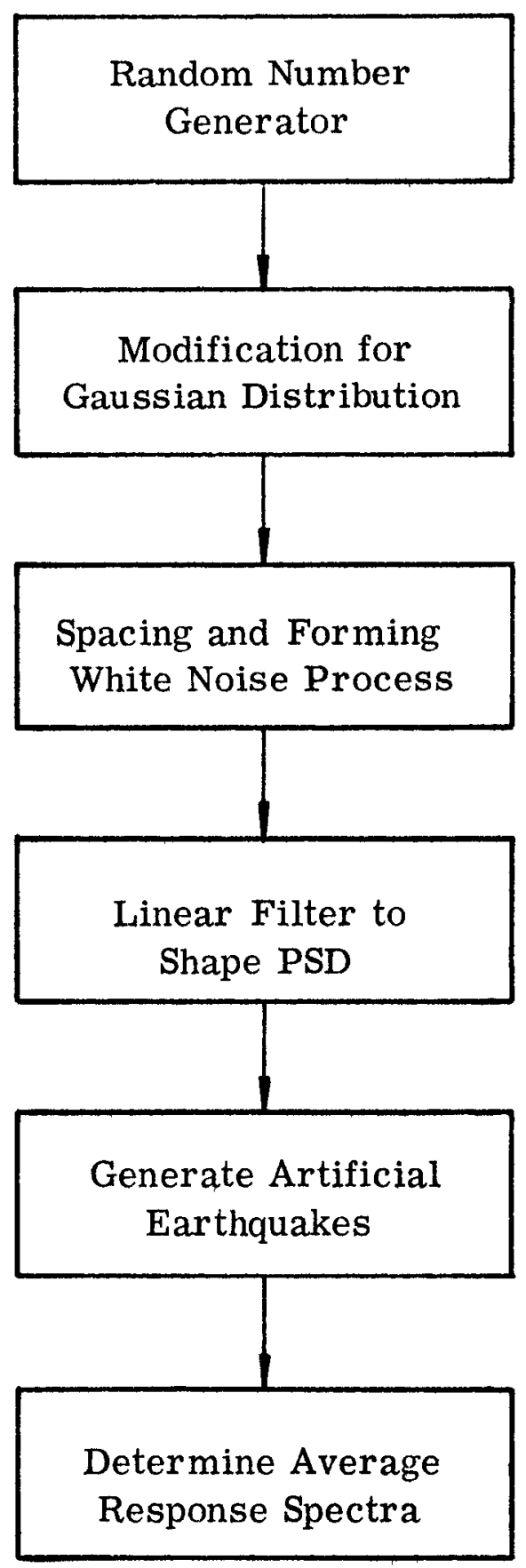

Fig. 8. 7 - Schematic Block Diagram Showing Nondeterministic Procedure to Obtain Artificial Earthquakes and Average Response Spectra 


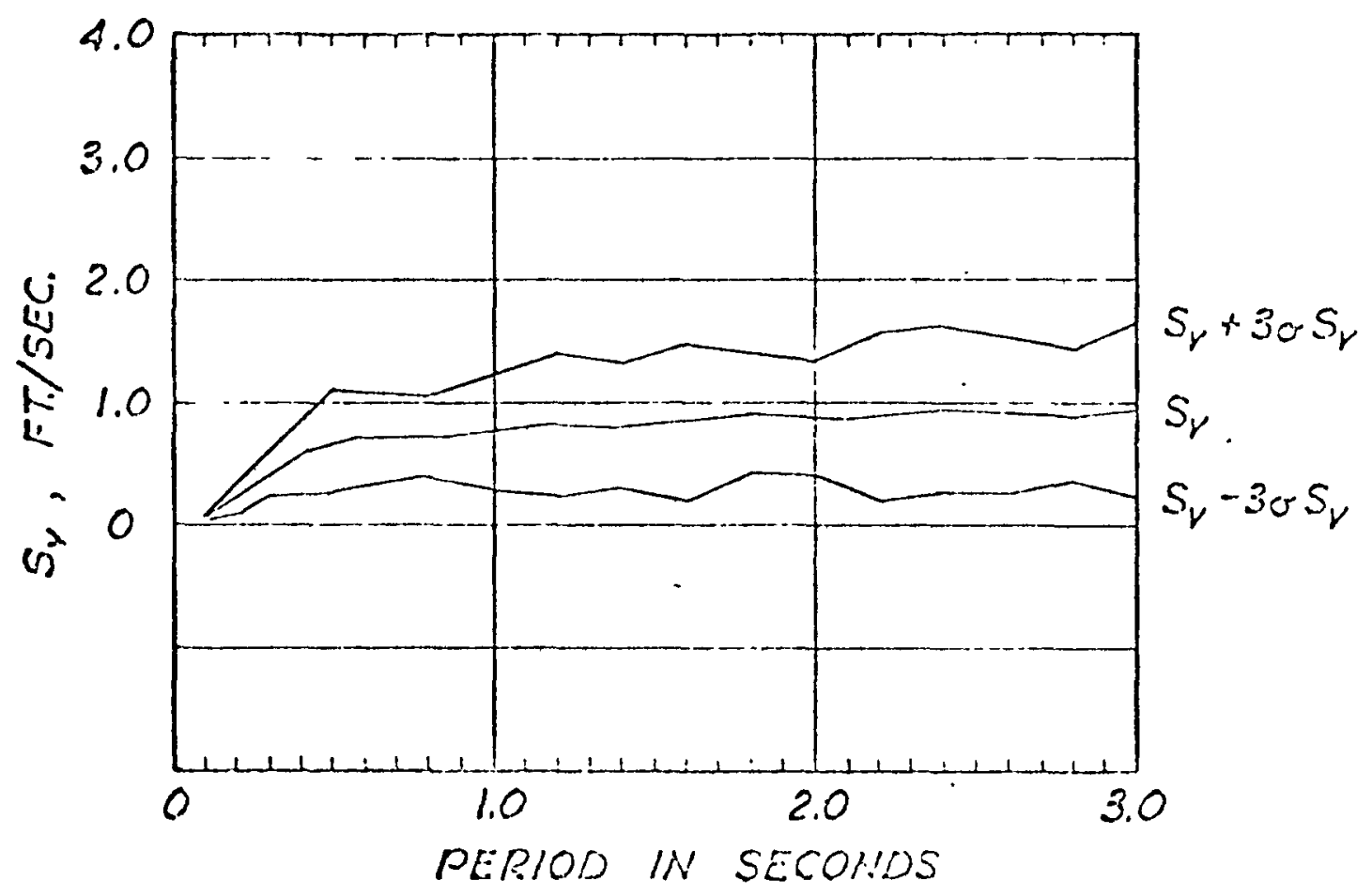

Fig. 8.8 - Variations and Confidence Limits for Average

Velocity Spectra of 50 Artificial Earthquakes, Damping $=0.02$ 


\subsubsection{Nonstationary Process with Filtered or Specified Power \\ Spectral Density Function}

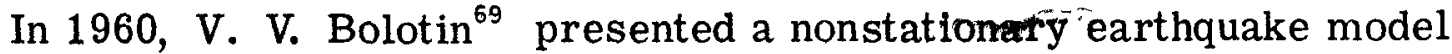
by multiplying a stationary process with a deterministic time function $\psi(t)$ :

$$
\psi(t)=A \mathrm{e}^{-\alpha t}, t>0
$$

where $\mathrm{A}$ and $\alpha$ are constants. A specified power spectral density function and certain earthquake parameters are used.

In 1963, Lin $^{65}$ presented a nonstationary model created by multiplying a stationary white noise process by a time varying intensity function, and then passing this through a selected filter to get the ground motion.

In 1966, Amin and Ang ${ }^{66}$ computed the ensemble variances of the eight earthquake records used by Housner and verified the nonstationarity of earthquake motions. They also simulated the accelerogram by passing Gaussian shot noise through some selected filters, and then compared their results with Housner's average response spectra.

In 1967, Shinozuka used a time function to multiply a stationary process either before or after the filtering. The filtered processes are simple Poisson shot noise ${ }^{67}$. The results are shown to be asymptotically Gaussian processes.

In 1968, Housner \& Jennings ${ }^{68,69}$, Amin \& Ang $^{70}$, and Hou ${ }^{36}$ developed the present nonstationary process with specified power spectral density function. The basic approaches of these different authors are quite similar in simulating the earthquake motion as a nonstationary random process represented as a product of an envelope intensity function (which is a deterministic function of time) and a stationary random process with arbitrary power spectral density developed by Taji $\mathrm{mi}^{42}$. The paper by Housner, et al. ${ }^{68,69,70}$ is more earthquake-simulation oriented, while Hou's paper $^{36}$ is more structural-response oriented for engineering applications.

The widely adopted Tajimi's power spectral density function $S_{0}(\omega)$ is as follows:

$$
S_{O}(\omega)=\frac{a\left(1+4 b^{2} \frac{\omega^{2}}{c^{2}}\right)}{\left(1-\frac{\omega^{2}}{c^{2}}\right)^{2}+4 b^{2} \frac{\omega^{2}}{c^{2}}}
$$

in which $\mathrm{a}, \mathrm{b}$, and $\mathrm{c}$ are constants. In the range from $\omega=2.1 \mathrm{rad} / \mathrm{sec}$. (corresponding to a natural period $T=3$ seconds) to $\omega=21 \mathrm{rad} / \mathrm{sec}$. 
$(\mathrm{T}=0.3$ seconds), these constants are given the values:

$$
a=0.2196 / t_{0} ; \quad b^{2}=0.410 ; \quad c^{2}=242 ;
$$

where: $t_{0}=$ equivalent duration of strong-motion earthquakes, seconds

$$
\begin{aligned}
\mathrm{S}_{\mathrm{O}}(\omega) & =\text { power spectral density, }\left(\mathrm{ft} / \mathrm{sec}^{2}\right)^{2}(\mathrm{rad} / \mathrm{sec})^{-1} \\
\omega & =\text { natural circular frequency of a linear oscillator, } \mathrm{rad} / \mathrm{sec} .
\end{aligned}
$$

The Multi-P model of $\mathrm{Hou}^{36}$ is selected as a typical nonstationary stochastic model. Its assumptions and conclusions are summarized below:

(1) The influence of seismic wave attenuation during the earthquake on the maximum response of simple linear structures is negligible. Thus, for such structural response purposes, the power distribution among different frequencies may be modeled as time invariant. Thus, in such modeling, we may consider the time variation of intensity as the only nonstationarity of the ground motion.

(2) Scaling factors between the "stationary" standard deviation and the expected peak value of the process are developed and used for both nonstationary excitation and response. The simulation results indicate that the observed average of the maximum ground acceleration and of the maximum structural response agree well with the analytically predicted mean values.

(3) The use of the power spectral density function of stationary processes in nonstationary models is based on "local stationarity", that is, that there is a relatively small variation in intensity during a motion of long duration relative to the correlation interval. However, for a structure of light damping or long natural period, the response function has a longer correlation interval. Hence, a "Correlation Correction" and a properly adjusted $\mathrm{C}_{\mathrm{r}}$ are introduced and fit in the response formulation.

(4) The analytical solutions conclude that, for both excitation and linear structural response, the square of the maximum value has a Gumbel distribution. The simulations confirm that, at (at least) a $5 \%$ significance level of the Komogorov and Smirnoff goodness-of-fit test, the distribution may be accepted. Nonetheless, the apparent and expected systematic deviation in the slope or dispersion of the Gumbel distribution curves for the maximum response of lightly damped and long natural period structures is adjusted empirically by "Correlation Corrections" for an even better fit. 
(5) In order to compare the results of the Multi-P nonstationary stochastic model with the deterministic methods of Newmark's Maximum Response Spectra (see Section 8.4.3) and Housner's Average Response Spectra (see Section 8. 4.2), Fig. 8.9 is a plot using the normalized El Centro May 14, 1940 earthquake as an example, showing the response spectrum obtained by these three methods.

The mean response spectrum of the Multi-P modeled earthquakes lies between the recommended design spectra of Newmark and Housner. Newmark's spectrum which is conservative and which is expected to be higher than the mean is very close to the mean plus one standard deviation.

\section{4.6 Nonstationary Processes with Superposition of Waves}

In 1955, Housner suggested that earthquake accelerogram might be modeled by superposition of full-period sine wave pulses occurring at random times ${ }^{71}$.

In 1961, J. L. Bogdanoff, J. E. Goldberg, and M. C. Bernard simulated some nonstationary accelerograms using superposition of continuous sinusoidal waves ${ }^{72}$. The amplitude of the waves vary deterministically with time, but the phase angle $\phi_{i}$ is a uniformly distributed random variable uniformly distributed over the interval

$$
x(t)=\sum_{i=1}^{n} a_{i} t e^{-\alpha_{i} t} \cos \left(\omega_{i} t+\phi_{i}\right), \quad t>0
$$

where $a_{i}, \alpha$, and $\omega_{i}$ are deterministic. Since $\alpha_{i} s$ are dependent on $\omega_{i}$, the effects of time variation in frequency could be included in such a model.

In 1964, Bogdanoff, Goldberg, and Sharp modified the previous model by considering $\omega_{j}$ as an additional random variable with uniform distribution over the interval from 6 to 46 radians per second ${ }^{73}$.

In 1966, Oto factored out the terms concerning the time variation of amplitudes as follows:

$$
x(t)=\operatorname{ate}^{-\alpha} \mathrm{i}_{\mathrm{i}} \sum_{\mathrm{i}=1}^{\mathrm{n}} \cos \left(\omega_{i} \mathrm{t}+\phi_{i}\right), \quad \mathrm{t}>0
$$

In 1968, Rascon and Cornel1 ${ }^{74,75}$ developed a model using the superposition of randomly occurring double-looped waves and nonhomogeneous filtered Poisson processes as suggested by Cornell in $1964^{75}$. 


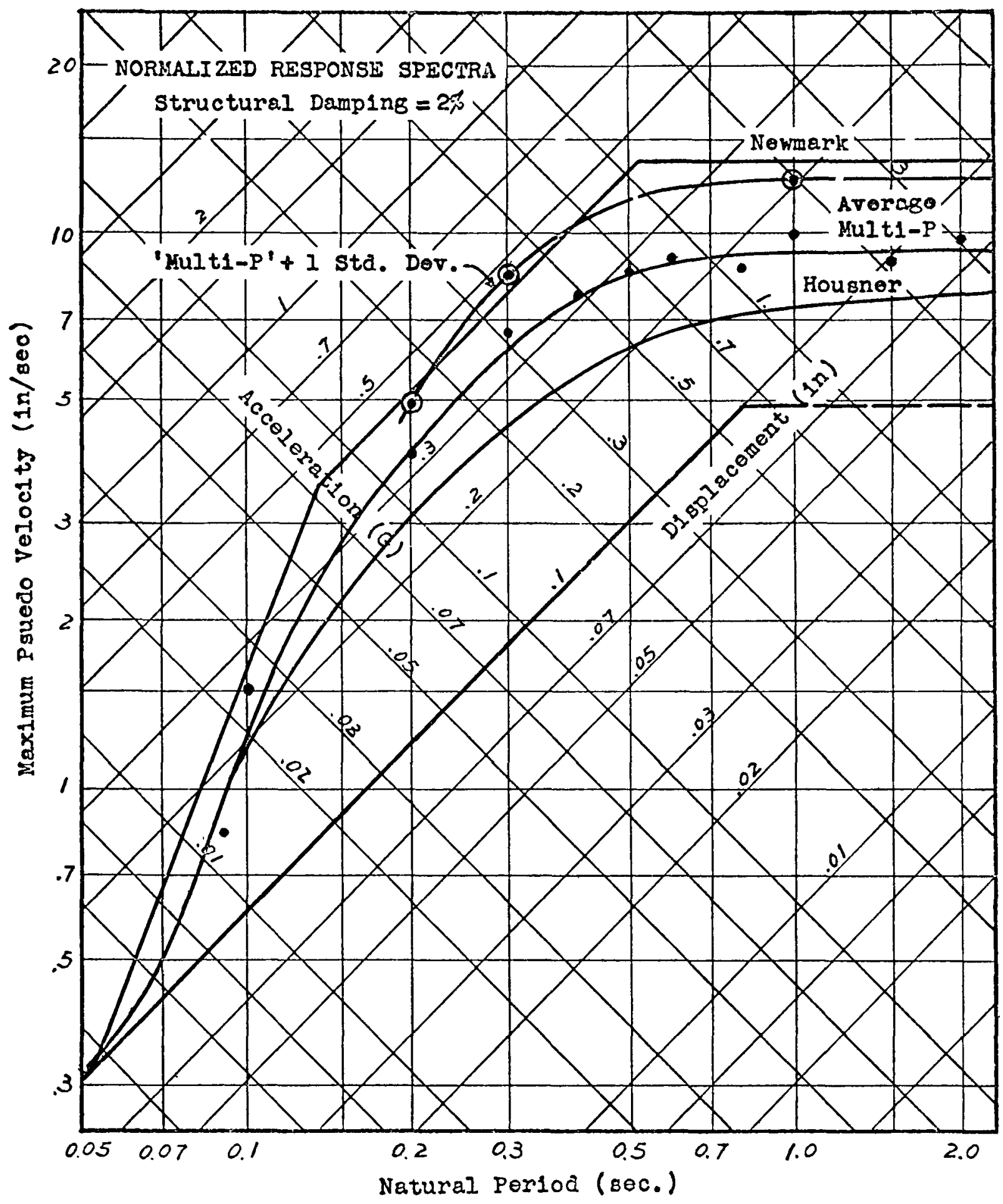

Fig. 8.9 - Normalized Response Spectra of El Centro 1940 Earthquake 
The modeling techniques of this method are beyond the point of simulating a "typical" earthquake record and are moving toward a broad consideration of basic earthquake properties for a simulation of general earthquake motions. Thus it may presently be considered as the most advanced state-of-the-art. This model permits generation of records of strong earthquakes with prescribed magnitudes on firm ground at moderate and large distances and with any orientation relative to the causative fault.

In comparison with previous stochastic earthquake models that have been evaluated by fitting the average response spectra or the autocorrelation function to the corresponding functions observed in real records, these models have not introduced explicitly most of the relevant physical characteristics of earthquakes. These factors include magnitude, type of source, relative position between site and source, types of waves and their attenuation during transmission, multiple wave reflection, etc. These characteristics determine such earthquake parameters as maximum ground acceleration, duration of the motion, arrival times of the different types of waves, periods of amplitudes of waves, etc., which, at the same time, cause a time variation of both the frequency content and the intensity of the motion. Consideration of both of these two variations in a model for simulating seismic motions would permit more accurate study of their effects on the response of structures, particularly those structures with nonlinear behavior, whose periods of vibration change with the amplitude of oscillation.

The general flow chart of the method of superposition of waves to simulated earthquake strong motion ${ }^{74}$ is shown in Fig. 8. 10. 


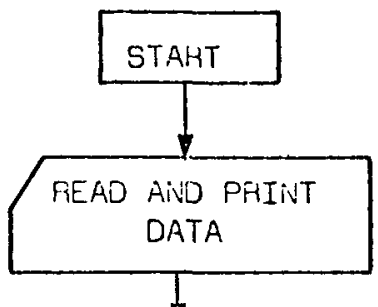

COA.APUTATION OF THE PARARIETERS DEFINING THE GEO:ETRY OF THE PROELEIA: LENGTH OF THE FAULT NUMBER OF ELEIIENTARY SOURCES, ELENENTARY WAGNITUDE, FOCAL DISTAINCES OF ELEINENTARY SOURCES GENERATION TIMES OF ELEISENTARY EARTHOUJAKES, FIRST ARRIVAL TIMES OF P AND $S$ V'AVES.

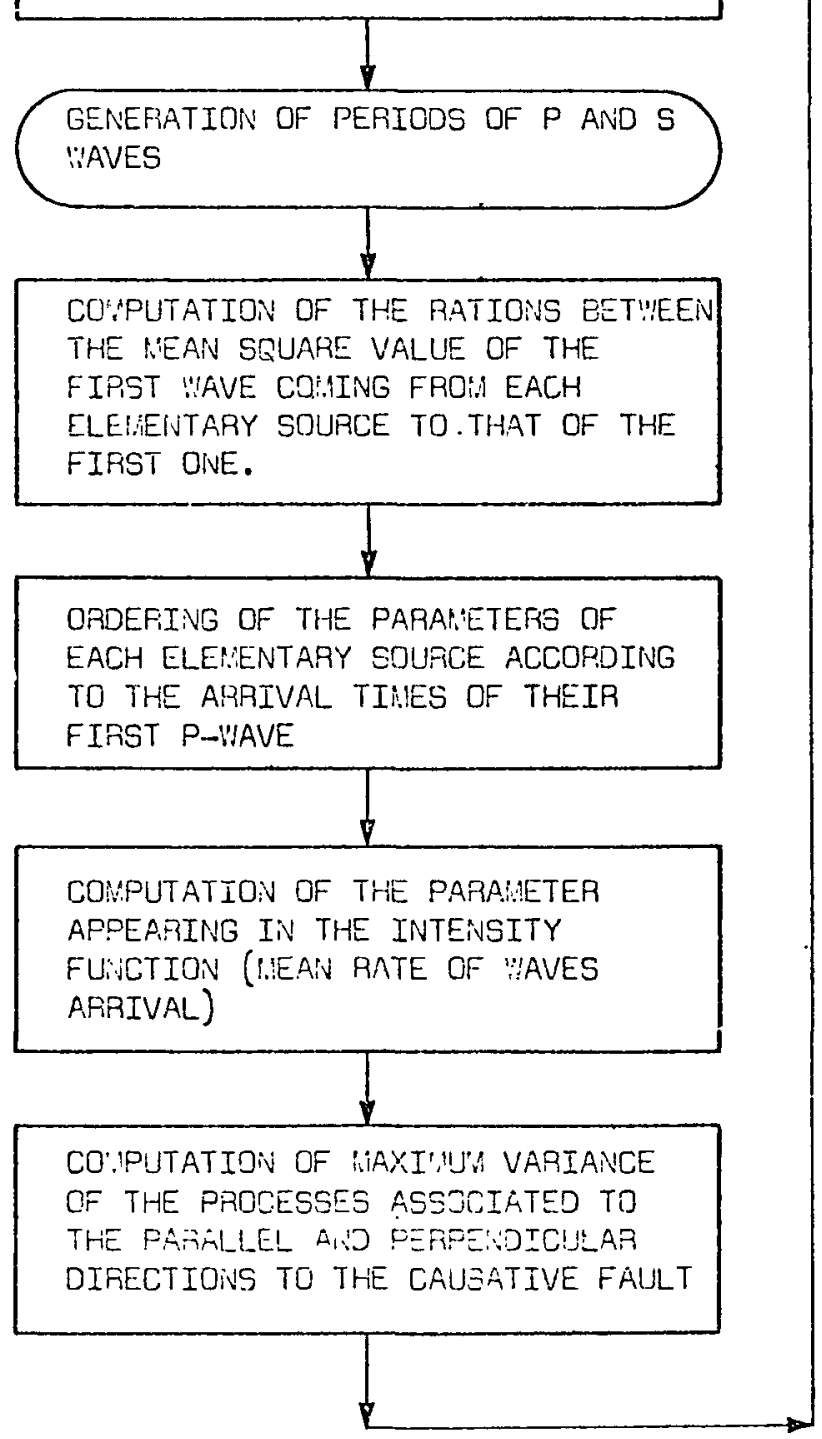

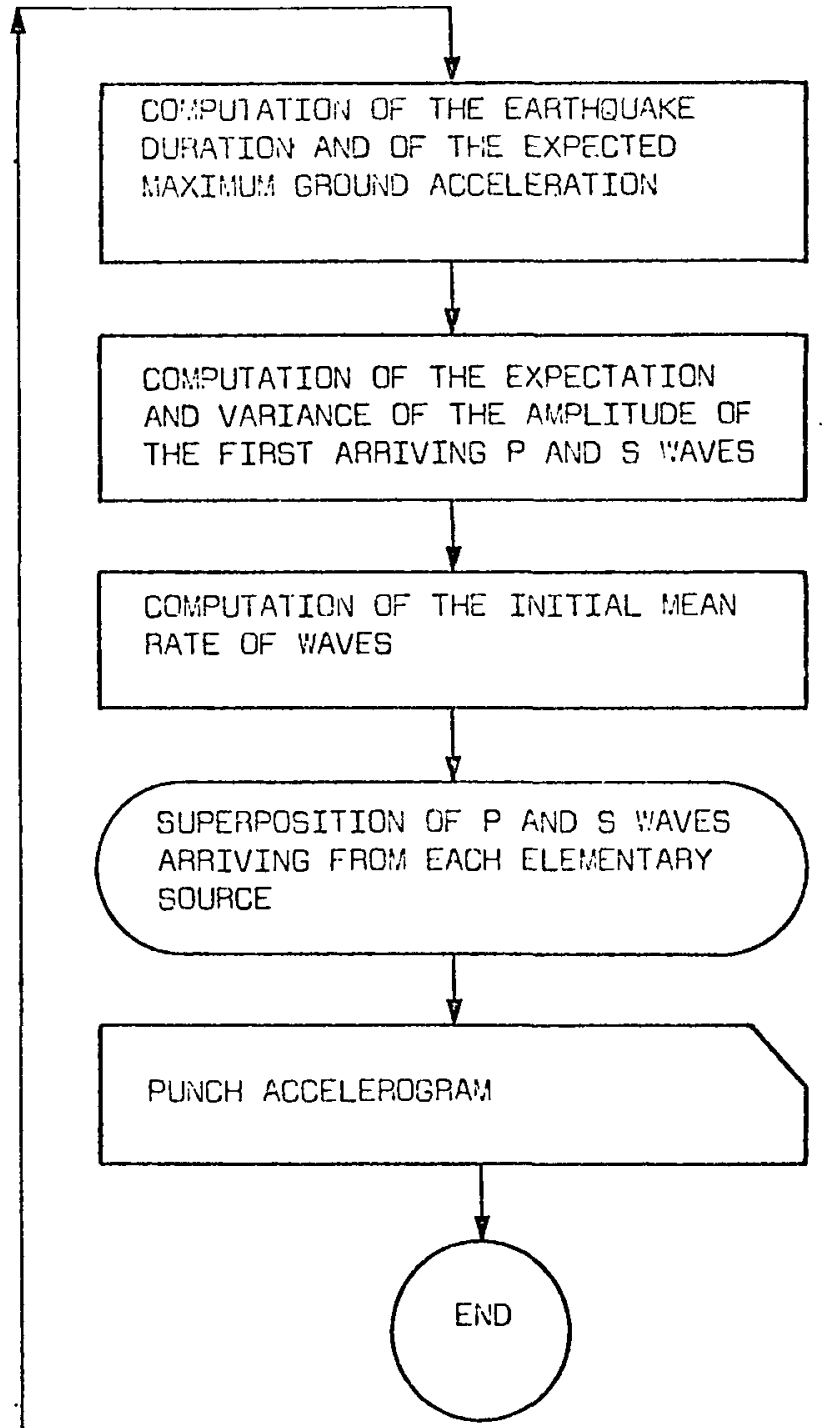

Fig. 8.10 - Digital Computer Program: General Flow Chart (Wave-Superposition Method of Earthquake Motion Simulation) 


\section{METHODS OF SOLUTION}

\subsection{STEADY-STATE PROBLEMS}

Computational procedures for calculating the dynamic responses in a stationary process, which includes both the sinusoidal and random forced vibrations, are briefly described as follows:

\subsubsection{Sinusoidal Vibration}

A forced sinusoidal vibration problem is completely defined by a set of equations of motion of the mechanical system as following:

$$
[\mathrm{M}]\{\ddot{\mathrm{q}}\}+[\mathrm{C}]\{\dot{\mathrm{q}}\}+[\mathrm{K}]\{\mathrm{q}\}=\{\mathrm{F} \sin (\omega \mathrm{t}+\gamma)\}
$$

where $[\mathrm{M}],[\mathrm{C}],[\mathrm{K}]=$ inertia, viscous damping, and stiffness matrix, respectively, in generalized coordinates

$\{\mathfrak{q}\},\{\dot{q}\},\{\ddot{q}\}=$ responses, in generalized displacement, velocity, and acceleration, respectively.

$\{\mathrm{F} \sin (\omega t+\gamma)\}=$ input sinusoidal forcing function vector (prescribed excitation)

$\{\gamma\}=$ phase angle vector associated with forcing function vector

$\mathrm{t}=$ time, sec

$\omega=2 \pi \mathrm{f}=$ circular frequency in sinusoidal excitation

$f=$ frequency, cps.

In order to solve the steady-state responses $\{\mathrm{q}\}$ of Eq. 9.1, which is also sinusoidal in the same frequency as $\{F \sin (\omega t+\gamma)\}$, let 


$$
\begin{aligned}
\{q\} & =\{A \sin (\omega t+\alpha)\}=\{A \cos \alpha\} \sin \omega t+\{A \sin \alpha\} \cos \omega t \\
& =\{\eta\} \sin \omega t+\{\beta\} \cos \omega t
\end{aligned}
$$

where $\{\eta\}=\{A \cos \alpha\}$,

$\{\beta\}=\{A \sin \alpha\}$.

$$
\begin{aligned}
\{F \sin (\omega t+\gamma)\}= & {\left[\left\{\mathbf{R}_{1}\right\}+\left\{\mathbf{R}_{2} / \omega^{2}\right\}+\left\{\mathbf{R}_{5} \omega^{2}\right\}\right] \cdot \sin \omega t+\left[\left\{\mathbf{R}_{3} \omega\right\}\right.} \\
& \left.+\left\{\mathbf{R}_{4} / \omega\right\}\right] \cdot \cos \omega t
\end{aligned}
$$

where $\left\{\mathbf{R}_{1}\right\},\left\{\mathbf{R}_{2}\right\},\left\{\mathbf{R}_{3}\right\},\left\{\mathbf{R}_{4}\right\},\left\{\mathbf{R}_{5}\right\}$ are constant vectors determined by the prescribed input forcing functions (see below).

By substituting Eqs. 9.2 and 9.3 into Eq. 9.1, we obtain

$$
\left[\begin{array}{rr:r}
{[\mathrm{K}]} & -\omega^{2} \cdot[\mathrm{M}] & -\omega[\mathrm{C}] \\
\omega[\mathrm{C}] & {[\mathrm{K}]} & -\omega^{2} \cdot[\mathrm{M}]
\end{array}\right]\left[\begin{array}{l}
\{\eta\} \\
\{\beta\}
\end{array}\right]=\left\{\begin{array}{l}
\left\{\mathrm{R}_{1}+\mathrm{R}_{2} / \omega^{2}+\mathrm{R}_{5} \omega^{2}\right\} \\
\left\{\mathrm{R}_{3} \omega+\mathrm{R}_{4} / \omega\right\}
\end{array}\right]
$$

We then proceed to calculate at each given $\omega_{\mathrm{i}}$ (where $\left.\omega_{\mathrm{i}}=2 \pi \mathrm{f}_{\mathrm{i}}\right)$ :

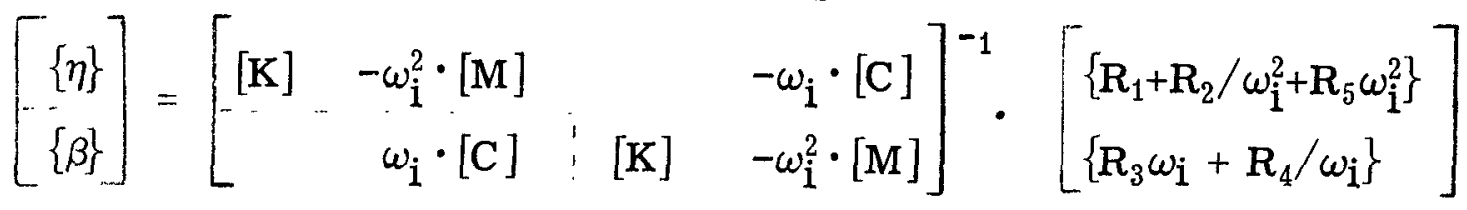

By using the relations defining $\{\eta\},\{\beta\}$, and $\{\alpha\}$ in Eq. 9.2 at the $\mathrm{j}^{\text {th }}$ coordinate and $\omega=\omega_{\mathrm{i}}$ :

$$
\begin{aligned}
& \mathrm{A}_{\mathrm{j}}=\sqrt{\eta_{\mathrm{j}}^{2}+\beta_{\mathrm{j}}^{2}}, \\
& \alpha_{\mathrm{j}}=\tan ^{-1}\left(\beta_{\mathrm{j}} / \eta_{\mathrm{j}}\right)
\end{aligned}
$$

To clarify $\left\{\mathbf{R}_{1}\right\},\left\{\mathbf{R}_{2}\right\}, \ldots,\left\{\mathbf{R}_{5}\right\}$, it is necessary to look into the input excitation magnitude $P$, and keep in mind that output $A_{j}$ is the displacement $\underline{\text { response }}$ at $j^{\text {th }}$ coordinate due to a constant input $P$. 
Suppose we set $\mathbf{P}=1.0$. If this is regarded as a unit sinusoidal displacement of 1.0 sin $\omega t$ (in.), then its velocity is $1.0 \omega \cos \omega t$, and its acceleration is $-1.0 \omega^{2} \sin \omega t$. Thus, the input forcing function may include $\left\{1.0 R_{1} \sin \omega t\right\}$, and/or $\left\{1.0 \omega R_{3} \cos \omega t\right\}$, and/or $\left\{1.0 \omega^{2} R_{5} \sin \omega t\right\}$, where $\left\{R_{1}\right\}=$ exciting force vector per unit displacement at $P=1.0$ sin $\omega t$ (displacement)

$\left\{R_{3}\right\}=$ exciting force vector per unit velocity at $P=1.0$ sin $\omega t$ (displacement)

$\left\{R_{5}\right\}=$ exciting force vector per unit acceleration at $\mathbf{P}=1.0 \mathrm{sin} \omega t$ (displacement).

In this case, dimensions of $R_{1}, R_{3}$, and $R_{5}$ are the spring constant, viscous damping constant, and inertia, respectively.

It is generally convenient to set $P=1.0$ and regard it as $1.0 \sin \omega t$ displacement, so that by definition:

$$
T_{j}=\frac{A_{j}}{P}=\frac{A_{j}}{1.0} \equiv A_{j}
$$

where $T_{j}\left(\omega_{i}\right)=$ transmissibility of $j^{\text {th }}$ coordinate at $\omega=\omega_{i}$.

$$
\mathrm{T}_{\mathbf{j}}\left(\omega_{\mathrm{i}}\right)=\frac{\text { Output displacement (or velocity, or acceleration) }}{\text { Input displacement (or velocity, or acceleration) }} .
$$

In summary, a transmissibility function $T_{j}(\omega)$ at any coordinate $j$ can be obtained by computing $A_{j}$ in as many $f_{i}$ 's as is desired.

\subsubsection{RMS Responses of Stationary Random Vibrations}

The properties of stationary random vibrations are summarized as follows:

1. The response of a structure to a narrow frequency-band random vibration follows the same rules as for a sinusoid, and the response of a structure to several narrow-band sections of random vibration follows the same rules as for several sinusoids.

2. The statistical vibration magnitude ( $\mathrm{rms}$ acceleration, displacement, or velocity) between any two frequency limits of a band is equal to the square root of the area in that band under the power spectrum. 
3. If a structure is excited by a random vibration having a Gaussian distribution, then the linear response also will have a Gaussian distribution.

Usually, the input excitation quantity in random vibration is specified by the experimental units $S_{E}(f)$ ' 'Mean Square $\sigma^{2} /$ cps'" between frequencies $f_{1}$ and $f_{2} . S_{E}(f)$ can be power spectral density, $g^{2} / c p s$, $\mathrm{in}^{2} / \mathrm{cps}$, or (in./sec) $)^{2} / \mathrm{cps}$. Since the mean square response of a structure to a narrow band (df) of random vibration is the same as its mean square response to a sinusoid, or

$$
d R_{j}=T_{j}^{2}(f) S_{E}(f) d f
$$

Therefore,

$$
R_{j}=\int_{f_{1}}^{f_{2}} T_{j}^{2}(f) S_{E}(f) d f
$$

where $R_{j}=$ mean square response at coordinate $j$ to wide band random vibration between $f_{1}$ and $f_{2}$

$\sqrt{R_{j}}=$ rms response at coordinate $j$.

Numerical integration of Eq. 9.8 by Simpson's Rule can be programmed into a digital computer program to compute $R_{j}$ and the square root of $R_{j}$ from the specified $S_{E}(f)$ and $f_{1}$ and $f_{2}$ inputs submitted.

\subsubsection{RMS Response of $\{\mathbf{s}\}$}

The mean square and the rms values for quantities which may represent shear, bending moment, or spring force, etc., can be determined. We denote these quantities as a vector $\{\mathbf{s}\}$ and express it as a linear combination of displacement, velocity, acceleration, and force as follows:

$$
\{\mathbf{s}\}=[\mathrm{a}]\{\mathrm{q}\}+[\mathrm{b}]\{\dot{\mathrm{q}}\}+[\mathrm{d}]\{\mathrm{F} \sin (\omega \mathrm{t}+\gamma)\}-[\mathrm{M}]\{\ddot{\mathrm{q}}\}
$$

Eq. 9.10 can be rearranged into the following form: 


$$
\{S\}=\{S \sin (\omega t+\phi)\}=\{D\} \sin \omega t+\{E\} \cos \omega t
$$

Transmissibility for the quantity $\{\mathbf{s}\}$ is defined as

$$
\bar{T}_{j}=\frac{S_{j}}{P} .
$$

Hence, the mean square and the root mean square values of the quantity $\{s\}$ are, respectively,

$$
\begin{aligned}
& \bar{R}_{j}=\int_{f_{1}}^{f_{2}}\left(T_{j}\right)^{2} S_{E} d f \\
& \sqrt{\bar{R}_{j}}=\sqrt{\int_{f_{1}}^{f_{2}}\left(T_{j}\right)^{2} S_{E} d f}
\end{aligned}
$$

The integration routines in Eq. 9.13 may be computed numerically by Simpson's Rule.

\subsection{TRANSIENT PROBLEMS}

Transient excitations, such as a half-sine pulse mechanical shock, can be represented by forcing functions $F(t)$. The methods of numerical computation of dynamic responses under transient loads by digital computer generally fall into the following two categories, namely: (1) the normal mode method; and (2) the numerical time-step integration method. The development of optimized computational procedures has been continuing in recent years as the core storage capacity and the speed of digital computers increases. Since most of the computer programs available from either industry or research institutes are proprietary, the description of both methods will be only of typical mathematical procedure as follows.

\subsubsection{Normal Mode Method}

Given the damped equations of motion of a system of $n$ degrees of freedom: 


$$
[\mathrm{M}]\{\ddot{\mathrm{q}}\}+[\mathrm{C}]\{\dot{\mathrm{q}}\}+[\mathrm{K}]\{\mathbf{q}\}=\{\mathbf{F}(\mathrm{t})\}
$$

By using the methods of modal analysis and modal damping described in Sections 6 and 7, we can transform Eq. 9.15 into n decoupled equations of motion in normal coordinates $\mathrm{y}$ as follows:

$$
\ddot{\mathrm{y}}_{\mathrm{r}}=2 \xi \omega_{\mathrm{r}} \dot{\mathrm{y}}_{\mathrm{r}}+\omega_{\mathrm{r}}^{2} \mathrm{y}_{\mathrm{r}}=\mathrm{Q}_{\mathrm{r}}(\mathrm{t}), \quad \mathrm{r}=1, \ldots, \mathrm{n}
$$

where $\mathrm{y}_{\mathrm{r}}=$ normal coordinate of $\mathrm{r}^{\text {th }}$ mode, defined by Eq. 6.13

$\xi=$ percent of critical damping

$$
\left.\mathrm{Q}_{\mathrm{r}}(\mathrm{t})=\phi_{1}^{(\mathrm{r})}, \ldots, \phi_{\mathrm{n}}^{(\mathrm{r})}\right\rfloor\{\mathrm{F}(\mathrm{t})\}=\text { generalized force of } \mathrm{r}^{\mathrm{th}} \text { mode }
$$

$\omega_{\mathrm{r}}=$ natural frequency of $\mathrm{rth}$ mode.

The solution of Eq. 9.16 can be obtained readily by the use of the Laplace Transform and is given as follows (see Reference 32, for example):

$$
\mathrm{y}_{\mathrm{r}}(\mathrm{t})=\frac{1}{\omega_{\mathrm{r}}} \int_{0}^{\mathrm{t}} \frac{\mathrm{e}^{\xi \omega_{\mathrm{r}}(\mathrm{t}-\tau)}}{\sqrt{1-\xi^{2}}} \sin \left[\omega_{\mathrm{r}} \sqrt{1-\xi^{2}}(\mathrm{t}-\tau)\right] \mathrm{Q}_{\mathrm{r}}(\tau) \mathrm{d} \tau
$$

For a lightly damped system of $\xi \leqslant 5 \%$, Eq. 9.17 can be approximated by:

$$
\mathrm{y}_{\mathbf{r}}(\mathrm{t})=\frac{1}{\omega_{\mathrm{r}}} \int_{0}^{\mathrm{t}} \mathrm{e}^{-\xi \omega_{\mathrm{r}}(\mathrm{t}-\tau)} \sin \left[\omega_{\mathrm{r}}(\mathrm{t}-\tau)\right] \mathrm{d} \tau
$$

The parameter $\tau$ is a dummy parameter which vanishes during the integration operation. Eq. $9.18 \mathrm{can}$ be integrated numerically (or by closed-form solution) by digital computer codes. The dynamic responses $\{q(\mathrm{t})\}$ can be readily computed from Eq. 6.13, and $\{q\}=[\phi]\{y\}$. Generally, only the lowest few normal modes in a complex system are excited and predominant in calculating $\{q(t)\}$. Many computer programs only compute and use these lower modes. As a typical example, the computer program 1384 on modal analysis of a dynamic system, developed by AVCO Missile Systems Division, uses up to $30^{\text {th }}$ mode to calculate dynamic responses for systems up to 100 degrees of freedom. 


\subsubsection{Numerical Time-Step Integration}

The procedure using the Runge-Kutta method $^{22,45}$ to solve the equations of motion is as follows:

$$
[\mathrm{M}]\{\ddot{\mathrm{q}}\}+[\mathrm{C}]\{\dot{\mathrm{q}}\}+[\mathrm{K}]\{\mathfrak{q}\}=\{\mathrm{F}(\mathrm{t})\}
$$

The equations are transformed into a set of first order equations which may be represented in normal form as:

$$
\{\dot{\gamma}\}=\left\{\begin{array}{l}
\dot{\mathbf{P}} \\
\dot{\mathrm{q}}
\end{array}\right\}=\left[\begin{array}{l}
\mathrm{M}^{-1}[\mathrm{~F}(\mathrm{t})-\mathrm{C} \dot{\mathrm{q}}-\mathrm{Kq}] \\
\mathrm{P}
\end{array}\right\}
$$

Eqs. 9.20 are numerically integrated by the method of Runge-Kutta, which is a single-step method and therefore does not require a starting solution of a Taylor series expansion. The 4th order Runge-Kutta formula is as follows:

$$
\begin{aligned}
& q_{n+1}=q_{n}+\frac{1}{6}\left(K_{1}+2 K_{2}+2 K_{3}+K_{4}\right) \\
& q_{n+1}^{\prime}=q_{n}^{\prime}+\frac{1}{6}\left(K_{1}^{\prime}+2 K_{2}^{\prime}+2 K_{3}^{\prime}+K_{4}^{\prime}\right)
\end{aligned}
$$

where $\mathrm{h}=$ time-step

$$
\begin{aligned}
& \mathrm{K}_{\mathrm{1}}=\mathrm{h} \mathrm{q}_{\mathrm{n}}^{\prime} \\
& \mathrm{K}_{2}=\mathrm{h}\left(\mathrm{q}_{\mathrm{n}}^{\prime}+1 / 2 \mathrm{~K}_{1}^{\prime}\right) \\
& \mathrm{K}_{3}=\mathrm{h}\left(\mathrm{q}_{\mathrm{n}}^{\prime}+1 / 2 \mathrm{~K}_{2}^{\prime}\right) \\
& \mathrm{K}_{4}=\mathrm{h}\left(\mathrm{q}_{\mathrm{n}}^{\prime}+\mathrm{K}_{3}^{\prime}\right) \\
& \mathrm{K}_{1}^{\prime}=\mathrm{hP}\left(\mathrm{T}_{\mathrm{n}}, \dot{\mathrm{q}}_{\mathrm{n}}, \dot{\mathrm{q}}_{\mathrm{n}}\right) \\
& \mathrm{K}_{2}^{\prime}=\mathrm{P}\left(\mathrm{T}_{\mathrm{n}}+1 / 2 \mathrm{~h}, \mathrm{q}_{\mathrm{n}}+1 / 2 \mathrm{~K}_{1}, \mathrm{q}_{\mathrm{n}}^{\prime}+1 / 2 \mathrm{~K}_{1}^{\prime}\right) \\
& \mathrm{K}_{3}^{\prime}=\mathrm{hP}\left(\mathrm{T}_{\mathrm{n}}+1 / 2 \mathrm{~h}, \mathrm{q}_{\mathrm{n}}=1 / 2 \mathrm{~K}_{2}, \mathrm{q}_{\mathrm{n}}^{\prime}+1 / 2 \mathrm{~K}_{2}^{\prime}\right) \\
& \mathrm{K}_{4}^{\prime}=\mathrm{hP}\left(\mathrm{T}_{\mathrm{n}}+\mathrm{h}, \mathrm{q}_{\mathrm{n}}+\mathrm{K}_{3}, \mathrm{q}_{\mathrm{n}}^{\prime}+\mathrm{K}_{3}^{\prime}\right)
\end{aligned}
$$


The time-step numerical integration procedure of the differential equations of motion (Eq. 9.15), with given initial values, is based on the repetition of a sequence of operations which uses the last computed value, say $\mathrm{y}_{\mathrm{n}}$, to obtain the next value $\mathrm{y}_{\mathrm{n}+1}$ of the requested function. If the result of each sequence of operations is affected by an error, the error usually is cumulative and the $\mathrm{n}^{\text {th }}$ value of $\mathrm{y}$ is affected by an accumulated error. If the rate of accumulation decreases, so that the error is bounded, the sequence of operation is said to be stable. Furthermore, even if the accumulated error increases, the accumulated relative error, that is, the error divided by $y$, may decrease so that the solution may still be meaningful for practical applications. Therefore, in order to control the stability and maintain the accuracy of computations, the following procedures ${ }^{45}$ are followed:

If a procedure using Runge-Kutta formula of $4^{\text {th }}$ order accuracy gives an ordinate $\mathrm{y}^{(1)}$ with two time-steps of $\mathrm{h} / 2$, and an ordinate $\mathrm{y}^{(2)}$ with time-step $h$, the error in $\mathrm{y}^{(1)}$ is approximately

$$
\frac{y^{(1)}-y^{(2)}}{(2)^{4}-1}
$$

and is added to $\mathrm{y}^{(1)}$ to give a better approximation. ${ }^{22}$

In actual computation, if we choose $h$ as the first time-step, the computer program is coded to perform two time-steps of $h$ and $h / 2$. The error estimate will be:

$$
E=\frac{y^{(1)}-y^{(2)}}{15}
$$

In order to improve $\mathrm{y}^{(1)}$, the error, E, is added

$$
y=y^{(1)}+E
$$

The relative error is next computed for each coordinate:

$$
\begin{aligned}
& R_{i}=\left|E_{i} / y_{i}\right| \\
& R=\max \left|R_{i}\right|, \quad i=1, \ldots, n
\end{aligned}
$$


$R$ is defined as "maximum relative error" (m.r.e), and is tested against two bounds, $E_{1}$ and $E_{2}$, to control the step size and error. $E_{1}$ is used to keep the interval from becoming too large. After testing the m。r.e. against $E_{1}$ and $E_{2}$, the program either halves the interval and repeats the step, continues at the same interval, or continues at twice the previous interval. In other words, we can designate the expected accuracy of the results, as accurately as we wish, by specifying $E_{1}$ and $E_{2}$. Of course, more accurate results will require longer computer processing time.

There are many other methods of approximation such as those which replace the first and second derivatives of displacement in the differential equations of motion. Levy ${ }^{46}$ employed the first and second central finite difference to replace, respectively, the first and second derivative of the differential equation of motion, while M. Salvadori ${ }^{47}$ replaced the second derivative by the first two terms of the central difference expansion consisting of the second and fourth central differences of displacements. J. Houbolt' ${ }^{48}$ method is based on the assumption of a cubic curve for the displacement of the moving body, considering that four excessive ordinates can be passed through by a cubic curve. Chan, Cox, and Benfield ${ }^{49}$ adopted the procedures developed by Newmark ${ }^{50}$ to compute the responses of shells of revolution under dynamic loading. This method was later adopted by S. Klein ${ }^{51}$ as the formulation of the DRASTIC computer program of the Aerospace Corporation.

It is not easy to compare the virtues of the classical normal mode method and the numerical time-step integration method, such comparisons depend upon the type and the size of problems involved. From the author's experience in the Runge-Kutta method used in time-step integration, it has the advantage of better accuracy as well as the ability to solve nonlinear problems, where the forcing function becomes $\{F(t, q, \dot{q})\}$. The normal mode method can solve only the linear problem, where the forcing function is $\{F(t)\}$. On the other hand, the normal mode method has the advantage of being able to handle a system with a larger number of degrees of freedom, in less computer time, by computing only the lower few modes. However, these computations do not have the benefit of an accuracy check. 


\section{DIGITAL COMPUTER PROGRAMS}

As indicated in Section 2, the computation of the dynamic responses of piping systems from a practical design standpoint makes the use of a computer mandatory. Analog computers may be used to solve for the system responses under dynamic loads, but the predominant industry practice is to solve such problems using digital computer programs.

The descriptions of computer programs described on the following pages have been obtained primarily from a survey of the literature, including such sources as reports and descriptive literature of COSMIC (University of Georgia), Franklin Institute Research Laboratory (FIRL), United Nuclear Corporation, AVCO Corporation, IBM Service Bureau, and the Electric Boat Division of General Dynamics Corporation. This survey work is continuing, and the authors of promising programs are being contacted to obtain more descriptive information and to answer the usual proprietary questions.

The following sections present abstracts of applicable programs identified thus far in the survey.

\subsection{COSMIC PROGRAM NUMBER MFS-2226}

Three-Dimensional Multiple Degree of Freedom Vibration of Hydraulic Lines Excited by Forced Displacements (North American Aviation - S \& ID)

This program determines the forced vibration in three-dimensional space of a multiple degree of freedom beam-type structural system. Pro- 
vision is made for the longitudinal axis of the analytical model to change orientation at any point along its length. In addition, either support of forcing input in any direction, or combination of directions, at any such point also may be provided for. Readout may be either tabular of CRT plotted.

This program was written in four parts: (1) Three-Dimensional Modal Beam Program; and (2) Beam Response Program; (3) ThreeDimensional Static Beam Program; and (4) Vibration of Lines Excited by Forced Displacement.

The first program has been developed to determine the natural frequencies and the associated three-dimensional modal vectors of a system of beam segments, concentrated masses, and springs.

The Beam Response Program has been developed to determine the steady-state response to sinusoidal forcing functions of structures whose natural frequencies and modal vectors are determined by the Three-Dimensional Modal Beam Program. The method used is the socalled generalized coordinate method.

The third program has been developed to determine the threedimensional static deflections of a system of beam segments and springs acted upon by concentrated forces and bending moments. The coordinates and vectors are set up as is the Modal Beam Program.

In the last program, as a portion of the analysis performed on the Saturn S-II, it is necessary to determine the vibration response of various lines. It is assumed that each line may be treated as a separate component deriving its vibration input through its supporting bracketry from the primary structure.

Language

Machine Requirements

Number of Cards
FORTRAN IV (70\%), MAP (30\%)

IBM 7090/7094

Approximately 6119 


\subsection{COSMIC PROGRAM NUMBER NPO-10129}

A Modal Combination for Dynamic Analysis of Structures (Jet Propulsion Laboratory)

The response of a composite linear structure subjected to lowfrequency sinusoidal base motion of a restrained structure or subjected to frequency sinusoidal forces at points of a free structure is determined by this program. The intention in developing the program was primarily to determine the undamped modes of a composite structure and secondarily to get response of sinusoidal forcing functions, which were required for problems related to current testing practices and closed loop stability of autopilot controlled space vehicles. Models of components in forms of geometry, normal modes, frequencies, lumped masses, and elastic properties are required. Systems are developed from the components when the required compatibility with the composite is imposed.

Language

Machine Requirements

Number of Cards
FORTRAN IV $(97 \%), \operatorname{MAP}(3 \%)$

IBM 7094

Approximately 3995

\subsection{IBM SERVICE BUREAU CORPORATION}

(Also listed by COSMIC Program No. NPO-10502) STIFF-EIG - Stiffness Matrix Structural Analysis (Developed by Jet Propulsion Laboratory)

This program was developed for the analysis of structural frameworks. It generates the stiffness matrix for a particular type of structure from geometrical data and performs static and normal mode analyses.

The program defines a structural network as a stable system of uniform, weightless members, and joints at which loads are applied and weights are lumped. The framework and its environment are described by the input quantities from which the program generates the stiffness matrix $K$. 
STIFF-EIG performs the static and/or dynamic structural analysis for normal modes and frequencies of structural framework.

\section{Method}

The program generates the stiffness matrix $\mathrm{K}$ for the structure from geometrical data, and performs static and normal-mode analyses by solving the equations

$$
\mathrm{U}=\mathrm{K}^{-1} \mathrm{~F}
$$

and

$$
\frac{1}{\omega} \mathrm{U}=\mathrm{K}^{-1} \mathrm{MU},
$$

where $F$ = a matrix of static loads,

$\mathbf{M}=\mathbf{a}$ matrix of inertia terms,

$\mathrm{U}=\mathrm{a}$ matrix of static deflections or a normal-mode shape

$\omega=$ the circular frequency of a normal mode.

Member loads for both static and dynamic cases are computed from a set of deflections $U$ and geometrical properties of the members.

Features of STIFF-EIG

1. Stiffness elements of a nonstandard member may be inserted as input data.

2. Accelerations of the lumped masses may be input for free vibration in a normal mode.

3. Deflections and member loads for thermal loadings may be considered.

4. STIFF-EIG will analyze five types of planar or space structures.

\section{Limitations}

Degrees of Freedom of Structure $\leqslant 130$

Joints in Structure $\quad \leqslant 60$

Members in Structure $\quad \leqslant 200$ 
Components of Restraint $\quad \leqslant 100$

Loadings

$\leqslant 6$

(Joints) $\times($ Degree of Freedom per Joint $) \leqslant 180$

\subsection{FIRL PROGRAM LUMS}

LUMS, Dynamic Response of Lumped Mass Systems Program No. 52-9

Program purpose is to determine natural frequencies, mode shapes, and the dynamic response for arbitrary loading excitation, earthquake, shock and vibration analysis.

\section{Applications}

Three-dimensional frame and axisymmetric shell structures, piping systems, containment vessels, multistoried buildings.

\section{Capabilities}

- Inclusion of modal damping

- Arbitrary loading history for each degree of freedom

- Arbitrary initial conditions

- Transient and steady-state response

- Earthquake analysis by using response spectra

- Earthquake analysis by computing time history.

Method

By using flexibility influence coefficients, computes natural frequencies and mode shapes by matrix iteration. Response is obtained by numerical quadrature of the convolution integral.

Input

- Flexibility coefficients (obtained from PIPSYS, GENSHL, etc.)

- Influence coefficients for response functions

- Mass matrix elements

- Initial displacements and velocities

- Forcing functions. 
Output

- Natural frequencies and mode shapes

- Displacement response

- Force and/or stress response (mode by mode and superimposed results).

\subsection{FIRL PROGRAM DRAS}

DRAS, Dynamic Response of Axisymmetric Solids - Program No. $52-10$

The program determines history of displacements, velocities, and stresses in arbitrary bodies of revolution subjected to axisymmetric transient mechanical and thermal loads; and impingement.

\section{Applications}

Dynamic analysis of containment vessels, ball mills, pressure vessels.

Capabilities

- Orthotropic material properties

- Axial acceleration loading

- Radial acceleration loading

- Spatially varying surface tractions and temperatures

- Triangular and quadrilateral elements

- Displacement boundary conditions

- Concentrated loads

- Nonlinear material properties and damping

- Arbitrary initial displacements and velocities.

Method

Displacement model of finite element analysis is used. The original structure is idealized into an assemblage of discrete elements. Element stiffnesses are evaluated by the displacement model theory and combined to form the overall system of equations. The mass matrix is adjoined to these equations to represent inertial forces. The result- 
ing system is integrated directly by a predictor-corrector method. Stresses are then computed from the known strain field.

Input

- Element geometry

- Element connectivity

- Material properties

- Surface tractions

- Concentrated loads

- Temperature distribution

- Axial and radial acceleration

- Boundary conditions

- Initial displacement field

- Damping coefficients

- Printing option.

Output

- Input data sort

- Nodal point displacements, velocities

- Stresses at the center of each element

- Monitoring station values can be printed continuously

- Output for various time steps may be selectively printed or suppressed.

\subsection{FIRL PROGRAM PIPSYS}

PIPSYS, Three-Dimensional Piping Systems Analysis Program No. 52 3

PIPSYS determines displacements, rotation, forces, and stresses for cylindrical pipes.

\section{Applications}

Piping systems, curved elbows, reducers, and special piping and supporting elements. 
Capabilities

- Three displacements and three rotations are computed at each joint

- Piping elements may have arbitrary, axially varying cross sections

- Flattening effects of piping elbows are considered

- Six degrees of freedom elastic foundations are included

- Definition of boundary condition and loads in arbitrary coordinate system is allowed

- Influence coefficient computation is readily performed

- Up to 100 loading conditions can be simultaneously evaluated

- Superposition of loading conditions can be performed

- Computer influence coefficient matrix for use with the LUMS program.

Method

The analysis is based on the Displacement Method. Force-displacement relations for each member of an idealized mathematical model of the structure are established. These are then transformed to the global system and combined to form an overall stiffness matrix for the entire structure. This matrix is solved for different loading conditions consisting of forces and moments applied at the joints. The resulting displacement and rotations are then used to compute stresses and reactions in each member.

Input

- Joint coordinates

- Pipe radius and wall thickness

- Material properties

- Boundary conditions

- Joint loads

- Thermal elongation 
Output

Displacement and rotations in global system

For Each Pipe:

- Displacements and rotations of forces and moments in member coordinates

- Stresses are given at four locations in each cross section for 20 cross sections

- Output formats can be modified to suit individual requirements.

\subsection{FIRL PROGRAM GENSHL}

GENSHL, Static and Steady-State Response of Shells of Revolution Program No. 52-1

The purpose of the program is to determine displacements, rotations, stress resultants, and stresses in shells of revolution subjected to surface tractions and ring loadings. The loadings may be static or periodic.

\section{Applications}

Containment vessels, reactor vessels, heat exchangers, valve housings, pressurizers, pipelines, submarine hulls, wet ball mills, cascade mills.

\section{Capabilities}

- Meridional shapes of the following form:

Radial plate

Arbitrary cone

Cylinder

Toroids of positive or negative curvature

Polynomial function of the form

$$
r(x)=\left(A+B x^{c}+D x^{e}\right)^{f}
$$

- Orthotropic multilayers 
- Four different types of branches and closed box sections

- Nonuniform layer thickness

- Boundary condition - traction, displacement, mixed, and elastic foundation

- Asymmetric loadings allowed

- Arbitrary reference surface allowed.

Method

The shell structure is regarded as an assemblage of various elements. Numerical integration is used for solution of shell equations for each element. These solutions are then made compatible.

Input

- Shell geometry

- Material properties

- Boundary conditions

- Loadings

Output

- Displacements, rotations

- Stress resultants, stresses for up to 30 stations in each element.

\subsection{PROGRAM CTAC-MODE}

(Developed by Westinghouse, Bettis Laboratory)

Available from Argonne Code Center

The CTAC-MODE program determines force distributions in a linear elastic structure by the following procedure:

1. The structure is first made statically determinate by cutting the structure at redundant joints and applying sets of equal but opposite redundant loads on the two surfaces of each cut.

2. The structure is separated into a set of simple elastic elements. 
3. The loads on each element are specified in terms of the external loads and redundant loads by means of a connection matrix.

4. The deformations of each element are specified in terms of the element loads by means of a flexibility matrix.

5. The code input consists of the external loads, connection matrices, and flexibility matrices.

6. From this input, the program determines the working deflections, redundant loads, and modes of vibration.

7. The effects of the loads and modes are then calculated for the elements.

8. Determines load distributions produced by pressure and temperature.

9. Determines mode responses for a shock spectrum of acceleration factor $\mathrm{N}_{\mathrm{g}}$ vs natural frequency $\mathrm{f}$.

10. Determines flexibility matrices for cantilever beams and cantilever subassembly plates under any plane combination of pressure, temperature, bending moment, shear force, and tensile force.

Capacity

Sixty (60) degrees of freedom.

\subsection{AVCO PROGRAM NO. 1520}

A Program for Dynamic Analysis of Structures ${ }^{45}$

The dynamic models of piping structures can be formulated by finite element and/or lumped parameter techniques. The resultant equations of equilibrium of motion are simultaneous, second-order, linear or nonlinear differential equations in generalized coordinates subjected to arbitrary forcing functions. The transient responses at each coordinate are computed by Runge-Kutta numerical integration scheme. The procedure is described in Section 9.2, with accuracy checking features included. 
A digital computer program has been written to solve this problem (up to 150 simultaneous differential equations) and is registered in the AVCO Mathematic's Department, under the code designation 1520. The machine language is FORTRAN IV (in double precision), to be used for IBM 360 computer.

\subsection{AVCO COMPUTER PROGRAM NO. 1536C}

A Program for the Forced Sinusoidal and Random Vibration Analysis of Structures ${ }^{52}$

The steady-state responses of finite element or lumped parameter structural model subjected to sinusoidal or random vibration are computed by procedures described in Section 9.1 and Reference 52 .

\section{Capacity}

One-hundred fifty degrees of freedom.

\subsection{AVCO COMPUTER PROGRAM NO. 1384}

A Program for the Modal Analysis of a Linear Dynamic System ${ }^{53}$

This program obtains the transient solution to the set of equations expressed in matrix form as:

$$
[\mathrm{M}]\{\ddot{\mathrm{q}}\}+[\mathrm{C}]\{\dot{\mathrm{q}}\}+[\mathrm{K}]\{\mathrm{q}\}=\{\mathrm{F}(\mathrm{t})\}
$$

where $[\mathrm{M}],[\mathrm{C}]$, and $[\mathrm{K}]$ are square, symmetric matrices of order $\mathrm{N}$, $\mathrm{N} \leqslant 100,[\mathrm{M}]$ is nonsingular and positive definite, $\{\mathrm{F}(\mathrm{t})\}$ is a known vector function of time, and $\{\mathrm{q}\}$ is the unknown displacement vector which is a function of time.

The solution, obtained using a classical modal analysis, is limited by the following assumptions:

1. The normal modes are not coupled by damping;

2. Response in modes higher than the $30^{\text {th }}$ is omitted. 


\subsection{AVCO COMPUTER PROGRAM NO. 2607}

A Program for Modal Analysis and Modal Damping Matrix ${ }^{31}$

The dynamic models of complex structures can be formulated by finite element and/or lumped parameter techniques. The resultant equations of equilibrium of motion are second-order simultaneous, differential equations in generalized coordinates.

This program is an improved version of AVCO program 1384 and has been written to compute the eigenvalues, eigenvectors, and modal damping matrix of the system (up to 150 degrees of freedom). The eigenvalue and eigenvector routine used is a modified HouseholderGivens routine.

\subsection{AVCO COMPUTER PROGRAM 2680 A, B, C, AND AEROSPACE COMPUTER PROGRAM DRASTIC \\ Dynamic Responses of Shell Structures Are Computed by These Codes. ${ }^{51,54}$}

AVCO received the Aerospace version of computer code (DRASTIC series) for finite element dynamic analysis of shells of revolution, which was developed by S. Klein and R. J. Sylvester. The stiffness matrix for a complex shell structure is obtained by idealizing the structure into conical frustums joined at the nodal circles. Program $2680 \mathrm{~A}$ calculates the stiffness matrix by minimizing the potential energy of the system for an assumed displacement. The dynamic responses of this linear elastic system under axisymmetric and/or asymmetric load are computed by $2680 \mathrm{~B}$, a numerical procedure developed by Chan, Cox, Benfield, ${ }^{40}$ and finally, the desired outputs of generalized displacements, stresses, strain and/or forces are printed by $2680 \mathrm{C}$.

\section{Capacity}

500 degrees of freedom. 


\subsection{ELECTRIC BOAT DIVISION (GENERAL DYNAMICS) COMPUTER PROGRAM GENSAM}

GENSAM is a General Structures and Matrix Program.

Electric Boat Division's main computer program for static and dynamic analysis has been the General Structures program. The General Structures program was developed to analyze highly redundant three-dimensional structures for static or dynamic loading conditions in the elastic range. Typical applications include analysis of equipment foundations, stress analysis of nozzles, plate and shell analysis. The program makes use of the stiffness or displacement approach to formulate the equations of elasticity and compatibility. Loading conditions include static, thermal, pressure, earthquake, and shock loadings and constraint and anchor movements. The calculated results for static analyses include deflections of joints, internal forces, constraint forces, and stresses, while the additional quantities of frequencies, mode shapes, modal weights, and inertial forces are calculated for dynamic analysis.

The present basic program on the UNIVAC 1107 computer has the following capabilities: maximum of 7200 unknowns, maximum of 1000 joints, maximum of 1000 constraints, maximum of 4000 pieces, maximum of 1000 anchors, and a maximum of 2000 loads in the system. For dynamic problems, up to 165 dynamic degrees of freedom can be allowed as many normal mode frequencies and mode shapes can be calculated. The utilization of the program, together with other programs such as Duhamel's Integral program of Mechanical Impedance program, makes it possible to predict the response of undamped or damped multidegrees of freedom systems excited by arbitrary forcing functions.

\subsection{COMPUTER PROGRAM STARDYNE}

Mechanical Research Institute (MRI), Los Angeles, California, developed this program.

This computer program makes use of the triangular finite element to form the structural model. Modal method of solutions for dynamic responses is employed. 
Capacity

Static Problem:

Dynamic Problem:
4000 degrees of freedom

1. Arbitrary forcing functions - use 150 modes.

2. Base-motion forcing functions - use the lowest 75 modes for a system up to 1300 degrees of freedom. 


\section{CONCLUSIONS}

Based on the present state of the art and consideration of the feasibility of applying various analytical methods to determining the dynamic responses of LMFBR piping systems, the analysis procedure recommendations may be summarized as follows.

1. It is recommended that the continuous piping system be represented by a linear elastic system composed of a discrete number of beam elements in three-dimensional space. More refined analytical models, such as the nonlinear elastic system. (large deformation theory) or the elastic-plastic system, have not been developed to the point where computer programs and attendant computational procedures as well as supporting input data are generally available for application to a complex structure (e.g., up to 200 degrees of freedom).

2. Due to its versatility and compatibility with most current computational procedures, the displacement method (based on the principle of minimum potential energy to approximate the elastic properties of the discrete elements by means of stiffness matrices) is recommended over the force method and flexibility matrix.

3. Representation of system damping characteristics is an important factor in determining system steady-state dynamic responses; it is of lesser significance in determining dynamic responses to transient excitations, especially for shocks with a short time duration. The modal damping matrix discussed in Section 7 is recommended as the representation of system damping characteristics. 
4. The finite element representation of the system is preferred over the lumped parameter representation. However, the computer code survey, while by no means complete at the time of this writing, has not indicated that a complete computer program of beam finite elements in three-dimensional space is available. Therefore, until the time when such a program is identified and available, the lumped parameter stiffness matrices listed in Appendix A are recommended as a reasonably close approximation.

The choice of beam finite elements to represent the piping system instead of shell finite elements is based upon the presumption that the piping system is physically a three-dimensional framework of long slender members. To represent a slender member by a large number of cylindrical shell elements will substantially increase the degrees of freedom, as compared with a fewer number of beam elements to get the same order of accuracy. A large number of degrees of freedom will lead to longer computation times on the digital computer, as well as other complications which are not felt to be justified for this application.

5. The consistent mass matrix and consistent forcing function vector described in Sections 5 and 8.1 are recommended. However, these formulations can be attributed only to a finite element model, as described in Reference 18. The consistent matrix formulations of beam element given by Reference 18 are only one-dimensional (thus without torsion). It is felt that further development effort can be made (within reasonable time) to formulate finite element beam consistent matrices in three-dimensional space (i.e., stiffness matrix, consistent mass matrix, and consistent nodal force vector) to be used for piping system dynamic analysis.

6. The computational procedures for dynamic analysis which will be chosen for incorporation into the LMFBR piping design guide will be influenced by the availability and accessibility of computer programs. Based on this review of dynamic analysis methods, the ideal computer program would be based upon a threedimensional beam-finite element representation of the system, 
would assemble and compute the consistent mass matrix, consistent nodal force vector, and modal damping matrix, and then would proceed to solve accurately for steady-state and/or transient responses (by the modal method and/or the time-step integration method) for systems of 150 degrees of freedom or more. This program should reflect considerations of result accuracy and economy of computer time.

Based on the preliminary survey of existing computer programs (see Section 10), the ideal program described above does not appear to be available. Many computer programs solve specific problems, such as the DRASTIC program which computes the dynamic responses of shells (finite element representation). Certain programs (such as those developed by AVCO) perform individual operations, with the output from one program computation used in conjunction with another program to perform the next computation. For example, the eigenvalues, eigenvectors, and modal damping matrix can be computed by the AVCO program 2607, and then these results can be used with the AVCO program 1536C (for steady-state responses) or AVCO program 1520 for transient responses. Since the stiffness and mass matrices are inputs in the above computational procedure, this approach is adaptable to either lumped parameter or finite element system models.

Limited information has been obtained on other programs which are based on the lumped parameter system representation, such as the FIRL program LUMS (No. 52-9) and the Electric Boat Division Program GENSAM. At the time of this writing, information has not been obtained regarding the mathematical procedures of these programs, so no conclusions can be drawn relating to their advantages or shortcomings.

If a further survey of available computer programs fails to disclose an "ideal program," the recommended dynamic analysis procedures for incorporation into the LMFBR Design Guide will be based upon use of the best available lumped parameter type computer programs. Preparation of a finite element beam model computer program, embodying the consistent mass matrix and consistent forcing vector, will be identified as a development requirement. 


\section{REFERENCES}

1. Bisplinghoff, Ashley, and Halfman: "Aeroelasticity," AddisonWesley Publishing Co., Inc., 1955.

2. Lazan: 'Damping of Materials in Structural Mechanics,' Pergamon Press Inc., 1967.

3. Turner, Clough, Martin, and Topp: Stiffness and Deflection Analysis of Complex Structures, J. of Aero. Sci. (Sept. 1956).

4. Argyris and Kelsey: "Energy Theorems and Structural Analysis," Butterworths, 1960.

5. Pestel and Leckie: "Matrix Methods in Elasto-Mechanics," McGraw-Hill Book Company, Inc., 1963.

6. Argyris, Kelsey, and Kamel: "Matrix Methods of Structural Analysis AGARD-72,"' Pergamon Press Inc., 1963.

7. Pian: Proceedings, Conferences on Matrix Methods in Structural Mechanics, AFFDL-TR-66-80 (1966).

8. Seven and Taylor: Proceedings, Institute of Civil Engineers, Vol. 54 (1966).

9. Yamamoto: Aeronautical Engineering Department Report, Massachusetts Institute of Technology (1966).

10. Sanders, McComb, and Schlichte: Creep Buckling Problem, NACA Report 1342 (1958).

11. Pian: Creep Buckling of Curved Bear under Uniform Distribution Load Proceedings, 3rd National Congress of Applied Mechanics (1958). 
12. Argyris: "Recent Advances in Matrix Methods of Structural Analysis,"' The Macmillan Company, New York, 1964.

13. Pian: Derivation of Stiffness Matrices, ALAA Journal, 2:3 (1964).

14. Pian: Derivation of Element Stiffness Matrices by Assumed Stress Distributions, AIAA Journal, 2:7 (1964).

15. Langhaar: 'Energy Methods in Applied Mechanics,' John Wiley and Sons, Inc., 1962.

16. Percy, Loden, and Navaratna: A Study of Matrix Analysis Methods for Inelastic Structures, AF-RDT-TDR-63-4032 (1963).

17. Tong and Pian: The Convergence of Finite Element Method in Solving Linear Elastic Problems, Int. J. Solid Structures (1967, 1968).

18. Archer: Consistent Matrix Formulation for Structural Analysis Using Finite Element, AIAA Journal, 3:10 (1965).

19. Archer: Consistent Mass Matrix for Distributed Mass Systems, Journal ASCE (1963).

20. Crandall: 'Engineering Analysis,' McGraw-Hill Book Company, Inc., 1956.

21. Marcus: Basic Theorems in Matrix Theory, National Bureau of Standards, Applied Mathematics Series No. 57 (1964).

22. Collatz: "Numerical Treatment of Differential Equations," Springer-Verlag, 1966.

23. Salvadori and Baron: "Numerical Methods in Engineering," Prentice-Hall Inc., 1961.

24. Hilderbrand: "Methods of Applied Mathematics," Prentice-Hall Inc., 1952.

25. White: Computations of Eigenvalues and Eigenvectors of a Matrix, J. Soc. for Ind. and Appl. Math. (Dec. 1958).

26. Givens: Numerical Computation of the Characteristic Values of a Real Symmetric Matrix, ORNL-1574 (1954).

27. Wilkinson: Householder's Method for the Solution of the Algebraic Eigenproblem, Computer Journal, Vol. 3 (1960). 
28. Ortega: On Strum Sequences for Tridiagonal Matrices, J. Assn. for Computing Machinery, 7:3 (1960).

29. Wilkinson: The Calculation of the Eigenvectors of Co-Diagonal Matrices, Computer Journal No. 1 (1958).

30. Young and McCallum: The Determination of Frequencies and Modes of Undamped Structures Using Finite Element Stiffness and Consistent Mass Matrices, Massachusetts Institute of Technology Report ASRL-TR-121-B (1965).

31. Nieh and Pavelack: AVCO Digital Computer Program 2606 User's Manual, Modal Analysis and Modal Damping Matrix, AVMSD-018767-RM, AVCO Technical Memorandum (1968).

32. Hurty and Rubinstein: 'Dynamics of Structures,' Prentice-Hall Inc., 1964.

33. Tocher, D.: Earthquake Energy and Ground Breakage, Bull. Seism. Soc. Am., 48 (1958).

34. Press, F.: Dimensions of the Source Region for Small, Shallow Earthquakes, VESIAC Report.

35. Esteva and Rosenbleuth: Spectra of Earthquakes at Moderate and Large Distances, Soc. Mex. de Ing. Sismica, II. No. 1 (1964).

36. Hou, S. N.: Earthquake Simulation Models and Their Applications, Ph.D. Thesis, Massachusetts Institute of Technology (1968).

37. Crandall and Mark: "Random Vibrations," Academic Press Inc., 1964.

38. Blume and Associates: Summary of Current Seismic Design Criteria for Nuclear Reactor Facilities, Report for ORNL (Sept. 1967).

39. Liu, S. C.: Non-Deterministic Analysis of Non-Linear Structures Subjected to Earthquake Motions, Ph.D. Thesis, University of California (1967).

40. Harris and Crede: "Shock and Vibration Handbook," McGrawHill Book Co., 1961.

41. Housner and Jennings: Generation of Artificial Earthquakes, Proc. ASCE, 90, No. EMI (1964). 
42. Tajimi, H.: A Statistical Method of Determining the Maximum Response of a Building Structure during an Earthquake, Proc. Second World Conference on Eq. Eng. II-781, Japan (1960).

43. Kanai, K.: Semi-Empirical Formula for the Seismic Characteristics of the Ground, Bull. Eq. Res. Inst., 35, Tokyo (1957).

44. Newmark, N. M.: Design Criteria for Nuclear Reactors Subjected to Earthquake Hazards, University of Illinois, Urbana, Ill. (1967).

45. Nieh, L. C.: Dynamic Analysis of Missile Structures - AVCO Digital Computer Program 1520 Application Manual, AVCO Missile Systems Division, AVMSD-0063-67-RM (1967).

46. Levy and Kroll: Errors Introduced by Step-by-Step Numerical Integration of Dynamic Responses, National Bureau of Standards (1951).

47. Whitney, Anderson, and Salvadori: Comprehensive Numerical Method for the Analysis of Earthquake Resistant Structures, J. Am. Concrete Institute, 23:1 (1957).

48. Houbolt, J. C.: Recurrence-Matrix Solution for the Dynamic Responses of Elastic Aircraft, NACA TN-2064 (1950).

49. Chan, Cox, and Benfield: Transient Analysis of Forced Vibrations of Complex Structural-Mechanical Systems, J. Royal Aero. Soc., Vol. 66 (1962).

50. Newmark, N. M.: A Method of Computation in Structural Dynamics, J. Eng. Mech. Div., ASCE (1959).

51. Klein, S.: Vibration of Multilayer Shells of Revolution under Dynamic and Impulsive Loading, Aerospace Corporation, San Bernardino, Calif. (1967).

52. Nieh, L. C.: Forced Sinusoidal and Random Vibration Digital Computer Program 1536C User's Guide, AVCO Technical Release S310-T-419 (1967).

53. Parker, D. and Moulton, P.: Modal Analysis of a Linear Dynamic System, AVCO Technical Release S310-T-195 (1965).

54. Nieh, L. C.: User's Manual for AVCO Computer Programs 2680A, B, C, AVCO Technical Release S310-T-451 (1968). 
55. Wada, B. : Stiffness Matrix Structural Analysis, Jet Propulsion Lab. Technical Report No. 32-774 (1965).

56. Trelin, Yu. S., Vasil'ev, I. V., and Roshchupken, V. V. : Measurement of the Ultrasound Velocity in Molten Alkali Metals, Translated in Soviet Atomic Energy, 9:955 (1960).

57. Ying, S.P. and Scott, C. C: Attenuation Measurements of Sound and UItrasonic Transducers in $600 \mathrm{~F}$ Liquid Sodium, USAEC Report APDA 180 (Dec. 15, 1965).

58. Letcher, S. V. and Beyer, R. T.: Measurement of Ultrasonic Attenuation in Liquid Sodium and Potassium, J. Acoust. Soc. Am., $35: 1571$ (1963).

59. Jarzynski, J. and Litovitz, T. A. : Ultrasonic Absorption in Liquid Sodium-Potassium Alloys, J. Chem. Phys. 41:1290 (1964).

60. Uniform Building Code - International Conf. of Building Officials, 50 S. Los Robles, Pasadena, Calif., (1964).

61. Dynamic Analysis of Hanford Atomics Primary Coolant System Report TSD-60-302, Electric Boat Div., General Dynamics, (December 1960).

62. Arias, Arturo and Petit Laurent, Luis: Un modelo teorico para los acelerogramas de temblores fuertes, Revista del IDIEM, Mexico, 4(1):29-60 (1965).

63. Penzien J. and Liu, S. C. : Non-Deterministic Analysis of Nonlinear Structures Subjected to Earthquake Excitations, Proc. of 4th World Conf. on Eq. Eng. , Jan. 1969.

64. Bolotin, V. V.: Statistical Theory of the Aseismic Design of Structures, Proc. Second World Conf. on Eq. Eng., Japan, II-1365 (1960).

65. Lin, Y. K. : Application of Nonstationary Shot Noise in the Study of System Response to a Class of Nonstationary Excitations, Trans. ASME, J. Appl. Nech., 30(E-4) 555-558 (1963).

66. Amin, M. and Ang, A. H. S. : A Nonstationary Stochastic Model of Earthquake Motions, Univ. of Illinois, Civil Eng. Studies (1966).

67. Shinozuka, M. and Sato, Y.: Simulation of Nonstationary Random Process, Proc. ASCE, 92, No. EMl, 11-40 (1967).

68. Jennings, P. C., Housner, G. W. and Tsai, N. C.: Simulated Earthquake Motions for Design Purposes, 4th World Conf. on Earthquake Eng., 1969.

69. Jennings, P. C., Housner, G. W., Tsai, N. C. : Simulated Earthquake Motions, (Calif. Inst. of Technology, Earthquake Engineering Research Lab. Report (April 1968). 
70. Amin, M., Ang., A. H. S.: Nonstationary Stochastic Model of Earthquake Motions, J. Eng. Mech. Niv., ASCE, Vol. 94, EM2, Paper 5906 (Apr. 1968).

71. Housner, G. D. : Properties of Strong Ground Motion Earthquakes, Bull. Seism. Soc. Am., 45:197-218 (1957).

72. Bogdanoff, J. L., Goldberg, J. E. and Bernard, M. C. :

Response of a Simple Structure to a Random Earthquake Type Disturbance, Bull. Seism. Soc. Am., 51:293-310 (1961).

73. Goldberg, J. E., Bogdanoff, J. L. and Sharpe, D. R. : The Response of Simple Nonlinear Systems to a Random Disturbance of the Earthquake Type, Bull. Seism. Soc. Am., 54:263-276 (1964).

74. Rascon, O. A., and Cornell, C. A.: Strong Motion Earthquake Simulation, M. I. T. Dept. of Civil Eng., Res. Report R68-15 (1968).

75. Brunk, H. D. : "An Introduction to Mathematical Statistics," Ginn and Co., Boston, Mass., 1960.

76. Rascon, O. A. and C. A. Cornell, C. A. : A Physically Based Model to Simulate Strong Earthquake Records on Firm Ground, 4th World Conf. on Earthquake Eng., 1969.

77. Parmakian, J.: "Waterhammer Analysis", Prentice-Hall Inc., New York, N. Y., 1955. 


\section{APPENDIX A - STIFFNESS MATRICES FOR VARIOUS BEAM MEMBER TYPES}

The following derivations are performed on typical members by introducing successive unit coordinate deflections of their ends and calculating forces reacting on the member. Coordinate deflections include both translations and rotations; loads are forces and moments. In each case, the first column of the required matrix. is derived in some detail to illustrate procedure.

Matrices relating forces and clisplacements in structure-oriented $\left(x_{1}\right)$ coordinates are desired here; but intermediate use of member-oriented $\left(\xi_{1}\right)$ coordinates is made in the more complicated derivations.

In the derivations below, the following quantities are input or computed for each member $p-q$ :

1. Input coordinates $x_{p_{i}}, x_{q_{t}}$

2. Input member properties, $A_{\imath}, E$

3. Compute member length

$$
S=\left[\left(x_{q 1}-x_{p 1}\right)^{2}+\left(x_{q 2}-x_{p 2}\right)^{2}+\left(x_{q 3}-x_{p 3}\right)^{2}\right]^{1 / 2}
$$

4. Compute direction cosines

$$
\begin{aligned}
& \gamma_{1}=\frac{\left(x_{q 1}-x_{p 1}\right)}{S} \\
& \gamma_{2}=\frac{\left(x_{q 2}-x_{p 2}\right)}{S}
\end{aligned}
$$

and

$$
\gamma_{3}=\frac{\left(x_{q 3}-x_{p 3}\right)}{S}
$$

Matrices $\mathbf{K}_{p p}, \mathbf{K}_{q p}$ are written satisfying the expression

$$
\left\{\begin{array}{l}
\mathbf{f}_{p} \\
\mathbf{f}_{q}
\end{array}\right\}=\left[\begin{array}{l}
\mathbf{K}_{p p} \\
\mathbf{K}_{q p}
\end{array}\right]\left\{\mathbf{u}_{p}\right\}
$$

1. Structure type 1, three-dimensional, pin-jointed members (Fig. A-1)

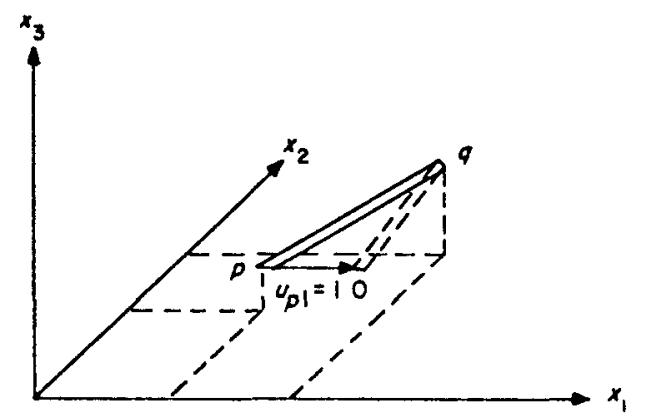

Fig. A-1. Three-dimensional pin-jointed member 
Section property:

$$
A=\mathbf{A}_{1} \text {, }
$$

or if

$$
\mathbf{A}_{s}=0
$$

then

$$
D=A_{1}
$$

and

$$
\begin{aligned}
T & =A_{z} \\
A & =\pi T(D-T)
\end{aligned}
$$

Introduce $u_{p_{1}}=1$

$$
\text { Axial load }=\frac{A E}{\mathrm{~S}} \gamma_{\mathrm{i}}
$$

Force components at joints $p$ and $q$ are

$$
\begin{aligned}
& f_{p 1}=-f_{q 1}=\frac{A E}{S} \gamma_{1}^{2} \\
& f_{p 2}=-f_{q 2}=\frac{A E}{S} \gamma_{1} \gamma_{2}
\end{aligned}
$$

and

$$
f_{p 1}=-f_{q 3}=\frac{A E}{S} \gamma_{1} \gamma_{3}
$$

The matrix relating displacements of joint $p$ to forces at joints $p$ and $q$ is

$$
\frac{A E}{S}\left[\begin{array}{ccc}
\gamma_{1}^{2} & \gamma_{1} \gamma_{2} & \gamma_{1} \gamma_{3} \\
\gamma_{1} \gamma_{2} & \gamma_{2}^{2} & \gamma_{2} \gamma_{3} \\
\gamma_{1} \gamma_{3} & \gamma_{2} \gamma_{3} & \gamma_{3}^{2} \\
\hdashline-\gamma_{1}^{2} & -\gamma_{1} \gamma_{2} & -\gamma_{1} \gamma_{3} \\
-\gamma_{1} \gamma_{2} & -\gamma_{2}^{2} & -\gamma_{2} \gamma_{3} \\
-\gamma_{1} \gamma_{3} & -\gamma_{2} \gamma_{3} & -\gamma_{3}^{2}
\end{array}\right]
$$

2. Structure type 2, three-dimensional, rigid-jointed members, equal member cross-section moment of inertia (Fig. A.2)

Section properties:

$$
\begin{aligned}
A & =\mathrm{A}_{1} \\
I & =\mathrm{A}_{2} \\
K & =\mathrm{A}_{3}
\end{aligned}
$$


Components of these load vectors are

$$
\begin{aligned}
& f_{p 1}=\text { force along } x_{1} \text { axis }=\frac{A E}{S} \gamma_{1}^{2}+\frac{12 E I}{S^{3}}\left(1-\gamma_{1}^{2}\right) \\
& f_{p 2}=\text { force along } x_{2} \text { axis }=\left(\frac{A E}{S}-\frac{12 E I}{S^{3}}\right) \gamma_{1} \gamma_{2} \\
& f_{p 3}=\text { force along } x_{3} \text { axis }=\left(\frac{A E}{S}-\frac{12 E I}{S^{3}}\right) \gamma_{1} \gamma_{3} \\
& f_{p 4}=\text { moment about } x_{1} \text { axis }=0 \\
& f_{p s}=\text { moment about } x_{2} \text { axis }=\frac{6 E I}{S^{2}} \gamma_{3} \\
& f_{p 1}=\text { moment about } x_{3} \text { axis }=-\frac{6 E I}{S^{2}} \gamma_{2}
\end{aligned}
$$

Similar load components at joint $q$ are

$$
\begin{aligned}
& f_{q 1}=-\frac{A E}{\mathrm{~S}} \gamma_{1}^{2}-\frac{12 E I}{S^{3}}\left(1-\gamma_{1}^{2}\right) \\
& f_{q 2}=\left(-\frac{A E}{\mathrm{~S}}+\frac{12 E I}{\mathrm{~S}^{3}}\right) \gamma_{1} \gamma_{2} \\
& f_{q 3}=\left(-\frac{A E}{\mathrm{~S}}+\frac{12 E I}{S^{3}}\right) \gamma_{1} \gamma_{3} \\
& f_{q 4}=0 \\
& f_{q 5}=+\frac{6 E I}{S^{2}} \gamma_{3} \\
& f_{q 8}=-\frac{6 E I}{S^{2}} \gamma_{2}
\end{aligned}
$$

The reçuired matrix will be written in terms of the quantities

$$
\begin{aligned}
C_{0} & =\frac{A E}{S} \\
C_{1} & =\frac{E K}{2 S(1+v)} \\
C_{21} & =\frac{12 E I}{S^{3}} \\
C_{2 B} & =\frac{6 E I}{S^{2}} \\
C_{2 C} & =\frac{2 E I}{S}
\end{aligned}
$$




\begin{tabular}{|c|c|c|c|c|c|}
\hline $\begin{aligned} & C_{0} \gamma_{1}^{2} \\
+ & C_{2.1}\left(1-\gamma_{1}^{2}\right)\end{aligned}$ & $\left(C_{0}-C_{2 A}\right) \gamma_{1} \gamma_{2}$ & $\left(C_{0}-C_{2 d}\right) \gamma_{1} \gamma_{3}$ & 0 & $C_{2 B} \gamma_{3}$ & $-C_{2 B} \gamma_{2}$ \\
\hline$\left(C_{n}-C_{2.1}\right)_{\gamma_{1} \gamma_{2}}$ & $\begin{aligned} & C_{0} \gamma_{2}^{2} \\
+ & C_{2 \Lambda}\left(1-\gamma_{2}^{2}\right)\end{aligned}$ & $\left(C_{0}-C_{2 A}\right) \gamma_{2} \gamma_{3}$ & $-C_{2 B} \gamma_{3}$ & 0 & $C_{2 B} \gamma_{1}$ \\
\hline$\left(C_{0}-C_{2.1}\right) \gamma_{1} \gamma_{3}$ & $\left(\dot{C}_{0}-C_{2.1}\right) \gamma_{2} \gamma_{3}$ & $\begin{aligned} & C_{0} \gamma_{3}^{2} \\
+ & C_{2 A}\left(1-\gamma_{3}^{2}\right)\end{aligned}$ & $C_{2 B} \gamma_{2}$ & $-C_{2 B} \gamma_{1}$ & 0 \\
\hline 0 & $-C_{3 B} \gamma_{3}$ & $C_{2 R \gamma_{2}}$ & $\begin{array}{c}C_{1} \gamma_{1}^{2} \\
+2 C_{2 c}\left(1-\gamma_{1}^{2}\right)\end{array}$ & $\left(C_{1}-2 C_{2 c}\right) \gamma_{1} \gamma_{2}$ & $\left(-C_{2}-2 C_{2 c}\right) \gamma_{1} \gamma_{3}$ \\
\hline$C_{2 B} \gamma_{3}$ & 0 & $-C_{2 B} \gamma_{1}$ & $\left(C_{1}-2 C_{2 C}\right) \gamma_{1} \gamma_{2}$ & $\begin{array}{c}C_{1} \gamma_{2}^{2} \\
+2 C_{2 c}\left(1-\gamma_{2}^{2}\right)\end{array}$ & $\left(C_{1}-2 C_{2} c\right) \gamma_{2} \gamma_{3}$ \\
\hline$-C_{2 B} \gamma_{2}$ & $C_{2 B \gamma_{1}}$ & 0 & $\left(C_{1}-2 C_{2 c}\right) \gamma_{1} \gamma_{3}$ & $\left(C_{1}-2 C_{2 c}\right) \gamma_{2} \gamma_{3}$ & $\begin{array}{l}C_{1 \gamma_{3}^{2}} \\
+2 C_{2 c}\left(1-\gamma_{3}^{2}\right)\end{array}$ \\
\hline $\begin{array}{l}-C_{0} \gamma_{2}^{2} \\
-C_{2 \Lambda}\left(1-\gamma_{1}^{2}\right)\end{array}$ & $\left(C_{2 \Lambda}-C_{0}\right) \gamma_{1} \gamma_{2}$ & $\left(C_{2.1}-C_{0}\right)_{\gamma_{1} \gamma_{3}}$ & 0 & $-C_{2 B \gamma_{3}}$ & $C_{2 B} \gamma_{2}$ \\
\hline$\left(C_{2 A}-C_{0}\right) \gamma_{1} \gamma_{2}$ & $\begin{array}{l}-C_{0} \gamma_{2}^{2} \\
-C_{2 A}\left(1-\gamma_{2}^{2}\right)\end{array}$ & $\left(C_{2.1}-C_{0}\right) \gamma_{2} \gamma_{3}$ & $C_{2 B} \gamma_{3}$ & 0 & $-C_{2 B} \gamma_{1}$ \\
\hline$\left(C_{2 A}-C_{0}\right) \gamma_{1} \gamma_{3}$ & $\left(C_{2.1}-C_{0}\right) \gamma_{2} \gamma_{3}$ & $\begin{array}{l}-C_{0} \gamma_{3}^{2} \\
-C_{2 A}\left(1-\gamma_{3}^{2}\right)\end{array}$ & $-C_{2 B} \gamma_{2}$ & $C_{2 B} \gamma_{1}$ & 0 \\
\hline 0 & $-C_{2 B} \gamma_{3}$ & $C_{2 B} \gamma_{2}$ & $\begin{array}{l}-C_{1} \gamma_{1}^{2} \\
+C_{2 c}\left(1-\gamma_{1}^{2}\right)\end{array}$ & $\left(-C_{1}-C_{2 c}\right) \gamma_{1} \gamma_{2}$ & $\left(-C_{1}-C_{2 c}\right) \gamma_{1} \gamma_{3}$ \\
\hline$C_{2 B} \gamma_{3}$ & 0 & $-C_{2 B} \gamma_{1}$ & $\left(-C_{1}-C_{2 c}\right) \gamma_{1} \gamma_{2}$ & $\begin{array}{l}-C_{1} \gamma_{2}^{2} \\
+C_{2} C\left(1-\gamma_{2}^{2}\right)\end{array}$ & $\left(-C_{1}-C_{2 c}\right) \gamma_{2} \gamma_{3}$ \\
\hline$-C_{2 B} \gamma_{2}$ & $C_{2 B} \gamma_{1}$ & 0 & $\left(-C_{1}-C_{2 c}\right) \gamma_{1} \gamma_{3}$ & $\left(-C_{1}-C_{2 c}\right) \gamma_{2} \gamma_{3}$ & $\begin{array}{l}-C_{1} \gamma_{3}^{2} \\
+C_{2 c}\left(1-\gamma_{3}^{2}\right)\end{array}$ \\
\hline
\end{tabular}

3. Structure type 3, two-dimensional, rigid-jointed members, loaded in-plane (Fig. A-3)

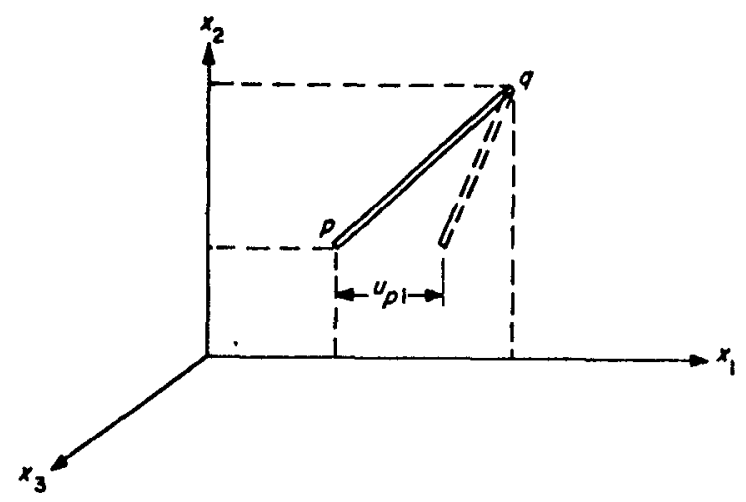

Fig. A-3. Two-dimensional rigid-jointed loaded in-plane member 
Section properties:

$$
\begin{gathered}
A=A_{1} \\
I=A_{2}
\end{gathered}
$$

or if

$$
\begin{aligned}
A_{3} & =0 \\
D & =A_{1} \\
T & =A_{2} \\
A & =T(D-T) \pi \\
I & =\frac{\pi}{4}\left(\frac{1}{2} D^{3} T-\frac{3}{2} D^{2} T^{2}+2 D T^{3}-T^{4}\right)
\end{aligned}
$$

The derivation is similar to that preceding with $\gamma_{3}=0$.

The matrix is written in terms of

$$
\begin{aligned}
C_{0} & =\frac{A E}{S} & C_{2 B} & =\frac{6 E I}{S^{2}} \\
C_{2 A} & =\frac{12 E I}{S^{3}} & C_{3} & =\frac{2 E I}{S}
\end{aligned}
$$

Loads at joint $p$ are in the order

$$
\begin{aligned}
& f_{p 1}=\text { force along } x_{1} \text { axis } \\
& f_{p 2}=\text { force along } x_{2} \text { axis } \\
& f_{p 3}=\text { moment about } x_{3} \text { axis }
\end{aligned}
$$

$\left[\begin{array}{clc}C_{0} \gamma_{1}^{2}+C_{2 A}\left(1-\gamma_{1}^{2}\right) & \left(C_{0}-C_{2 A}\right) \gamma_{1} \gamma_{2} & -C_{2 B} \gamma_{2} \\ \left(C_{0}-C_{2 A}\right) \gamma_{1} \gamma_{2} & C_{0 \gamma_{2}^{2}}+C_{2 A}\left(1-\gamma_{2}^{2}\right) & C_{2 B \gamma_{1}} \\ -C_{2 B \gamma_{2}} & C_{2 B \gamma_{1}} & 2 C_{3} \\ \hdashline-C_{0 \gamma_{1}^{2}}-C_{2 A}\left(1-\gamma_{1}^{2}\right) & \left(C_{2 A}-C_{0}\right) \gamma_{1} \gamma_{2} & C_{2 B \gamma_{2}}^{-} \\ \left(C_{2.1}-C_{0}\right) \gamma_{1} \gamma_{2} & -C_{0} \gamma_{2}^{2}-C_{2 A}\left(1-\gamma_{2}^{2}\right) & -C_{2 B \gamma_{1}} \\ -C_{2 B \gamma_{2}}^{-} & C_{2 B \gamma_{1}} & C_{3}\end{array}\right]$

4. Structure type 4, two-dimensional, rigid-jointed, loaded normal-to-plane (grid) (Fig. A.4)

Section properites:

$$
\begin{aligned}
& I=\mathrm{A}_{2} \\
& K=\mathrm{A}_{\mathbf{J}}
\end{aligned}
$$




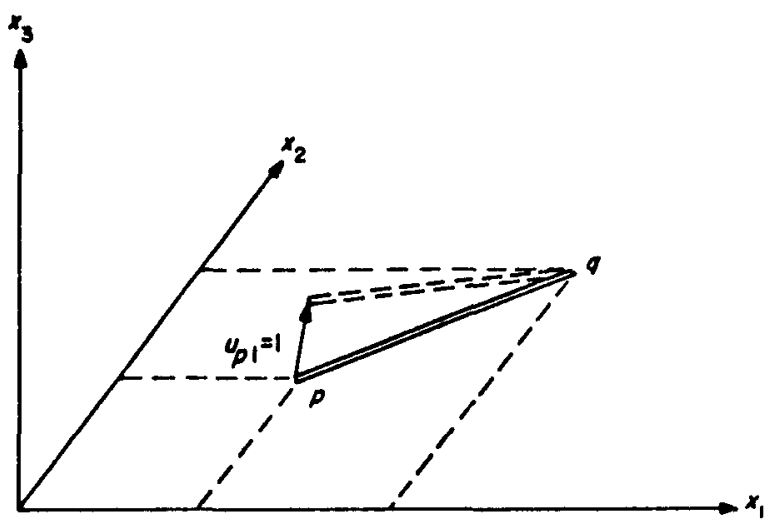

Fig. A-4. Two-dimensional rigid-jointed loaded normal-fo-plane member

or if

$$
\begin{aligned}
A_{3} & =0 \\
D & =A_{1} \\
T & =A_{2} \\
I & =\frac{\pi}{4}\left(\frac{1}{2} D^{3} T-\frac{3}{2} D^{2} T^{2}+2 D T^{3}-T^{4}\right) \\
K & =2 I
\end{aligned}
$$

Introduce $u_{p 1}=1$. Moment about an axis transverse to the member is of magnitude $6 E I / S^{2}$. Components of load exerted on joints $p$ and $q$ are:

$$
\begin{aligned}
& f_{p 1}=-f_{q 1}=\text { force in } x_{3} \text { direction }=\frac{12 E I}{S^{3}} \\
& f_{p 2}=f_{q 2}=\text { moment about } x_{1} \text { axis }=\frac{6 E I}{S^{2}} \gamma_{2} \\
& f_{p 3}=f_{q 3}=\text { moment about } x_{2} \text { axis }=-\frac{6 E I}{S^{2}} \gamma_{1}
\end{aligned}
$$

As before, the matrix is written in terms of the parameters

$$
\begin{aligned}
& C_{1}=\frac{E K}{2 S(1+\nu)} \quad C_{2 A}=\frac{12 E I}{S^{3}} \\
& C_{2 B}=\frac{6 E I}{S^{2}} \quad C_{3}=\frac{2 E I}{S} \\
& {\left[\begin{array}{ccc}
C_{2 A} & C_{2 B} \gamma_{2} & -C_{2 B} \gamma_{1} \\
C_{2 B} \gamma_{2} & C_{1} \gamma_{1}^{2}+2 C_{3} \gamma_{2}^{2} & \left(C_{1}-2 C_{3}\right) \gamma_{1} \gamma_{2} \\
-C_{2 B} \gamma_{1} & \left(C_{1}-2 C_{3}\right) \gamma_{1} \gamma_{2} & C_{1} \gamma_{2}^{2}+2 C_{3} \gamma_{1}^{2} \\
\hdashline-C_{2 A} & -C_{2 B} \gamma_{2} & C_{2 B} \gamma_{1} \\
C_{2 B} \gamma_{2} & -C_{1} \gamma_{1}^{2}+C_{3} \gamma_{2}^{2} & -\left(C_{1}+C_{3}\right) \gamma_{1} \gamma_{2} \\
-C_{2 B} \gamma_{1} & -\left(C_{1}+C_{3}\right) \gamma_{1} \gamma_{2} & -C_{1} \gamma_{2}^{2}+C_{3} \gamma_{1}^{2}
\end{array}\right]}
\end{aligned}
$$




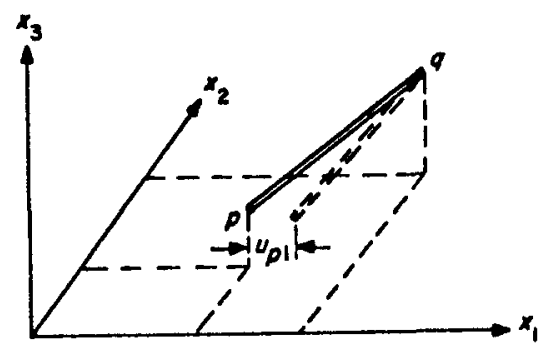

Fig. A-5. Three-dimensional rigid-jointed member, doubly symmetric cross-section member

5. Structure type 5, three-dimensional, rigid-jointed member, doubly symmetrical cross-section (Fig. A-5)

Section properties:

$$
\begin{aligned}
A & =\mathrm{A}_{1} \\
I_{1} & =\mathrm{A}_{2} \\
I_{2} & =\mathrm{A}_{3} \\
I_{3} & =\mathrm{A}_{4} \\
\text { Joint } r & =\mathrm{A}_{7}
\end{aligned}
$$

Calculate the direction cosine of the vector $\mathbf{p q} \times \mathbf{p r}$ and define the vector to be $\xi_{3}=\xi_{13} \mathbf{x}_{1}+\xi_{23} \mathbf{x}_{2}+\xi_{33} \mathbf{x}_{3}$ or the $I_{3}$ axis of the member. Using the right-handed coordinate system define the axis of $I_{2}$ to be

$$
\begin{aligned}
\boldsymbol{\xi}_{2}=\frac{\xi_{3} \times \xi_{1}}{\left|\xi_{3}\right|\left|\xi_{1}\right|}= & \mathbf{x}_{1}\left(\xi_{23} \gamma_{3}-\xi_{33} \gamma_{2}\right)+\mathbf{x}_{2}\left(\xi_{33} \gamma_{1}\right. \\
& \left.-\xi_{13} \gamma_{3}\right)+\mathbf{x}_{3}\left(\xi_{13} \gamma_{2}-\xi_{23} \gamma_{1}\right) \\
= & x_{1} \beta_{1}+\mathbf{x}_{2} \beta_{2}+\mathbf{x}_{3} \beta_{3}
\end{aligned}
$$

where $\xi_{1}$ is a unit vector along the member.

Introduce $u_{p 1}=1$. Vector displacements of point $p$ in the member-oriented coordinate system $\left(\xi_{i}\right)$ are

$$
\begin{aligned}
\boldsymbol{\delta}_{1}= & \gamma_{1}^{2} \mathbf{x}_{1}+\gamma_{1} \gamma_{2} \mathbf{x}_{2}+\gamma_{1} \gamma_{3} \mathbf{x}_{3} \\
\boldsymbol{\delta}_{2}= & \left(\xi_{23} \gamma_{3}-\xi_{33} \gamma_{2}\right)^{2} \mathbf{x}_{1}+\left(\xi_{23} \gamma_{3}-\xi_{3: 1} \gamma_{2}\right)\left(\xi_{33} \gamma_{1}-\xi_{13} \gamma_{3}\right) \mathbf{x}_{2} \\
& +\left(\xi_{23} \gamma_{3}-\xi_{33} \gamma_{2}\right)\left(\xi_{13} \gamma_{2}-\xi_{23} \gamma_{1}\right) \mathbf{x}_{3} \\
= & \beta_{1}^{2} \mathbf{x}_{1}+\beta_{1} \beta_{2} \mathbf{x}_{2}+\beta_{1} \beta_{3} \mathbf{x}_{3} \\
\boldsymbol{\delta}_{3}= & \xi_{13}^{2} \mathbf{x}_{1}+\xi_{13} \xi_{23} \mathbf{x}_{2}+\xi_{13} \xi_{33} \mathbf{x}_{3}
\end{aligned}
$$

The vector force exerted on joints

$$
-q \text { and } p=\frac{A E}{S} \delta_{1}+\frac{12 E I_{3}}{S^{3}} \delta_{2}+\frac{12 E I_{2}}{S^{3}} \delta_{3}
$$


and the vector moment exerted on joints

$$
p \text { and } q=-\frac{6 E I_{2}}{S^{2}}\left|\delta_{3}\right| \xi_{2:}+\frac{6 E I_{3}}{S^{2}}\left|\delta_{2}\right| \xi_{3}
$$

Components of these load vectors are:

$$
\begin{aligned}
f_{p 1}=-f_{q 1}=\text { force along } x_{1} \text { axis }= & \frac{A E}{S} \gamma_{1}^{2}+\frac{12 E I_{3}}{S^{3}}\left(\xi_{23} \gamma_{3}-\xi_{33} \gamma_{2}\right)^{2} \\
& +\frac{12 E I_{2}}{S^{3}} \xi_{13}^{2} \\
f_{p 2}=-f_{q 2}=\text { force along } x_{2} \text { axis }= & \frac{A E}{S} \gamma_{1} \gamma_{2}+\frac{12 E I_{3}}{S^{3}}\left(\xi_{23} \gamma_{3}-\xi_{33} \gamma_{2}\right) \\
& \times\left(\xi_{33} \gamma_{1}-\xi_{13} \gamma_{3}\right)+\frac{12 E I_{2}}{S^{3}} \xi_{13} \xi_{23} \\
f_{p 3}=-f_{p 3}=\text { force along } x_{3} \text { axis }= & \frac{A E}{S} \gamma_{1} \gamma_{3}+\frac{12 E I_{3}}{S^{3}}\left(\xi_{23} \gamma_{3}-\xi_{33} \gamma_{2}\right) \\
& \times\left(\xi_{13} \gamma_{2}-\xi_{23} \gamma_{1}\right)+\frac{12 E I_{2}}{S^{3}} \xi_{13} \xi_{33} \\
f_{p 4}=+f_{q 4}=\text { moment about } x_{1} \text { axis }= & \xi_{13}\left(\xi_{23} \gamma_{3}-\xi_{33} \gamma_{2}\right)\left(\frac{6 E I_{3}}{S^{2}}-\frac{6 E I_{2}}{S^{2}}\right) \\
f_{p 5}=f_{q 5}=\text { moment about } x_{2} \text { axis }= & -\frac{6 E I_{2}}{S^{2}} \xi_{13}\left(\xi_{33} \gamma_{1}-\xi_{13} \gamma_{3}\right) \\
& +\frac{6 E I_{3}}{S^{2}} \xi_{23}\left(\xi_{23} \gamma_{3}-\xi_{33} \gamma_{2}\right) \\
& +\frac{6 E I_{3}}{S^{2}} \xi_{33}\left(\xi_{23} \gamma_{3}-\xi_{33} \gamma_{2}\right) \\
f_{p 6}=f_{q 3}=\text { moment about } x_{3} \text { axis }= & -\frac{6 E I_{2}}{S^{2}} \xi_{13}\left(\xi_{13} \gamma_{2}-\xi_{23} \gamma_{1}\right)
\end{aligned}
$$

The stiffness matrix is written in terms of the parameters

$$
\begin{array}{ll}
C_{1}=\frac{6 E I_{2}}{S^{2}} & K_{1}=\frac{2 E I_{2}}{S}=\frac{L_{1}}{2} \\
C_{2}=\frac{6 E I_{3}}{S^{2}} & K_{2}=\frac{2 E I_{3}}{S}=\frac{L_{2}}{2} \\
C_{3}=\frac{E I_{1}}{2 S(1+v)} & K_{3}=\frac{12 E I_{2}}{S^{3}} \\
C_{4}=\frac{A E}{S} & K_{4}=\frac{12 E I_{3}}{S^{3}}
\end{array}
$$




\begin{tabular}{|c|c|c|c|c|c|}
\hline $\begin{aligned} & C_{4} \gamma_{i}^{i}+K_{4} \beta_{i} \\
+ & K_{3} \xi_{i}^{\prime}\end{aligned}$ & $K(2,1, p)$ & $K(3,1, p)$ & $K(4,1, p)$ & $K(5,1, p)$ & $K(6,1, p)$ \\
\hline $\begin{aligned} & C_{4} \gamma_{1} \psi_{2}+K_{1} \beta_{1} \beta_{2} \\
+ & K_{3} \xi_{1} \xi_{23}\end{aligned}$ & $\begin{aligned} & C_{4} \gamma_{2}^{2}+K_{4} \beta_{2}^{2} \\
+ & K_{3} \xi_{23}^{2}\end{aligned}$ & $K(3,2, p)$ & $K(4,2, p)$ & $K(5,2, p)$ & $K(6,2, p)$ \\
\hline $\begin{aligned} & C_{1} \gamma_{1} \%_{3}+K_{4} \beta_{1} \beta_{3} \\
+ & K_{3} \xi_{13} \xi_{33}\end{aligned}$ & $\begin{aligned} & C_{+\gamma_{2} \gamma_{3}}+K_{4} \beta_{3} \beta_{3} \\
+ & K_{3} \xi_{23} \xi_{33}\end{aligned}$ & $\begin{aligned} & C_{4} \gamma_{3}^{2}+K_{4} \beta_{3}^{2} \\
+ & K_{3} \xi_{33}^{2}\end{aligned}$ & $K(4,3, p)$ & $K(5,3, p)$ & $K(6,3, p)$ \\
\hline$\xi_{1}, \beta_{1}\left(C_{2}-C_{1}\right)$ & $-C_{1 \xi_{2} \beta_{1}}+C_{2} \beta_{2} \xi_{11}$ & $C_{2} \xi_{1}, \beta_{3}-C_{1} \xi_{33} \beta_{1}$ & $\begin{aligned} & C_{3} \gamma_{1}^{2}+L_{2} \xi_{13}^{2} \\
+ & L_{1} \beta_{1}^{2}\end{aligned}$ & $K(5,4, p)$ & $K(6,4, p)$ \\
\hline$-C_{1} \xi_{1}, \beta_{2}+C_{2} \xi_{2} \beta_{1}$ & $-\xi_{23} \beta_{2}\left(C_{2}-C_{1}\right)$ & $\begin{array}{l}-C_{1} \xi_{13} \beta_{2} \\
+C_{2} \xi_{23} \beta_{3}\end{array}$ & $\begin{aligned} & C_{3} \gamma_{1} \gamma_{2}+L_{2} \xi_{13} \xi_{23} \\
+ & L_{1} \beta_{1} \beta_{2}\end{aligned}$ & $\begin{aligned} & C_{3} \gamma_{2}^{2}+L_{2} \xi_{23}^{2} \\
+ & L_{1} \beta_{2}^{2}\end{aligned}$ & $K(6,5, p)$ \\
\hline $\begin{array}{l}-C_{1} \xi_{1} \beta_{3} \\
+C_{2} \xi_{33} \beta_{1}\end{array}$ & $\begin{array}{l}-C_{1} \xi_{23} \beta_{3} \\
+C_{2} \beta_{2} \xi_{33}\end{array}$ & $\xi_{3} \beta_{3}\left(C_{2}-C_{1}\right)$ & $\begin{aligned} & C_{3} \gamma_{1} \gamma_{3}+L_{2} \xi_{13} \xi_{33} \\
+ & L_{1} \beta_{1} \beta_{3}\end{aligned}$ & $\begin{aligned} & C_{3} \gamma_{2} \gamma_{3}+L_{2} \xi_{23} \xi_{3 s} \\
+ & L_{1} \beta_{2} \beta_{3}\end{aligned}$ & $\begin{aligned} & C_{3} \gamma_{3}^{2}+L_{2} \xi_{33}^{2} \\
+ & L_{1} \beta_{3}^{2}\end{aligned}$ \\
\hline$-K(1,1, p)$ & $-K(2,1, p)$ & $-K(3,1, p)$ & $-K(4,1, p)$ & $-K(5,1, p)$ & $-K(6,1, p)$ \\
\hline$-K(2,1, p)$ & $-K(2,2, p)$ & $-K(3,2, p)$ & $-K(4,2, p)$ & $-K(5,2, p)$ & $-K(6,2, p)$ \\
\hline$-K(3,1, p)$ & $-K(3,2, p)$ & $-K(3,3, p)$ & $-\boldsymbol{K}(4,3, p)$ & $-K(5,3, p)$ & $-K(6,3, p)$ \\
\hline$K(4,1, p)$ & $K(4,2, p)$ & $K(4,3, p)$ & $\begin{array}{l}-C_{3} \gamma_{1}^{2}+K_{\varepsilon} \xi_{13}^{2} \\
+K_{1} \beta_{1}^{2}\end{array}$ & $\begin{array}{l}-C_{3 \gamma_{1} \gamma_{2}}+K_{2} \xi_{13} \xi_{23} \\
+K_{1} \beta_{1} \beta_{2}\end{array}$ & $\begin{array}{l}3-C_{3} \gamma_{1} \gamma_{3}+K_{2} \xi_{23} \xi_{33} \\
+K_{1} \beta_{1} \beta_{3}\end{array}$ \\
\hline$K(5,1, p)$ & $K(5,2, p)$ & $K(5,3, p)$ & $\begin{array}{l}-C_{3} \gamma_{1} \gamma_{2}+K_{2} \xi_{13} \xi_{23} \\
+K_{1} \beta_{1} \beta_{2}\end{array}$ & $\begin{array}{l}-C_{3} \gamma_{2}^{2}+K_{2} \xi_{23}^{2} \\
+K_{1} \beta_{2}^{2}\end{array}$ & $\begin{array}{l}-C_{3} \gamma_{2} \gamma_{3}+K_{2} \xi_{23} \xi_{33} \\
+K_{1} \beta_{2} \beta_{3}\end{array}$ \\
\hline$K(6,1, p)$ & $K(6,2, p)$ & $K(6,3, p)$ & $\begin{array}{l}-C_{3} \gamma_{1} \gamma_{3}+K_{2} \xi_{13} \xi_{33} \\
+K_{1} \beta_{1} \beta_{3}\end{array}$ & $\begin{array}{l}-C_{3} \gamma_{2} \gamma_{3}+K_{2} \xi_{23} \xi_{33} \\
+K_{1} \beta_{2} \beta_{3}\end{array}$ & $\begin{array}{l}-C_{3} \gamma_{3}^{2}+K_{2} \xi_{33}^{2} \\
+K_{1} \beta_{3}^{2}\end{array}$ \\
\hline
\end{tabular}




\section{APPENDIX B - DERIVATION OF PLATE BENDING STIFFNESS MATRIX}

Objective: Find the element stiffness matrix of a square plate in plane stress ( $x-y$ plane). $\quad E=$ Young's modulus, $\nu=$ Poisson's ratio, $t=$ thickness of the plate.

\section{Solution}

Assume the linear displacement function

$$
\begin{aligned}
& \mathrm{u}=\alpha_{1}+\alpha_{2} \mathrm{x}+\alpha_{3} \mathrm{y}+\alpha_{4} \mathrm{xy} \\
& \mathrm{v}=\alpha_{5}+\alpha_{6} \mathrm{x}+\alpha_{7} \mathrm{y}+\alpha_{8} \mathrm{xy}
\end{aligned}
$$

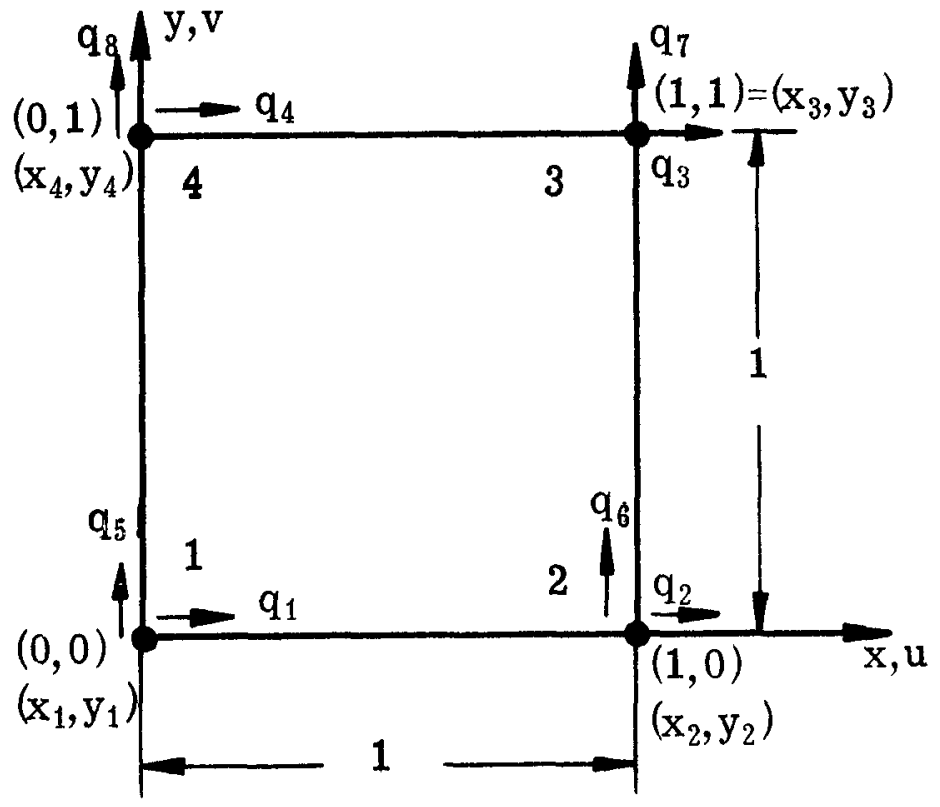




$$
\{q\}=\left[\begin{array}{l}
q_{1} \\
q_{2} \\
q_{3} \\
q_{4} \\
q_{5} \\
q_{6} \\
q_{7} \\
q_{8}
\end{array}\right]=\left[\begin{array}{l}
u_{1} \\
u_{2} \\
u_{3} \\
u_{4} \\
v_{1} \\
v_{2} \\
v_{3} \\
v_{4}
\end{array}\right] \equiv\left[\begin{array}{l}
\alpha_{1} \\
\alpha_{1}+\alpha_{2} \\
\alpha_{1}+\alpha_{2}+\alpha_{3}+\alpha_{4} \\
\alpha_{1}+\alpha_{3} \\
\alpha_{5} \\
\alpha_{5}+\alpha_{6} \\
\alpha_{5}+\alpha_{6}+\alpha_{7}+\alpha_{8} \\
\alpha_{5}+\alpha_{7}
\end{array}\right] \text {, }
$$

Solve for $\{\alpha\}$ :

$$
\text { Obtain }\left\{\begin{array}{l}
\alpha_{1}=q_{1} \\
\alpha_{2}=q_{2}-\alpha_{1}=\left(q_{2}-q_{1}\right) \\
\alpha_{3}=q_{4}-\alpha_{1}=\left(q_{4}-q_{1}\right) \\
\alpha_{4}=q_{3}-\left(\alpha_{1}+\alpha_{2}+\alpha_{3}\right)=\left(q_{1}-q_{2}+q_{3}-q_{4}\right) \\
\alpha_{5}=q_{5}, \alpha_{6}=\left(q_{6}-q_{5}\right), \alpha_{7}=\left(q_{8}-q_{5}\right) \\
\alpha_{8}=\left(q_{5}-q_{6}+q_{7}-q_{8}\right)
\end{array}\right.
$$

$\therefore$

$$
\left\{\begin{array}{l}
u=q_{1}+\left(q_{2}-q_{1}\right) x+\left(q_{4}-q_{1}\right) y+\left(q_{1}-q_{2}+q_{3}-q_{4}\right) x y \\
v=q_{5}+\left(q_{5}-q_{5}\right) x+\left(q_{8}-q_{5}\right) y+\left(q_{5}-q_{6}+q_{7}-q_{8}\right) x y
\end{array}\right.
$$

Use engineering notation

$$
\{\epsilon\}=\left[\begin{array}{l}
\epsilon_{\mathrm{xx}} \\
\epsilon_{\mathrm{yy}} \\
\epsilon_{\mathrm{xy}}
\end{array}\right]=\left[\begin{array}{l}
\partial \mathrm{u} / \partial \mathrm{x} \\
\partial \mathrm{v} / \partial \mathrm{y} \\
(\partial \mathrm{u} / \partial \mathrm{y})+(\partial \mathrm{v} / \partial \mathrm{x})
\end{array}\right]=
$$




$$
=\left\{\begin{array}{l}
\left(q_{2}-q_{1}\right)+\left(q_{1}-q_{2}+q_{3}-q_{4}\right) y \\
\left(q_{8}-q_{5}\right)+\left(q_{b}-q_{6}+q_{7}-q_{8}\right) x \\
\left(q_{4}-q_{1}\right)+\left(q_{6}-q_{5}\right)+\left(q_{1}-q_{2}+q_{3}-q_{4}\right) x+\left(q_{5}-q_{6}+q_{7}-q_{8}\right) y
\end{array}\right]
$$

$\mathrm{A}=\frac{1}{2} \frac{\mathrm{E}}{1-\nu^{3}}\left[\epsilon_{\mathrm{xx}}^{2}+2 \nu \epsilon_{\mathrm{xx}} \epsilon_{\mathrm{yy}}+\epsilon_{\mathrm{yy}}^{2}\right]+\frac{\mathrm{E}}{4(1+\nu)} \epsilon_{\mathrm{xy}}^{2}=$ strain energy densit. $\mathrm{U}=$ total strain energy $=\int_{\mathrm{V}} \mathrm{Adv}=\int_{0}^{1} \int_{0}^{1} \int_{-\mathrm{t} / 2}^{\mathrm{t} / 2} \mathrm{Adx} \mathrm{dy} d \mathrm{z}$

Let:

$$
\begin{aligned}
a= & \left(q_{2}-q_{1}\right), b=\left(q_{1}-q_{2}+q_{3}-q_{4}\right), c=\left(q_{8}-q_{5}\right) \\
d= & \left(q_{5}-q_{6}+q_{7}-q_{8}\right), e=\left(q_{4}-q_{1}+q_{6}-q_{5}\right) \\
U= & \frac{t}{2} \frac{E}{1-\nu^{2}} \int_{0}^{1} \int_{0}^{1}\left[(a+b y)^{2}+(c+d x)^{2}+2 \nu(a+b y)(c+d x)\right] d x d y \\
& +\frac{t E}{4(1+\nu)} \int_{0}^{1} \int_{0}^{1}(e+b x+d y)^{2} d x d y \\
= & \frac{t E}{2\left(1-\nu^{2}\right)}\left[\left(a^{2}+a b+\frac{b^{2}}{3}\right)+\left(c^{2}+c d+\frac{d^{2}}{3}\right)+2 \nu\left(a c+\frac{a d}{2}+\frac{b c}{2}+\frac{b d}{4}\right)\right] \\
& +\frac{t E}{4(1+\nu)}\left(e^{2}+\frac{b^{2}}{3}+\frac{d^{2}}{3}+e b+e d+\frac{b d}{2}\right)
\end{aligned}
$$

To express

$$
\mathrm{U}=\frac{1}{2}\lfloor\mathrm{q}\rfloor[\mathrm{K}]\{\mathrm{q}\}
$$

Use

$$
k_{i j}=\frac{\partial U}{\partial q_{i} \cdot \partial q_{j}}
$$


To find $k_{i j}$ (stiffness influence coefficient),

$$
\frac{\partial U}{\partial q_{i}}=[K]\{q\}
$$

Rearranging the terms,

$$
\begin{aligned}
U= & \frac{t E}{4\left(1-\nu^{2}\right)}\left[\left(2 a^{2}+2 a b+b^{2}\right)+\left(2 c^{2}+2 c d+d^{2}\right)+\left(e^{2}+e b+e d+\frac{b d}{2}\right)\right. \\
& \left.+\nu\left(4 a c+2 a d+2 b c+\frac{b d}{2}\right)-e^{2}-\frac{b^{2}}{3}-\frac{d^{2}}{3}-e b-e d\right]
\end{aligned}
$$

Typically,

$$
\begin{aligned}
& \frac{\partial \mathrm{a}^{2}}{\partial \mathrm{q}_{1}}=2 \mathrm{a} \frac{\partial \mathrm{a}}{\partial \mathrm{q}_{1}}=-2 \mathrm{a}, \\
& \frac{\partial \mathrm{ab}}{\partial \mathrm{q}_{1}}=\mathrm{a} \frac{\partial \mathrm{b}}{\partial \mathrm{q}_{1}}+\mathrm{b} \frac{\partial \mathrm{a}}{\partial \mathrm{q}_{1}}=\mathrm{a}-\mathrm{b}, \text { etc. }
\end{aligned}
$$

We obtain

$$
\begin{aligned}
\frac{\partial U}{\partial q_{1}}= & {\left[(-4 a+2 a-2 b+2 b)+\left(-2 e+e-b-d+\frac{d}{2}\right)\right.} \\
& \left.+\nu\left(-4 c-2 d+2 c+\frac{d}{2}+2 e-\frac{2}{3} b-e+b+d\right)\right] \frac{t E}{4\left(1-\nu^{2}\right)} \\
= & \frac{t E}{4\left(1-\nu^{2}\right)}\left[\left(-b-2 a-e-\frac{d}{2}\right)+\nu\left(e-2 c-\frac{d}{2}+\frac{b}{3}\right)\right] \\
= & 4 \frac{t E}{\left(1-\nu^{2}\right)}\left[\left(2-\frac{2 \nu}{3}\right) q_{1}-\left(1+\frac{\nu}{3}\right) q_{2}+\left(-1+\frac{\nu}{3}\right) q_{3}+\left(\frac{2}{3} \nu\right) q_{4}\right. \\
& \left.+\frac{(1+\nu)}{2} q_{5}+\frac{(3 \nu-1)}{2} q_{6}-\frac{(1+\nu)}{2} q_{7}+\frac{(1-3 \nu)}{2} q_{8}\right]
\end{aligned}
$$




$$
\begin{aligned}
& \frac{\partial \mathrm{U}}{\partial \mathrm{q}_{2}}=\frac{\mathrm{tE}}{1\left(1-\nu^{2}\right)}\left[-\left(1+\frac{\nu}{3}\right) \mathrm{q}_{1}+\left(2-\frac{2 \nu}{3}\right) \mathrm{q}_{2}+\left(\frac{2}{3} \nu\right) \mathrm{q}_{3}+\left(-1+\frac{\nu}{3}\right) \mathrm{q}_{4}\right. \\
& \left.+\left(\frac{1-3 \nu}{2}\right) \mathrm{q}_{5}-\left(\frac{1+\nu}{2}\right) \mathrm{q}_{6}-\frac{(1-3 \nu)}{2} \mathrm{q}_{7}+\frac{1+\nu}{2} \mathrm{q}_{8}\right] \\
& \frac{\partial \mathrm{U}}{\partial \mathrm{q}_{3}}=\frac{\mathrm{tE}}{4\left(1-\nu^{2}\right)}\left[\left(-1+\frac{\nu}{3}\right) \mathrm{q}_{1}+\left(\frac{2}{3} \nu\right) \mathrm{q}_{2}+\left(2-\frac{2}{3} \nu\right) \mathrm{q}_{3}-\left(1+\frac{\nu}{3}\right) \mathrm{q}_{4}\right. \\
& \left.-\frac{(1+\nu)}{2} \mathrm{q}_{5}+\frac{(1-3 \nu)}{2} \mathrm{q}_{6}+\frac{(1+\nu)}{2} \mathrm{q}_{7}-\left(\frac{1-3 \nu}{2}\right) \mathrm{q}_{8}\right] \\
& \frac{\partial \mathrm{U}}{\partial \mathrm{q}_{4}}=\frac{\mathrm{tE}}{4\left(1-\nu^{2}\right)}\left[\left(\frac{2}{3} \nu\right) \mathrm{q}_{1}+\left(-1+\frac{\nu}{3}\right) \mathrm{q}_{2}-\left(1+\frac{\nu}{3}\right) \mathrm{q}_{3}+\left(2-\frac{2}{3} \nu\right) \mathrm{q}_{4}\right. \\
& \left.-\left(\frac{1-3 \nu}{2}\right) q_{5}+\frac{(1+\nu)}{2} q_{6}+\frac{(1-3 \nu)}{2} q_{7}-\frac{(1+\nu)}{2} q_{8}\right] \\
& \frac{\partial U}{\partial q_{5}}=\frac{t E}{4\left(1-\nu^{2}\right)}\left[\frac{(1+\nu)}{2} q_{1}+\left(\frac{1-3 \nu}{2}\right) q_{2}-\frac{(1+\nu)}{2} q_{3}-\frac{(1-3 \nu)}{2} q_{4}\right. \\
& \left.+\left(2-\frac{2}{3} \nu\right) \mathrm{q}_{5}+\left(\frac{2}{3} \nu\right) \mathrm{q}_{6}+\left(-1+\frac{\nu}{3}\right) \mathrm{q}_{7}-\left(1+\frac{\nu}{3}\right) \mathrm{q}_{8}\right] \\
& \frac{\partial \mathrm{U}}{\partial \mathrm{q}_{6}}=\frac{\mathrm{tE}}{4\left(1-\nu^{2}\right)}\left(\frac{3 \nu-1}{2}\right) \mathrm{q}_{1}-\left(\frac{1+\nu}{2}\right) \mathrm{q}_{2}+\left(\frac{1-3 \nu}{2}\right) \mathrm{q}_{3}+\frac{(1+\nu)}{2} \mathrm{q}_{4} \\
& \left.+\left(\frac{2}{3} \nu\right) \mathrm{q}_{5}+\left(2-\frac{2}{3} \nu\right) \mathrm{q}_{6}-\left(1+\frac{\nu}{3}\right) \mathrm{q}_{7}+\left(-1+\frac{\nu}{3}\right) \mathrm{q}_{8}\right] \\
& \frac{\partial \mathrm{U}}{\partial \mathrm{q}_{\mathrm{\eta}}}=\frac{\mathrm{tE}}{4\left(1-\nu^{2}\right)}\left[\frac{-(1+\nu)}{2} \mathrm{q}_{1}-\frac{(1-3 \nu)}{2} \mathrm{q}_{2}+\frac{(1+\nu)}{2} \mathrm{q}_{3}+\frac{(1-3 \nu)}{2} \mathrm{q}_{4}\right. \\
& +\left(-1+\frac{\nu}{3}\right) \mathrm{q}_{5}-\left(1+\frac{\nu}{3}\right) \mathrm{q}_{6}+\left(2-\frac{2}{3} \nu\right) \mathrm{q}_{7}+\left(\frac{2}{3} \nu\right) \mathrm{q}_{8}
\end{aligned}
$$




$$
\begin{aligned}
\frac{\partial \mathrm{U}}{\partial \mathrm{q}_{8}}= & \frac{\mathrm{tE}}{4\left(1-\nu^{2}\right)}\left[\frac{(1-3 \nu)}{2} \mathrm{q}_{1}+\frac{(1+\nu)}{2} \mathrm{q}_{2}-\frac{(1-3 \nu)}{2} \mathrm{q}_{3}-\frac{(1+\nu)}{2} \mathrm{q}_{4}-\right. \\
& \left.-\left(1+\frac{\nu}{3}\right) \mathrm{q}_{5}+\left(-1+\frac{\nu}{3}\right) \mathrm{q}_{6}+\left(\frac{2}{3} \nu\right) \mathrm{q}_{7}+\left(2-\frac{2}{3} \nu\right) \mathrm{q}_{8}\right]
\end{aligned}
$$

$\{q\}=\left\{q_{1} q_{2} q_{3} q_{4} q_{5} q_{6} q_{7} q_{8}\right\} \quad(8 \times 1)$

$$
U=\underset{1 \times 8 \quad 8 \times 8}{\lfloor q\rfloor}[\mathrm{K}] \quad\{\times 1
$$

$$
\begin{aligned}
& {\left[\left(2-\frac{2}{3} \nu\right)-\left(1+\frac{\nu}{3}\right)\left(-1+\frac{\nu}{3}\right)\left(\frac{2}{3} \nu\right)\left(\frac{1+\nu}{2}\right)-\left(\frac{1-3 \nu}{2}\right)-\left(\frac{1+\nu}{2}\right)\left(\frac{1-3 \nu}{2}\right)\right]} \\
& \left(2-\frac{2}{3} \nu\right)\left(\frac{2}{3} \nu\right) \quad\left(-1+\frac{\nu}{3}\right)\left(\frac{1-3 \nu}{2}\right)-\left(\frac{1+\nu}{2}\right)-\left(\frac{1-3 \nu}{2}\right)\left(\frac{1+\nu}{2}\right) \\
& \left(2-\frac{2}{3} \nu\right)-\left(1+\frac{\nu}{3}\right)-\left(\frac{1+\nu}{2}\right)\left(\frac{1-3 \nu}{2}\right)\left(\frac{1+\nu}{2}\right)-\left(\frac{1-3 \nu}{2}\right) \\
& \left(2-\frac{2}{3} \nu\right)-\left(\frac{1-3 \nu}{2}\right)\left(\frac{1+\nu}{2}\right)\left(\frac{1-3 \nu}{2}\right)-\left(\frac{1+\nu}{2}\right) \\
& \left(2-\frac{2}{3} \nu\right)\left(\frac{2}{3} \nu\right) \quad\left(-1+\frac{\nu}{3}\right)-\left(1+\frac{\nu}{3}\right)
\end{aligned}
$$

$\mathrm{K}]=\frac{\mathrm{tE}}{4\left(1-\nu^{2}\right)}$

Symmetric

$$
\begin{array}{r}
\left(2-\frac{2}{3} \nu\right)-\left(1+\frac{\nu}{3}\right)\left(-1+\frac{\nu}{3}\right) \\
\left(2-\frac{2}{3} \nu\right)\left(\frac{2}{3} \nu\right) \\
v\left(2-\frac{2}{3} \nu\right)
\end{array}
$$

It is to be noted, that the above solution is not an exact solution, it is only an approximate solution. 


\section{APPENDIX C - COMPUTATIONS OF EIGENVALUES AND EIGENVECTORS OF $[\mathrm{M}]^{-1}[\mathrm{~K}][\phi]=[\phi][\Lambda]$ USING ONLY SYMMETRIC MATRICES}

The procedure for computation which involves only symmetric matrices is described as follows:

To compute $[\Lambda]$ and $[\phi]$ of the given equation

$$
[\mathrm{M}]^{-1}[\mathrm{~K}][\phi]=[\phi][\Lambda] \text {, }
$$

first, the eigenvalue diagonal matrix $\mu$ and associated ortho-normal matrix of eigenvectors $\psi$ of the symmetric matrix [M] are calculated. Since $\psi$ is ortho-normal and $\mu$ is diagonal, the inverse of $\mathbf{M}$ is calculated from

$$
\mathbf{M}=\psi \mu \psi^{\mathrm{T}}
$$

which results in

$$
\mathbf{M}^{-1}=\left[\psi \mu \psi^{\mathbf{T}}\right]^{-1}=\left[\psi^{\mathbf{T}}\right]^{-1}[\mu]^{-1}[\psi]^{-1}=[\psi][\mu]^{-1}[\psi]^{\mathbf{T}}
$$

(since $\psi^{\mathrm{T}}=\psi^{-1}$ ).

Second, form the product

$$
\mu^{-1 / 2} \psi^{\mathbf{T}} \mathbf{K} \psi \mu^{-1 / 2}
$$


and note that

$$
\left[\mu^{-1 / 2} \psi^{\mathrm{T}} \mathrm{K} \psi \mu^{-1 / 2}\right]^{\mathrm{T}}=\mu^{-1 / 2} \psi \mathrm{T} \mathrm{K} \psi \mu^{-1 / 2}
$$

since $\psi$ is ortho-normal, $K$ is symmetric, and $\mu^{-1 / 2}$ is diagonal; hence, the product matrix in Eq. C.3 is symmetric.

Let

$$
\left[\mu^{-1 / 2} \psi^{\mathrm{T}} \mathrm{K} \psi \mu^{-1 / 2}\right]=[\mathrm{G}]
$$

Thus, again the routine for symmetric matrices is employed to compute $[\Lambda]$ (the desired diagonal eigenvalue matrix) and $[\beta]$ (the associated eigenvector matrix) of $[\mathrm{G}]$ rather than the general procedure before.

The procedure thus becomes

$$
\text { Given: } \mathbf{M}^{-1} \mathbf{K} \phi=\phi
$$

Find: $\phi$ and $\beta$ from the eigenvalues and eigenvectors of $[G]$.

Substituting Eq. C. 2 into Eq. C.5,

$$
\psi \mu^{-1} \psi^{\mathrm{T}} \mathbf{K} \phi=\phi \Lambda
$$

Since $\psi$ is ortho-normal, $\psi \mathbf{T}_{\psi}=\mathrm{I}$; therefore,

$$
\mu^{-1} \psi^{\mathrm{T}} \mathrm{K} \phi=\psi^{\mathrm{T}} \phi \Lambda
$$

Premultiply Eq. C. 7 by $\mu^{-1 / 2}$, which is real, since by hypothesis [M] is positive definite:

$$
\mu^{-1 / 2} \psi^{\mathbf{T}}{ }_{\mathrm{K} \phi}=\mu^{1 / 2} \psi^{\mathbf{T}} \phi \Lambda
$$

Thus,

$$
\mu^{-1 / 2} \psi^{\mathrm{T}} \psi \psi^{\mathrm{T}} \phi=\mu^{1 / 2} \mathrm{~T}_{\phi \Lambda}
$$

Also,

$$
\left[\mu^{-1 / 2} \psi^{\mathbf{T}} \mathbf{K} \psi \mu^{-1 / 2}\right]\left[\mu^{1 / 2} \psi^{\mathbf{T}} \phi\right]=\mu^{1 / 2} \psi^{\mathbf{T}} \phi \Lambda
$$


Using Eq. C.4,

$$
[\mathrm{G}]\left[\mu^{1 / 2} \psi^{\mathrm{T}} \phi\right]=\left[\mu^{1 / 2} \psi^{\mathrm{T}} \phi\right][\Lambda]
$$

By comparing Eq. C.11 with Eq. C.1, it can be seen that the eigenvalues of $[\mathrm{G}]$ are equal to eigenvalues of $[\mathrm{M}]^{-1}[\mathrm{~K}]$, namely $[\Lambda]$. It can also be seen that the eigenvectors are

$$
[\beta]=\left[\mu^{1 / 2} \psi^{\mathrm{T}} \phi\right]
$$

Solving for $\theta$

$$
[\phi]=\left[\psi \mu^{-1 / 2} \beta\right]
$$

Therefore,

$$
\phi^{\mathrm{T}} \mathbf{M} \phi=\beta^{\mathrm{T}} \mu^{-1 / 2} \psi_{\mathrm{T}} \mathbf{M}^{-1 / 2} \beta=\beta^{\mathrm{T}} \mu^{-1 / 2} \mu \mu^{-1 / 2} \beta=\beta \mathbf{T} \beta=\mathbf{I}
$$

From Eq. C.1,

$$
\mathrm{K}=\mathrm{M} \phi \Lambda \phi^{\mathrm{T}}
$$

Therefore,

$$
\phi^{\mathrm{T}} \mathrm{K}=\phi_{\mathrm{M} \phi \Lambda \phi^{\mathrm{T}}} \mathrm{T}_{\mathrm{M}}=\mathrm{I} \Lambda \mathrm{I}=\Lambda \quad \text { (Q.E.D.) }
$$

